OPEN ACCESS

Edited by:

Yong-Ho Choa,

Hanyang University, South Korea

Reviewed by:

Kun-Jae Lee,

Dankook University, South Korea

Hyo-Ryoung Lim,

Pukyong National University, South

Korea

*Correspondence:

Tingjun Wu

tingjun.wu@hotmail.com

Jiwon Kim

jkim@iae.re.kr

Specialty section: This article was submitted to

Electrochemistry,

a section of the journal

Frontiers in Chemistry

Received: 23 August 2021

Accepted: 04 October 2021

Published: 21 December 2021

Citation:

Wu T, Kim J, Lim J-H, Kim M-S and Myung NV (2021) Comprehensive

Review on Thermoelectric

Electrodeposits: Enhancing

Thermoelectric Performance

Through Nanoengineering.

Front. Chem. 9:762896.

doi: 10.3389/fchem.2021.762896

\section{Comprehensive Review on Thermoelectric Electrodeposits: Enhancing Thermoelectric Performance Through Nanoengineering}

\author{
Tingjun $\mathrm{Wu}^{1 *}$, Jiwon $\mathrm{Kim}^{2 *}$, Jae-Hong $\mathrm{Lim}^{3}$, Min-Seok Kim ${ }^{3}$ and Nosang V. Myung ${ }^{4}$ \\ ${ }^{1}$ Shanghai Institute of Microsystem and Information Technology, Chinese Academy of Sciences, Shanghai, China, ${ }^{2}$ Materials \\ Science and Chemical Engineering Center, Institute for Advanced Engineering, Yongin-si, Korea, ${ }^{3}$ Department of Materials \\ Science and Engineering, Gachon University, Seongnam-si, Korea, ${ }^{4}$ Department of Chemical and Biomolecular Engineering, \\ University of Notre Dame, Notre Dame, IN, United States
}

Thermoelectric devices based power generation and cooling systemsystem have lot of advantages over conventional refrigerator and power generators, becausebecause of solid-state devicesdevices, compact size, good scalability, nono-emissions and low maintenance requirement with long operating lifetime. However, the applications of thermoelectric devices have been limited owingowing to their low energy conversion efficiency. It has drawn tremendous attention in the field of thermoelectric materials and devices in the 21st century because of the need of sustainable energy harvesting technology and the ability to develop higher performance thermoelectric materials through nanoscale science and defect engineering. Among various fabrication methods, electrodeposition is one of the most promising synthesis methods to fabricate devices because of its ability to control morphology, composition, crystallinity, and crystal structure of materials through controlling electrodeposition parameters. Additionally, it is an additive manufacturing technique with minimum waste materials that operates at near room temperature. Furthermore, its growth rate is significantly higher (i.e., a few hundred microns per hour) than the vacuum processes, which allows device fabrication in cost effective matter. In this paper, the latest development of various electrodeposited thermoelectric materials (i.e., Te, $\mathrm{PbTe}, \mathrm{Bi}_{2} \mathrm{Te}_{3}$ and their derivatives, $\mathrm{BiSe}, \mathrm{BiS}, \mathrm{Sb}_{2} \mathrm{Te}_{3}$ ) in different forms including thin films, nanowires, and nanocomposites were comprehensively reviewed. Additionally, their thermoelectric properties are correlated to the composition, morphology, and crystal structure.

Keywords: electrodeposition, electroplating, thermoelectrics, nanoengineering, defect engineering

\section{OVERVIEW OF THERMOELECTRICS}

Thermoelectric power generators and coolers are based on the Seebeck and the Peltier effect, respectively, where the Seebeck effect allows direct conversion of temperature gradient into electricity (Figure 1). When establishing temperature gradient at the two sides of materials, charge carriers (i.e., electronsin $n$-type semiconductor and holes in p-type semiconductor) would transfertransfer from 


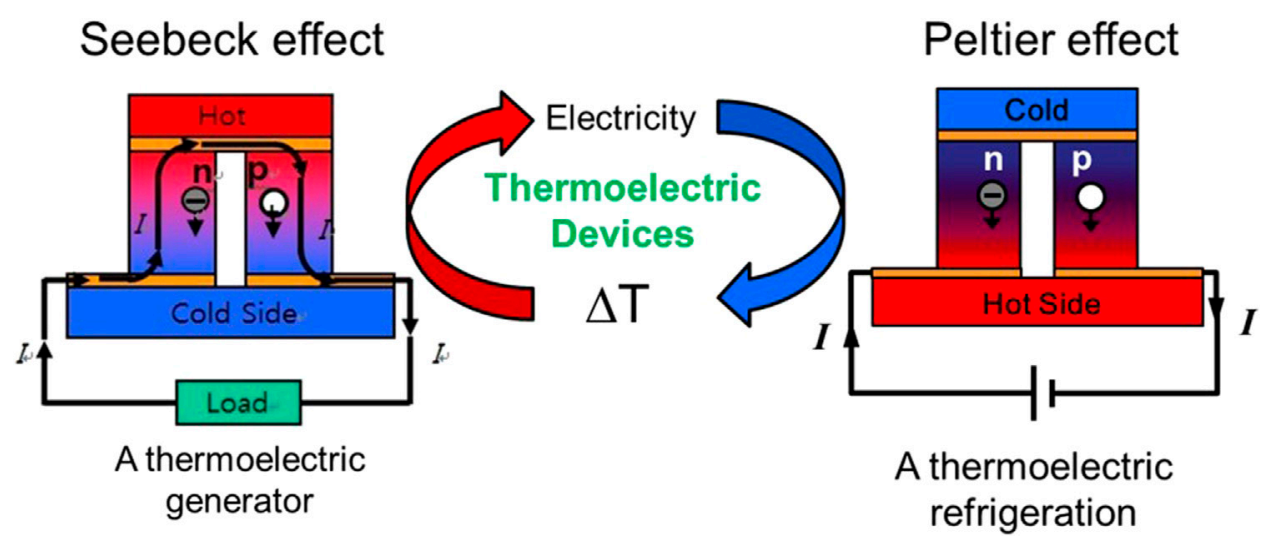

FIGURE 1 | Schematic illustration of thermoelectric effect including the Seebeck effect and Peltier effect.

hot side to cold side, which would create a voltage. voltage. The generated voltage, $\Delta \mathrm{V}$, is given by $\Delta \mathrm{V}=\mathrm{S} \cdot \Delta \mathrm{T}$, where $\mathrm{S}$ is the Seebeck coefficient and $\Delta \mathrm{T}$ is the temperature difference. On the other hand, the Peltier effect is the generation of temperature gradient by applying electric energy. When electric energy is applied to the materials, charge carriers flow to one end of the thermoelectric materials. The charge carriers also transport energy, resulting in a temperature difference between the two ends.

In thermoelectric devices, the performance can be characterized by the dimensionless thermoelectric figure-ofmerit (ZT), which is defined asas following equation:

$$
Z T=\frac{S^{2} \sigma}{\kappa} T
$$

where $\mathrm{S}$ is the Seebeck coefficient $(\mathrm{V} / \mathrm{K}), \sigma$ is the electrical conductivity $(\mathrm{S} / \mathrm{m}), \kappa$ is the thermal conductivity $(\mathrm{W} / \mathrm{mK})$ and $\mathrm{T}$ is the absolute temperature (K). (Zebarjadi et al., 2012) $\mathrm{S}^{2} \sigma$ is defineddefined as the thermoelectric power factor (P. F.).

Additionally, the maximum energy conversion efficiency $(\eta)$ of a thermoelectric device is defined as the energy produced toproduced the workwork (W) divided by the thermal energy consumed at the hot junction $(\mathrm{Q})$, which is dependent on dependent onZT as well as the temperature difference of the hot and cold side $\left(\mathrm{T}_{\mathrm{H}}, \mathrm{T}_{\mathrm{C}}\right)$. (Nolas et al., 2001; Snyder and Ursell, 2003; Sootsman et al., 2009; Zebarjadi et al., 2012).

$$
\eta=\frac{W}{Q}=\frac{T_{H}-T_{C}}{T_{H}} \frac{\sqrt{1+Z T}-1}{\sqrt{1+Z T}+\frac{T_{H}}{T_{C}}}
$$

Based on the definitions, high energy efficiency would be achieved by improving the thermoelectric power factor $\left(S^{2} \sigma\right)$ and suppressing the thermal conductivity. However, Seebeck coefficient, electrical conductivity and thermal conductivity are interdependent to each other, lead to significant difficulties to enhancing the energy efficiency (Szczech et al., 2011). For example, the Seebeck coefficient (S) is a function of the charge carrier (i.e., electrons or holes) effective mass and charge carrier concentration as shown in Eq. 3,

$$
S=\frac{8 \pi^{2} k_{B}^{2}}{3 e h^{2}} m^{*} T\left(\frac{\pi}{3 n}\right)^{\frac{2}{3}}
$$

where $\mathrm{e}$ is the elementary carrier charge, $\mathrm{k}_{\mathrm{B}}$ is Boltzmann constant, $\mathrm{m}^{*}$ is the charge carrier effective mass, $\mathrm{h}$ is Planck's constant, and $n$ is the charge carrier concentration. The electrical conductivity $(\sigma)$ is proportional to the product of carrier concentration and carrier mobility represented (Eq. 4).

$$
\sigma=e\left(n_{e} \mu_{e}+n_{h} \mu_{h}\right)
$$

where $e$ is the elementary charge; $n_{e}$ and $n_{h}$ are the carrier concentrations of electrons and holes, respectively; $\mu_{e}$ and $\mu_{h}$ are the carrier mobility of electrons and holes, respectively. Based on these two equations, increasing the carrier concentration enhances the electrical conductivity, but decreases the Seebeck coefficient.

The electrical conductivity $(\sigma)$ and thermal conductivity $(k)$ are also interdependent since thermal conductivity $(\kappa)$ is combination of the lattice thermal conductivity $\left(\kappa_{1}\right)$ and electrical thermal conductivity $\left(\kappa_{\mathrm{e}}\right) . \kappa_{\mathrm{e}}$ is proportional to the electrical conductivity $\left(\kappa_{e}=\sigma L T\right)$, by Wiedemann-Franz law (Szczech et al., 2011). Thus, increasing the carrier concentration increases both electrical conductivity and thermal conductivity. Figure 2 shows the interdependency of the Seebeck coefficient, the electrical conductivity and the thermal conductivity (Snyder and Toberer, 2008; Szczech et al., 2011).

In order to overcome this intrinsic demerit, numerous researchers endeavored to independently control these parameters by utilizing quantum confinement effect, phonon scattering effect, and energy filtering effect. Historical approaches to enhance the ZT have been focused on altering phonon scattering mechanism, called phonon-glass electroncrystal (PGEC), by introducing complex lattice structures such as skutterudites, superlattices, heterostructure, and nanocomposites. The enhancement of ZT in these systems was mainly achieved by reducing the thermal conductivity due to the increased phonon scattering at the interfaces. (Poudel et al., 2008). However, there is a limit for reducing the lattice thermal conductivity. Recent advancements have been 


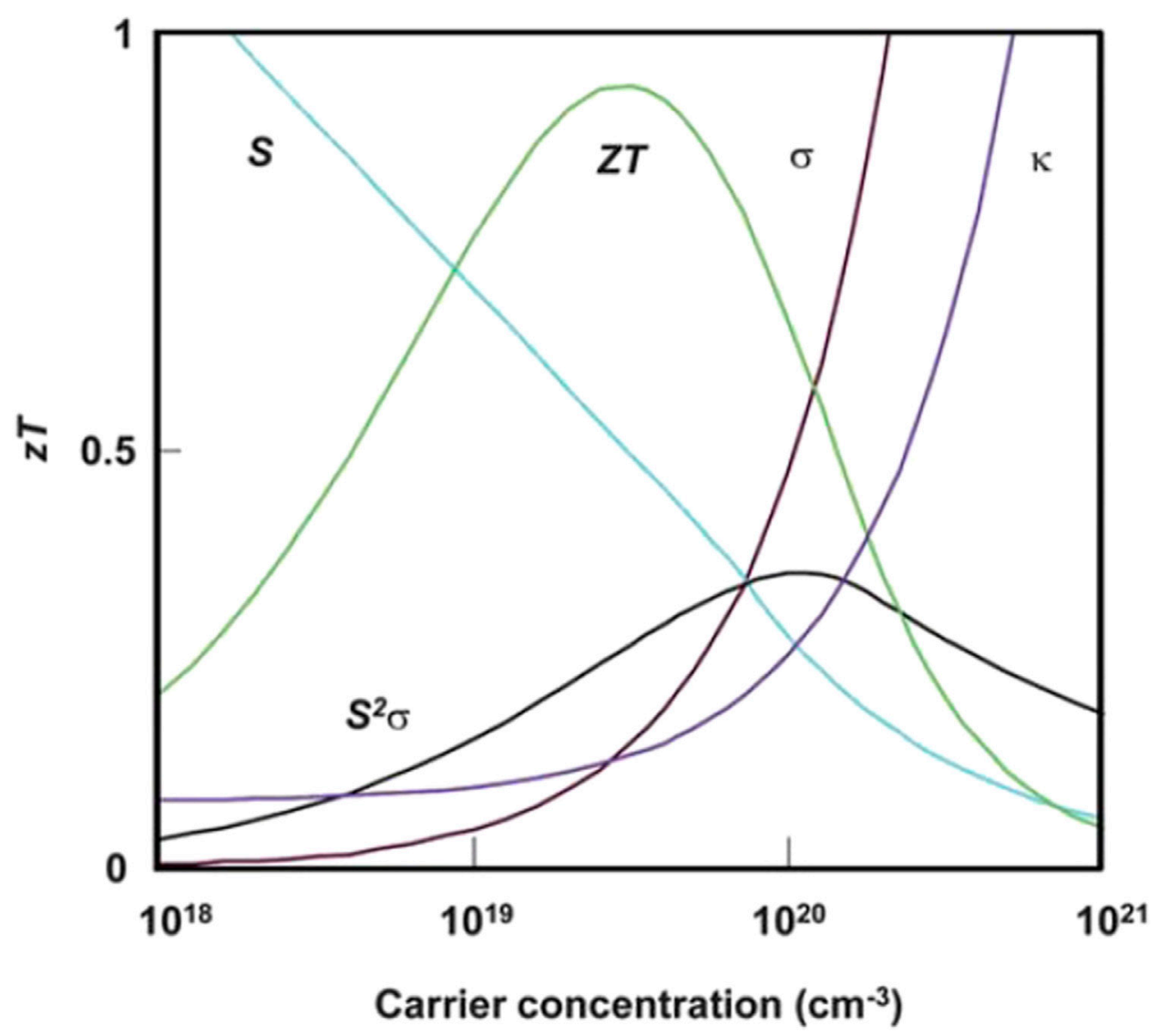

FIGURE 2 | Interdependence of the Seebeck coefficient (S), electrical conductivity $(\sigma)$, and thermal conductivity $(\kappa)$ (Snyder and Toberer, 2008; Szczech et al., 2011).

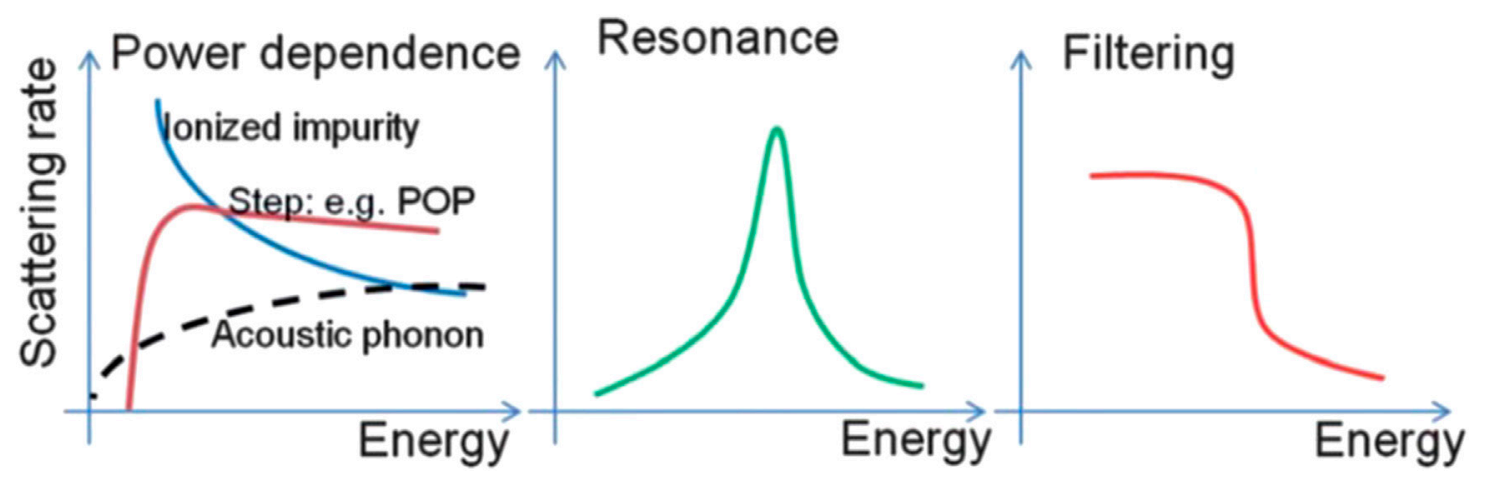

FIGURE 3 | Several possible behaviors of total relation rate $(1 / \tau(E))$ in a few $k_{B} T$ window. (Zebarjadi et al., 2012).

achieved by incorporating metallic and/or semiconducting nanoparticles in thermoelectric matrices. (Hsu et al., 2004; Zeng et al., 2007; Zide et al., 2006). The distortions of the density of states (DOS) near Fermi level as results of carrier localization, resonant state, and carrier filtering effect fulfilled the sharp increase of the Seebeck coefficient without suppressing electrical conductivity. As shown in Figure 3, the large Seebeck coefficient can be dependent on the behavior of the scattering rates $(1 / \tau)$ as a function of energy in the materials (Zebarjadi et al., 2012). The $1 / \tau$, which is inverse function of the energy dependence of the relaxation times $\left(\tau=\tau_{0} \mathrm{Er}\right)$, where the exponent $r$ is called the scattering parameter. This scattering parameter, which is determined by different scatterings for example, in the case of acoustic phonon scattering, the $r$ is $-1 /$ 
TABLE 1 | Correlation of material composition and microstructure with electrical and thermoelectric properties.

Morphology

Microstructure

Preferred (Crystallineldiameter) orientation

\begin{tabular}{|c|c|c|c|}
\hline $\begin{array}{l}\text { Grain } \\
\text { size } \\
(\mathrm{nm})\end{array}$ & $\begin{array}{c}\text { Seebeck } \\
\text { coefficient } \\
(\mu \mathrm{V} \\
\left.\mathrm{K}^{-1}\right)\end{array}$ & $\begin{array}{l}\text { Electrical } \\
\text { conductivity } \\
\left(\mathrm{S} \mathrm{cm}^{-1}\right)\end{array}$ & 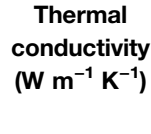 \\
\hline
\end{tabular}

Power

actor

ZT

Measure$\mathrm{K}^{-1}$ )

Abad et al. (2015)

Jiang et al. (2012)

Wu et al. (2016a)

Lee et al. (2008)

Li and Wang, (2009)

Diliberto et al. (2008)

Suresh et al. (2009)

Kim and Oh, (2009)

Mannam et al. (2009)

Kim and Oh (2010a)

Lee et al. (2010)

Richoux et al. (2010)

Li and Wang, (2010)

Chen et al. (2010)

Li et al. (2010a)

Rostek et al. (2011)

Ma et al. (2011)

Pinisetty et al. (2011a)

Zhu and Wang, (2012)

Zou et al. (2012)

Kim and Oh (2013)

Manzano et al. (2013)

Rashid et al. (2013)

Cao et al. (2013)

Wu et al. (2013)

Yoo et al. (2013a)

Wang et al. (2013)

Rashid and Chung, (2013)

Zou et al. (2014)

Maas et al. (2014)

Szymczak et al. (2014)

Jiang et al. (2014)

Caballero-Calero et al.

(2014)

Matsuoka et al. (2015)

\section{Te}

$\mathrm{Pb}_{49} \mathrm{Te}_{51}$

$\mathrm{Bi}_{2} \mathrm{Te}_{3}$

$\mathrm{Bi}_{0.22} \mathrm{Sb}_{1.48} \mathrm{Te}_{3.30}$

$\mathrm{Bi}_{1.93} \mathrm{Te}_{3.07}$

$\mathrm{Bi}_{2} \mathrm{Te}_{3}$

$\mathrm{Bi}_{2} \mathrm{Te}_{3}$

$\mathrm{Sb}_{2} \mathrm{Te}_{3}$
$\mathrm{n}-\mathrm{Bi}_{2} \mathrm{Te}_{3}$

$\mathrm{p}-\mathrm{Bi}_{2} \mathrm{Te}_{3}$

$\mathrm{Bi}_{39} \mathrm{Te}_{61}$

$\mathrm{Sb}_{35} \mathrm{Te}_{65}$

$\mathrm{Bi}_{2} \mathrm{Te}_{3}$

$\mathrm{Bi}_{0.38} \mathrm{Sb}_{1.43} \mathrm{Te}_{3.19}$

$\mathrm{Bi}_{0.49} \mathrm{Sb}_{1.53} \mathrm{Te}_{2.98}$

$\mathrm{Bi}_{2} \mathrm{Te}_{3}$

$\mathrm{Bi}_{2} \mathrm{Te}_{3}$

$\mathrm{Bi}_{0.5} \mathrm{Sb}_{1.5} \mathrm{Te}_{3}$

$\mathrm{Bi}_{39.6} \mathrm{Te}_{60.4}$

$\mathrm{Bi}_{39.3} \mathrm{Te}_{60.7}$

Te-rich $\mathrm{Bi}_{2} \mathrm{Te}_{3}$

Te-rich $\mathrm{Bi}_{2} \mathrm{Te}_{3}$

$\mathrm{Bi}_{0.40} \mathrm{Sb}_{1.28} \mathrm{Te}_{3.14} \mathrm{Se}_{0.18}$

$\mathrm{Bi}_{2} \mathrm{Te}_{2.7} \mathrm{Se}_{0.5}$

$\mathrm{Bi}_{39.5} \mathrm{Te}_{60.5}$

$\mathrm{Bi}_{46} \mathrm{Te}_{54}$

$\mathrm{Bi}_{2} \mathrm{Te}_{3}$

$\mathrm{Bi}_{2} \mathrm{Te}_{3}$

$\mathrm{Bi}_{2} \mathrm{Te}_{3}$

$\mathrm{Bi}_{2} \mathrm{Te}_{3}$

$\mathrm{Bi}_{11} \mathrm{Te}_{10}$

$\mathrm{Bi}_{0.47} \mathrm{Sb}_{1.44} \mathrm{Te}_{3.00}$

$\mathrm{Bi}_{1.98} \mathrm{Te}_{2.73} \mathrm{Se}_{0.29}$

$\mathrm{Bi}_{1.9} \mathrm{Te}_{3.1}$

$\mathrm{Bi}_{2} \mathrm{Te}_{2.65} \mathrm{Se}_{0.44}$

$\mathrm{Bi}_{2} \mathrm{Te}_{3}$

$\mathrm{Bi}_{2} \mathrm{Te}_{3}$ /PEDOT:PSS

$\mathrm{Bi}_{2} \mathrm{Te}_{3}$

$\mathrm{Bi}_{37.7} \mathrm{Te}_{62.3}$

$\mathrm{Bi}_{54} \mathrm{Te}_{46} / \mathrm{BiSe}$
Poly-crystalline

Thin film

Thick film

Nanowires

Thin film

Thin film

Nanowires

Nanowires

Film

Film

Nanowires

Film

Film

Nanowires

Nanowires

Film

Thin film

Thin film

Nanowire

Nanotube

Thin film

Thin film

Thick film
Thick film

Film

Thin film

Film

Thin film

Film

Film

Thin film

Film

Thick film

Film

Film

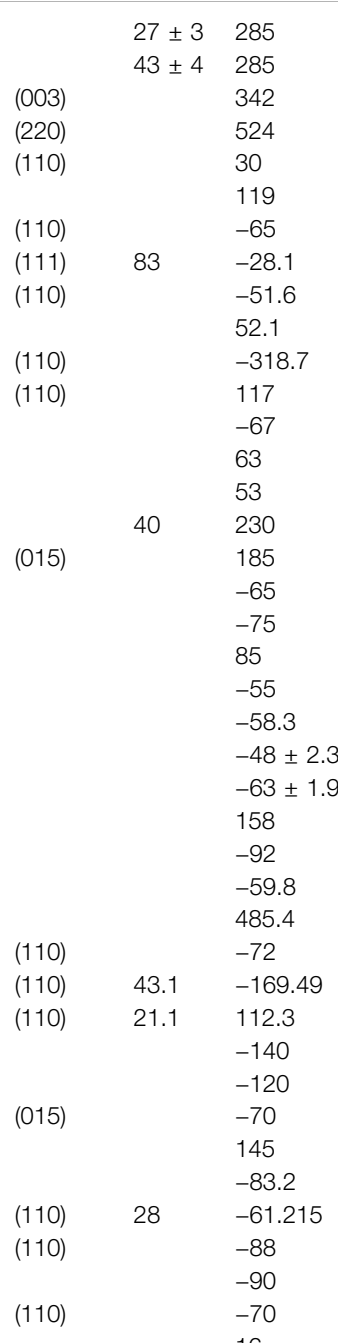

(110)

$-80$

$38 / 15 \quad-46$

\begin{tabular}{|c|c|c|c|c|}
\hline 12.5 & 1 & 280 & 0.09 & RT \\
\hline 43.7 & 1 & 82 & 0.03 & RT \\
\hline \multirow[t]{2}{*}{0.14} & & 3.9 & & 296 \\
\hline & & & & RT \\
\hline 78.7 & & 111.5 & & RT \\
\hline \multirow{6}{*}{833.3} & & 352 & & RT \\
\hline & & & & 313 \\
\hline & & 710 & & RT \\
\hline & & 170 & & $\mathrm{RT}$ \\
\hline & & & & 300 \\
\hline & & & & 300 \\
\hline $1,204.8$ & & 540 & & $\mathrm{RT}$ \\
\hline 179.5 & & 70 & & $\mathrm{RT}$ \\
\hline 1,690 & & 476.3 & & RT \\
\hline 54.3 & & 287 & & RT \\
\hline \multirow[t]{5}{*}{299.4} & & & & $\mathrm{RT}$ \\
\hline & 0.75 & & 0.45 & 300 \\
\hline & 0.75 & & 0.9 & 350 \\
\hline & & & & $\mathrm{RT}$ \\
\hline & & & & RT \\
\hline \multirow[t]{3}{*}{1,036} & & 352.2 & & $\mathrm{RT}$ \\
\hline & & & & RT \\
\hline & & & & RT \\
\hline \multicolumn{2}{|l|}{138.9} & & & $\mathrm{RT}$ \\
\hline \multicolumn{2}{|l|}{95.0} & 80.4 & & RT \\
\hline \multicolumn{2}{|l|}{$1,408.5$} & 506 & & $\mathrm{RT}$ \\
\hline \multicolumn{2}{|l|}{210.5} & 4,960 & & $\mathrm{RT}$ \\
\hline \multirow[t]{3}{*}{851.1} & & 440 & & 380 \\
\hline & & 1737 & & $\mathrm{RT}$ \\
\hline & & 443 & & RT \\
\hline \multirow[t]{6}{*}{600} & & 1,247 & & $\mathrm{RT}$ \\
\hline & & & & RT \\
\hline & & 336.2 & & RT \\
\hline & & 220 & & $\mathrm{RT}$ \\
\hline & & 210 & & RT \\
\hline & & 820 & & RT \\
\hline \multicolumn{2}{|l|}{142} & 110.0 & & $\mathrm{RT}$ \\
\hline \multirow{2}{*}{\multicolumn{2}{|c|}{$\begin{array}{c}512.8 \\
75.2\end{array}$}} & 500 & & RT \\
\hline & & & & $\mathrm{RT}$ \\
\hline
\end{tabular}

402.5

0.17

0.017 RT

358

144 RT

(Continued on following page) 
TABLE 1 | (Continued) Correlation of material composition and microstructure with electrical and thermoelectric properties.

\begin{tabular}{|c|c|c|c|c|c|c|c|c|c|c|c|}
\hline Ref & Materials & Morphology & $\begin{array}{c}\text { Microstructure } \\
\text { (Crystallineldiameter) }\end{array}$ & $\begin{array}{l}\text { Preferred } \\
\text { orientation }\end{array}$ & $\begin{array}{l}\text { Grain } \\
\text { size } \\
(\mathrm{nm})\end{array}$ & $\begin{array}{c}\text { Seebeck } \\
\text { coefficient } \\
(\mu \mathrm{V} \\
\left.\mathrm{K}^{-1}\right)\end{array}$ & $\begin{array}{l}\text { Electrical } \\
\text { conductivity } \\
\left(\mathrm{S} \mathrm{cm}^{-1}\right)\end{array}$ & $\begin{array}{l}\text { Thermal } \\
\text { conductivity } \\
\left(\mathrm{W} \mathrm{m}^{-1} \mathrm{~K}^{-1}\right)\end{array}$ & $\begin{array}{c}\text { Power } \\
\text { factor } \\
(\mu \mathrm{W} \\
\mathrm{K}^{-2} \\
\left.\mathrm{~m}^{-1}\right)\end{array}$ & $\mathbf{Z T}$ & $\begin{array}{l}\text { Measure- } \\
\text { temp.(K) }\end{array}$ \\
\hline & & $\begin{array}{l}\text { Layered } \\
\text { structure }\end{array}$ & & & & & & & & & \\
\hline $\begin{array}{l}\text { Caballero-Calero et al. } \\
\text { (2015) }\end{array}$ & $\mathrm{Bi}_{1.7} \mathrm{Te}_{3.1} \mathrm{Se}_{0.2}$ & Thin film & & (110) & & -100 & & & & & 353 \\
\hline Zhou et al. (2015) & $\mathrm{Bi}_{2} \mathrm{Te}_{3}$ & Thin film & & (110) & & -81 & 520 & & 340 & 0.16 & $\mathrm{RT}$ \\
\hline Li et al. (2015) & $\mathrm{Bi}_{0.5} \mathrm{Sb}_{1.5} \mathrm{Te}_{3}$ & Nanowires & Dia. 67nm & (110) & & 143 & 480 & 0.28 & & 1.14 & 330 \\
\hline Uda et al. (2015) & $\mathrm{Bi}_{37.5} \mathrm{Te}_{62.5}$ & Film & & & & -81.9 & 526.3 & & 354 & & RT \\
\hline Chang et al. (2015) & $\mathrm{Bi}_{39} \mathrm{Te}_{61}$ & Nanowires & Dia. 60nm & & & 71 & 390 & & 195.8 & & 300 \\
\hline \multirow[t]{2}{*}{ Shin and Oh (2015) } & $\mathrm{Bi}_{39.4} \mathrm{Te}_{60.6}$ & Film & & & & -59.5 & $1,587.3$ & & 559 & & $\mathrm{RT}$ \\
\hline & $\mathrm{Sb}_{43.1} \mathrm{Te}_{56.9}$ & Film & & & & 441.2 & 281.7 & & 5,480 & & $\mathrm{RT}$ \\
\hline Kulsi et al. (2015) & $\mathrm{Bi}_{1.6} \mathrm{Te}_{3.4}$ & Thin film & & (018) & 55 & -29 & 4,033 & & 340 & 0.28 & $\mathrm{RT}$ \\
\hline Lei et al. (2016a) & $\mathrm{Bi}_{2} \mathrm{Te}_{3}$ & Thick film & & (110) & & -200 & 400 & & 1,600 & & RT \\
\hline Yang et al. (2016) & Te-Bi-Sb & Film & & & & 32.9 & & & 34 & & $\mathrm{RT}$ \\
\hline Na et al. (2016) & $\mathrm{Bi}_{2.17} \mathrm{Te}_{2.83}$ & Film & & (110) & 35.7 & -146 & 691 & & 1,473 & & $\mathrm{RT}$ \\
\hline Kulsi et al. (2016) & $\mathrm{Bi}-\mathrm{Te}$ & Film & & & 127 & -32 & 1,247 & 0.46 & 130 & 0.08 & RT \\
\hline Lei et al. (2016b) & $\mathrm{Bi}_{2} \mathrm{Te}_{3}$ & Thick film & & (110) & 17 & -80 & 330 & & & & $\mathrm{RT}$ \\
\hline Manzano et al. (2016) & $\mathrm{Bi}_{2} \mathrm{Te}_{3}$ & Film & & (110) & & --58 & 670 & & 225 & 0.056 & 300 \\
\hline Jagadish et al. (2015) & $\mathrm{Bi}_{2} \mathrm{Te}_{2.53}$ & Film & & & & -20 & & & & & RT \\
\hline Lal et al. (2017) & $\left(\mathrm{Sb}_{0.68} \mathrm{Bi}_{1.10}\right)_{2} \mathrm{Te}_{3.25}$ & Film & & & 17.6 & 11 & & & & & $\mathrm{RT}$ \\
\hline Kang et al. (2017) & $\mathrm{Bi}_{2} \mathrm{Te}_{3}$ & Thick film & & & & -72.3 & 1,408 & & 732 & & $\mathrm{RT}$ \\
\hline Lei et al. (2017) & $\mathrm{Bi}_{0.5} \mathrm{Sb}_{1.5} \mathrm{Te}_{3}$ & Thick film & & (015) & 17 & 150 & 100 & & 230 & & $\mathrm{RT}$ \\
\hline Wu et al. (2017b) & $\mathrm{Bi}_{2} \mathrm{Te}_{3}$-silica particle & Film & & & & 78 & & & & & RT \\
\hline Xiaolong and Zhen, (2014) & $\mathrm{Bi}_{2} \mathrm{Se}_{3}$ & Thick film & & & & 20 & 1,309 & & 52.57 & & $\mathrm{RT}$ \\
\hline Jagadish et al. (2016) & $\mathrm{Bi}_{2} \mathrm{~S}_{2.34}$ & Film & & & & -16.3 & & & & & $\mathrm{RT}$ \\
\hline Kim and Oh, (2010b) & $\mathrm{Sb}_{2} \mathrm{Te}_{3}$ & Thin film & & & & 322 & & & & & $\mathrm{RT}$ \\
\hline \multirow[t]{2}{*}{ Pinisetty et al. (2011b) } & $\mathrm{Sb}_{2} \mathrm{Te}_{3}$ & Nanowires & Dia. 100nm & & 36 & 359 & & & & & 300 \\
\hline & $\mathrm{Sb}_{2} \mathrm{Te}_{3}$ & Nanotubes & Dia. 400nm & & 43 & 332 & & & & & 300 \\
\hline Lim et al. (2011) & $\mathrm{Sb}_{2} \mathrm{Te}_{3}$ & Film & & (015) & & 118 & & & & & RT \\
\hline Qiu et al. (2011) & $\mathrm{Sb}_{2} \mathrm{Te}_{5}$ & Thin film & & & & 532 & & & 1,580 & & $\mathrm{RT}$ \\
\hline Schumacher et al. (2012) & $\mathrm{Sb}_{39.08} \mathrm{Te}_{60.92}$ & Film & & (015) & 543 & 161 & 280 & & 726 & & $\mathrm{RT}$ \\
\hline Lim et al. (2012b) & $\mathrm{Sb}_{5} \mathrm{Te}_{8}$ & Thin film & & (015) & & 118 & & & 44.2 & & 473 \\
\hline Yoo et al. (2013c) & $\mathrm{Sb}_{2} \mathrm{Te}_{3}$ & Thin film & & & & 280 & & & 100 & & RT \\
\hline Kim et al. (2016) & $\mathrm{AgSbTe}_{2}$ & Thin film & Nano-crystalline & & & 300 & & & 553 & & $\mathrm{RT}$ \\
\hline
\end{tabular}


2 , and weak impurity scattering, the $r$ is $3 / 2$. Therefore, an increase of the scattering parameter leads to an increase in the slope of the differential conductivity, thus also in the Seebeck coefficient.

Recently, the energy filtering effect where the creation of band bending induced by charge transfer at the interfaces causes the energy-dependent scattering of charge carriers was used to decouple $S$ and $\sigma$. In the concrete, a barrier height $\left(E_{b}\right)$ can be generated on the pathways of charge carriers by interfaces, where the charge carriers with higher energy would pass though but the charge carriers with low energy would be scattered. The carrier charge scattering, which is dependent on energy, would improve Seebeck coefficient, owing to its correlation with the energy derivative of the relaxation time at the Fermi energy;

$$
\begin{gathered}
S=\frac{\pi^{2} k B^{2} T}{3 e}\left(\frac{\partial \ln N(E)}{\partial E}+\frac{\partial \ln \tau(E) v(E)^{2}}{\partial E}\right) E_{F} \\
\tau^{-1}(E)=\frac{V_{b}^{2} x}{R} E^{-3 / 2}=\frac{e \mu}{m^{*}}
\end{gathered}
$$

Where $v(E)$ is the velocity of average charge, $N(E)$ is the density of states, $\tau(E)$ is the charge carrier relaxation time. Furthermore, as shown in Eq. 6, the carrier relaxation time is proportional to the barrier potential $\left(V_{b}\right)$ by inversion, which means tailoring a potential barrier to an effective height can be utilized to enhancing the Seebeck coefficient. (Faleev and Léonard, 2008; Martin et al., 2009; Ko et al., 2011; Sumithra et al., 2011; Narducci et al., 2012; Zhang et al., 2012).

\section{ELECTRODEPOSITION OF THERMOELECTRIC MATERIALS}

Xiao et al. (2008) and Boulanger (2010) reviewed the advances in the electrodeposition of thermoelectric materials in 2008 and 2010, respectively, where major focus was devoted to electrochemistry of thermoelectric materials. Rostek et al. (2015) and others (Snyder et al., 2003; Wang et al., 2013; Roth et al., 2014; Shin and Oh, 2015; Uda et al., 2015; Pelz et al., 2016) reviewed the advancement of electrodeposition of $\mathrm{Bi}_{2}(\mathrm{Te}, \mathrm{Se})_{3}$ and $(\mathrm{Bi}, \mathrm{Sb})_{2} \mathrm{Te}_{3}$ thin films and electrodeposition-based processes to form TE microdevices.

Here, the latest development of various electrodeposited thermoelectric thin films and nanostructured materials (i.e., Te, PbTe, $\mathrm{Bi}_{2} \mathrm{Te}_{3}, \mathrm{BiSe}, \mathrm{BiS}, \mathrm{Sb}_{2} \mathrm{Te}_{3}, \mathrm{Cu}_{2} \mathrm{Se}, \mathrm{CoSb}_{3}, \mathrm{Ag}_{8} \mathrm{SnS}_{6}$, and their derivatives) were comprehensively reviewed in last 10 years. Especially, their thermoelectric properties were summarized and correlated to their composition, morphology, and crystal structure (Table $\mathbf{1}$ ).

\section{Electrodeposition of Tellurium}

Electrodeposition of tellurium has been investigated in both acidic and alkaline media. Qiu et al. (1989) electrodeposited Te thin films with a thickness up to $4 \mu \mathrm{m}$ on monocrystalline tellurium substrate from a $\mathrm{TeO}_{2}$-saturated aqueous solution. The thickness was relatively uniform. The needle-like surface morphology with random crystal orientation was observed when deposited on (10 $\overline{1}$ 0 $)$ surfaces. At high current densities, polycrystalline films consisting of $1 \mu \mathrm{m}$ blades with random crystal orientation were produced (Qiu and Shih, 1989).

Suggs et al. (1991) investigate the electrochemical nucleation and growth of Te on gold $(\mathrm{Au})$ (100) surface in acidic sulfate baths (i.e., $0.4 \mathrm{mM} \mathrm{TeO}_{3}{ }^{2-}$ in $\mathrm{X} \mathrm{M} \mathrm{H}_{2} \mathrm{SO}_{4}$ ). Under potentiodynamic deposition, $\mathrm{Te}$ initially electrodeposited under underpotential deposition (UPD). As the deposition potential becomes more cathodic, Te electrodeposits under overpotential deposition (OPD) to from three dimensional nuclei. (Suggs and Stickney, 1991).

Ikemiya et al. (1996) electrodeposited Te films on $\mathrm{Au}$ (100) and $\mathrm{Au}(111)$ from acidic sulfate solutions $\left(0.1 \mathrm{mM} \mathrm{HTeO}_{2}{ }^{+}+\right.$ $\left.0.05 \mathrm{M} \mathrm{H}_{2} \mathrm{SO}_{4}\right)$. The atomic structures and growth morphologies of the films were investigated by in situ atomic force microscopy. Accordingly, the atomic structure of the Te deposits was independent to the substrate crystal orientation, this support the conclusion that the surface diffusion process of Te adsorbed atoms is rate-limiting steps (Ikemiya et al., 1996).

Yagi et al. (1996) electrodeposited Te in acidic perchlorate solutions with $0.1 \mathrm{M} \quad \mathrm{HClO}_{4}$ and $0.5 \mathrm{mM}^{\mathrm{TeO}_{2}}$ using polycrystalline gold as substrate. AuAdditionally, in situ optical second harmonic (SH) generation at two different excitation wavelengths was utilized. On $1,064 \mathrm{~nm}$ excitation, the SH signal varied with the surface coverage of Te (Yagi et al., 1996).

Sorenson et al. synthesized tellurium atomic layers on $\mathrm{Au}$ (110) by electrodeposition in the acidic bath (i.e., $0.25 \mathrm{mM} \mathrm{TeO}_{2}$ $+20 \mathrm{mM} \mathrm{H}_{2} \mathrm{SO}_{4}$ ). Additionally, the phase transitions associated with those layers was investigated. The voltammetry indicates two sub-monolayer deposition features and one for bulk. The result of the slow deposition kinetics is that surfaces composed of a single atomic layer structure are not observed. (Sorenson et al., 1999; Sorenson et al., 2001)

Jiang et al. electrodeposited Te film on polyaniline-coated macroporous phenolic foam in the solution with $1 \mathrm{M} \mathrm{HNO}_{3}$ and $10 \mathrm{mM} \mathrm{HTeO}_{2}{ }^{+}$. The deposited film was composed of columnar structures and had a growth direction along c-axis direction (Jiang et al., 2011). The highest Seebeck coefficient achieved for the macroporous Te film is $342 \mu \mathrm{V} / \mathrm{K}$ at $473 \mathrm{~K}$ (Jiang et al., 2012).

Abad et al. (2015) electrodeposited Te films from acidic nitrate baths (e.g., $10 \mathrm{mM} \mathrm{HTeO}_{2}{ }^{+}$and $1 \mathrm{M} \mathrm{HNO}_{3}$ ) with sodium lignosulfonate (SLS) as additives. The presence of SLS reduced the average grain size resulted in higher electrical resistivity $(\sim 798 \mu \Omega \mathrm{m})$ compared to Te electrodeposits $(\sim 229 \mu \Omega \mathrm{m})$ in the absence of SLS. The Seebeck coefficient values were about $285 \mu \mathrm{V} / \mathrm{K}$ for both samples which resulted in the power factor of $280 \mu \mathrm{W} /\left(\mathrm{mK}^{2}\right)$ and $82 \mu \mathrm{W} /\left(\mathrm{mK}^{2}\right)$ without SLS and with SLS, respectively, at room temperature (Abad et al., 2015).

$\mathrm{Ha}$ et al. (2000) reported the electrochemical behavior of tellurium in alkaline baths (e.g., $10 \mathrm{mM} \mathrm{TeO}_{3}{ }^{2-}$ in $2.5 \mathrm{M}$ $\mathrm{NaOH}$ ). In this bath, Te was able to electrodeposit between $-0.8 \mathrm{~V}$ and $-0.95 \mathrm{~V}$ vs. $\mathrm{Hg} / \mathrm{HgO}$, but the Te morphology was porous with needle-like radial growth (Ha et al., 2000).

Sadeghi et al. (2008) electrodeposited Te using a nickel-coated copper as substrate in alkaline plating baths. The influence of 
current density, temperature, and $\mathrm{pH}$ were systematically studied. They found that the optimum conditions to electrodeposit $\mathrm{Te}$ was: $6 \mathrm{~g} / \mathrm{L}(37.6 \mathrm{mM}) \mathrm{TeO}_{2}, \mathrm{pH}$ of 10 , and $\mathrm{DC}$ current density of $8.55 \mathrm{~mA} / \mathrm{cm}^{2}$ at room temperature (Sadeghi et al., 2008).

Our group also demonstrated the ability to electrodeposit thick Te films from alkaline baths (Wu et al., 2017a) where the applied potentials were optimized to electrochemically reduced $\mathrm{TeO}_{3}{ }^{-2}(a q)$ to $\mathrm{Te}_{(\mathrm{s})}$ without further reduction of Te to $\mathrm{Te}_{2}{ }^{2-}(a q)$. The XRD data revealed that the preferred orientation of thick Te films altered from (001) to (101) as the applied potential varied from $-0.9 \mathrm{~V}$ to $-1.0 \mathrm{~V}$. The optimum $\mathrm{pH}$ ranges to deposit compact thick films was between 11.3 and 12.5. Additionally, sufficient magnetic agitation is also essential to deposit compact films. The average grain size ranged from 66 to $135 \mathrm{~nm}$ where larger grain size resulted in lower carrier concentration (e.g., $n=7.1 \times 10^{18} \mathrm{~cm}^{-3}$ ) which might be due to lower defect density. The Highest deposition rate (upto $130 \mu \mathrm{m} / \mathrm{h}$ ) with high current efficiency (upto 85\%) was achieved by adjusting deposition conditions. Additionally, galvanic displacement reaction which is another facile method to synthesize various nanostructured Te was investigated (Chang et al., 2010; Chen et al., 2010; Hangarter et al., 2010; Lee et al., 2011; Jung et al., 2012; Elazem et al., 2013; Park et al., 2013; Suh et al., 2014; Suh et al., 2017).

\section{Electrodeposition of Lead Telluride Based Materials}

$\mathrm{PbTe}$ is also a narrow band-gap semiconductor with $\mathrm{E}_{\mathrm{g}}$ of $0.31 \mathrm{eV}$ measured at room temperature and a rock-salt crystal structure. $\mathrm{PbTe}$ can be n-type or p-type as a result of departures from stoichiometry (n-type for $\mathrm{Pb}$-rich $\mathrm{PbTe}$, while p-type for Te-rich PbTe). (Dughaish, 2002). The state-of-the-art commercially available $\mathrm{PbTe}$ based thermoelectric materials have the highest ZT of $\sim 0.8$ at $\sim 600 \mathrm{~K}$, which makes the materials a good candidate for thermoelectric application in the middle-high temperature range.

The Electrodeposition of PbTe was investigated by several groups. Saloniemi et al. reported electrodeposition of Te-rich PbTe thin films in alkaline electrolytes containing $\mathrm{TeO}_{2}$, disodium salt of ethylenediaminetetraacetic acid (EDTA), and $\mathrm{Pb}\left(\mathrm{CH}_{3} \mathrm{COO}\right)_{2}$ ethylenediaminetetraacetic. They utilized various electrochemical analysis methods including cyclic voltammetry and quartz crystal microbalance to investigate the electrodeposition of PbTe. They observed that Te-rich $\mathrm{PbTe}$ deposition through UPD of $\mathrm{Pb}$ on $\mathrm{Te}$ via six electron reduction (Saloniemi et al., 1998). The reduction of the PbEDTA $^{2-}$ complex to $\mathrm{Pb}_{(0)}$ was a two-electron reaction whereas $\mathrm{Te}$ deposits via a four-electron reaction. As the potential becomes more negative, the film becomes powdery and $\mathrm{Te}_{(0)}$ further reduced to $\mathrm{Te}_{2}{ }^{2-}$ as the deposition potential becomes more negative (Saloniemi et al., 2000).

Miranda et al. electrodeposited polycrystalline PbTe thin films on porous silicon from alkaline solutions with EDTA as a complexing agent for $\mathrm{Pb}$. They were able to deposit $\mathrm{PbTe}$ thin films with the average grain size of $100 \mathrm{~nm}$ (Miranda et al., 2004).
Qiu et al. (2005) synthesized uniform and single-crystalline PbTe nanorods with a diameter in the sub-10-nm regime at ambient conditions using sonoelectrochemical method. In the experiment, the $\mathrm{Pb}^{2+}$ and $\mathrm{TeO}_{3}{ }^{2-}$ ions concentration were fixed at $10 \mathrm{mM}$, and the solution $\mathrm{pH}$ was kept at approximately 8 . Nitrilotriacetic acid (NTA) was used as a complex reagent. The composition of $\mathrm{PbTe}$ can be controlled by ratio of precusor ion/ligand concentration. When the $\left[\mathrm{Pb}^{2+}\right] /[\mathrm{NTA}]$ changed from $0.20: 1$ to $0.10: 1$ to $0.05: 1$, the composition of deposits changed from pure $\mathrm{PbTe}$ to a mixture of $\mathrm{PbTe} / \mathrm{Te}$ to pure Te (Qiu et al., 2005).

Yang et al. (2008) electrodeposited PbTe nanowire arrays using template which is patterned by lithographic method. The cross-section of the synthesized $\mathrm{PbTe}$ nanowires is rectangular, and the width and height of the nanowires can be tuned from 60 to $400 \mathrm{~nm}$ and $20-100 \mathrm{~nm}$, respectively. Polycrystalline $\mathrm{PbTe}$ with face centered cubic crystal structure and was produced by a cyclic electrodeposition-stripping method, which have grain size ranged from 10 to $20 \mathrm{~nm}$. The nanowires have a length over $1 \mathrm{~mm}$ (Yang et al., 2008).

Erdogan et al. (2009) electrodeposited stoichiometric PbTe thin films on $\mathrm{Au}$ (111) substrates from alkaline baths containing EDTA, $\mathrm{Pb}^{2+}$, and $\mathrm{TeO}_{3}{ }^{2-}$ ions. They observed two dimensional nucleation and growth with the preferred orientation of (200) (Erdoğan et al., 2009).

Li et al. (2008a) electrodeposited symmetrical PbTe dendritic structures in the solution containing $10 \mathrm{mM} \mathrm{Na} \mathrm{Na}_{2} \mathrm{TeO}_{3}$, $5 \mathrm{mM} \mathrm{Pb}\left(\mathrm{NO}_{3}\right)_{2}$ and $0.1 \mathrm{M}$ tartaric acid. The formation of the $\mathrm{PbTe}$ dendritic structure is affected by the potential oscillation. The morphology of particle with dendritic structures were starlike or trigonal, and the size of the particles were varied from 100 to $500 \mathrm{~nm}$. The deposited PbTe structures had a band gap energy of about $0.272 \mathrm{eV}$ (Li et al., 2008a).

Additionally, many other groups reported the results of characterization of $\mathrm{PbTe}$ electrodeposits based on various experimental conditions which are summarized on the Table 1. (Banga et al., 2008; Diliberto et al., 2008; Jung et al., 2011; Ni et al., 2011; Frantz et al., 2015; Wu et al., 2016a; Frantz et al., 2016; Bae et al., 2017).

\section{Electrodeposition of Bismuth Telluride $\left(\mathrm{Bi}_{2} \mathrm{Te}_{3}\right)$ Based Materials Including BiTe, $\mathrm{BiSbTe}, \mathrm{BiTeSe}$ and BiSbTeSe}

$\mathrm{Bi}_{2} \mathrm{Te}_{3}$ with a bandgap of $0.16 \mathrm{eV}$ is an excellent candidate for $\mathrm{TE}$ application near room temperature range (Figure 4). Electrodeposition of $\mathrm{Bi}_{2} \mathrm{Te}_{3}$ was investigated by various groups.

Wang et al. (2008) synthesized high-density thermoelectric $\mathrm{Bi}_{2} \mathrm{Te}_{3} / \mathrm{Sb}$ heterostructure nanowire arrays with diameter of tens using AAO template-directed pulsed electrodeposition. The electrolyte included $12 \mathrm{mM} \mathrm{TeO}, 4 \mathrm{mM} \mathrm{Bi}\left(\mathrm{NO}_{3}\right)_{3}, \quad 0.1 \mathrm{M}$ $\mathrm{Sb}_{2} \mathrm{O}_{3}, \quad 0.5 \mathrm{M} \quad \mathrm{K}_{2} \mathrm{C}_{6} \mathrm{H}_{5} \mathrm{O}_{7}, \quad 1 \mathrm{M} \quad \mathrm{C}_{6} \mathrm{H}_{8} \mathrm{O}_{7}$, and $2 \mathrm{M} \mathrm{HNO}_{3}$. Additionally, was used as template (Wang et al., 2008).

$\mathrm{Li}$ et al. synthesized the hierarchical $\mathrm{Bi}_{2} \mathrm{Te}_{3}$ nanostructures by electrodeposition in the solution with $10 \mathrm{mM} \mathrm{Na}_{2} \mathrm{TeO}_{3}, 5 \mathrm{mM}$ $\mathrm{Bi}\left(\mathrm{NO}_{3}\right)_{3}, 10 \mathrm{mM}$ tartaric acid and $1 \mathrm{M} \mathrm{HNO}_{3}$ at room temperature (Li et al., 2008b; Li et al., 2008c). 

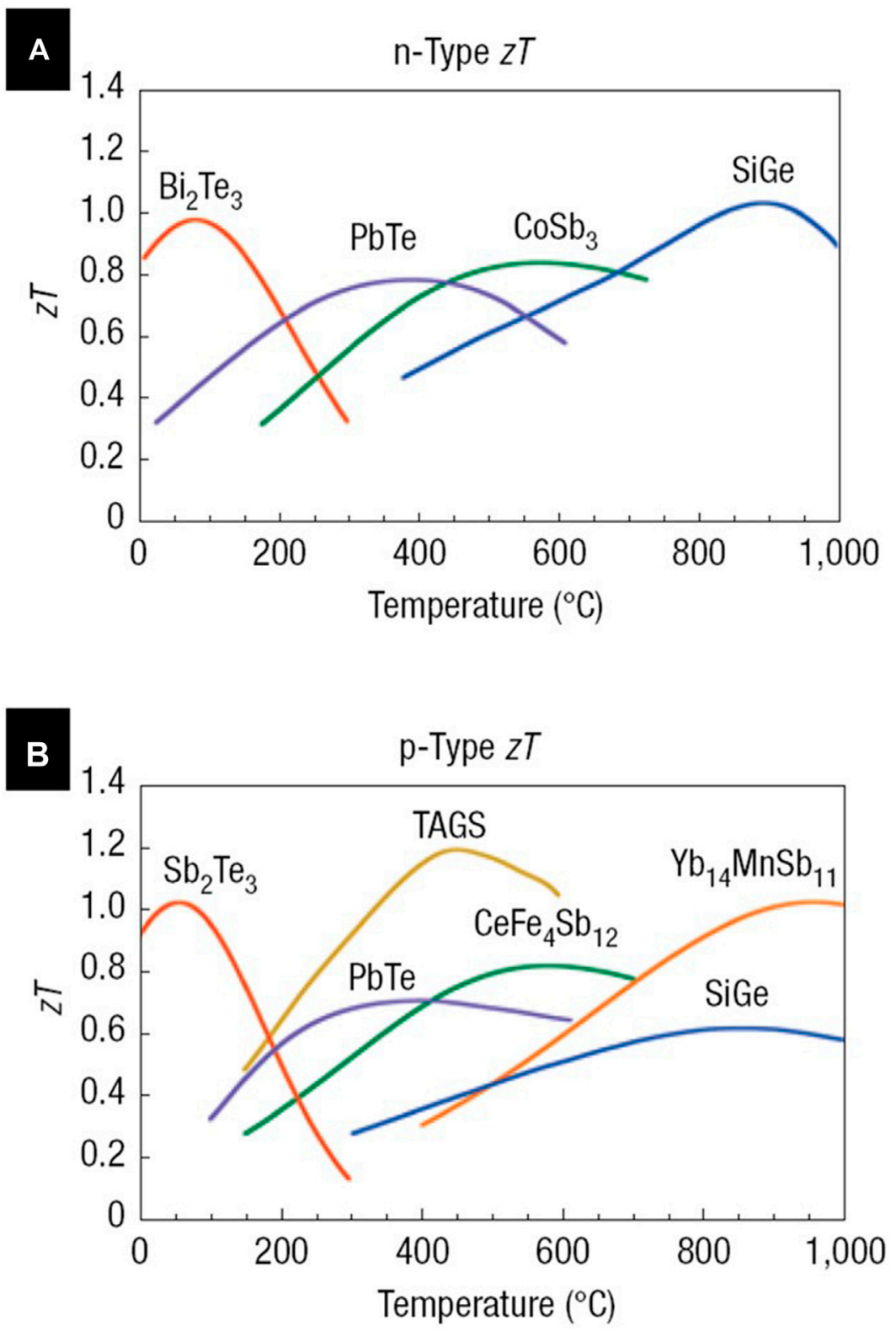

FIGURE 4 | Thermoelectric performance (ZT) of the state-of-art commercial thermoelectric materials: (A) n-type and (B) p-type, as function of temperature (Snyder and Toberer, 2008).

Liu and $\mathrm{Li}$ (2008) reported that electrodeposited $\mathrm{Bi}_{2} \mathrm{Te}_{3}$ films had a preferential orientation of (110) and platelet grain morphology. The grain morphology changed from single-to multi-order platelets, and the texture decreased when the deposition potential became more negative, which was explained by considering geometrical selection growth and (1i010) (i 105) twinning of $\mathrm{Bi}_{2} \mathrm{Te}_{3}$ crystals (Liu and $\mathrm{Li}, 2008$ ).

Glatz et al. (2008) electrodeposited $\mathrm{Bi}_{2+\mathrm{x}} \mathrm{Te}_{3-\mathrm{x}}$ by combining potential controlled deposition pulses with galvanostaticcontrolled resting pulses. The deposited had a uniform stoichiometry composition along the entire thickness. A deposition rates of $50 \mu \mathrm{m} / \mathrm{h}$ was achieved, and Layers thickness of $800 \mu \mathrm{m}$ was obtained. The composition of $\mathrm{Bi}_{2+\mathrm{x}} \mathrm{Te}_{3-\mathrm{x}}$ can be controlled by varying $\mathrm{Bi}$ ion concentration in the electrolyte with $80 \mathrm{mM} \mathrm{HTeO}_{2}{ }^{+}$and $2 \mathrm{M} \mathrm{HNO}_{3}$. Bath $\mathrm{n}$-type and p-type $\mathrm{Bi}_{2+\mathrm{x}} \mathrm{Te}_{3-\mathrm{x}}$, which is determined by Seebeck coefficients, was deposited (Glatz et al., 2008).

Lee et al. (2008) electrodeposited $\mathrm{Bi}_{2} \mathrm{Te}_{3}$ nanowires arrays using $\mathrm{AAO}$ as template by potentiostatic, galvanostatic, and pulsed method in aqueous solution at room temperature. Uniform $\mathrm{Bi}_{2} \mathrm{Te}_{3}$ nanowire arrays with highly oriented crystalline structure was synthesized, The bandgap of the deposited can be controlled from 0.21 to $0.29 \mathrm{eV}$ by different relaxation times in the pulsed electrodeposition. The electrical 
resistances increased slightly with increasing temperatures, which was owing to enhanced carrier-phonon scattering. All samples showed a positive Seebeck coefficient $(12-33 \mu \mathrm{V} / \mathrm{K})$. (Lee et al., 2008).

$\mathrm{Li}$ et al. electrodeposited $\mathrm{Bi}_{\mathrm{x}} \mathrm{Sb}_{2-\mathrm{x}} \mathrm{Te}_{\mathrm{y}}$ in nitric acid and hydrochloric acid solutions. A composition of $\mathrm{Bi}_{0.5} \mathrm{Sb}_{1.5} \mathrm{Te}_{3}$ was gained in both acid solutions with significantly different morphology. The $\mathrm{Bi}_{0.47} \mathrm{Sb}_{1.36} \mathrm{Te}_{3.17}$ thin film prepared in the nitric acid solution has the highest Seebeck coefficient of $213 \mu \mathrm{V} / \mathrm{K}$. The $\mathrm{Bi}_{0.22} \mathrm{Sb}_{1.48} \mathrm{Te}_{3.30}$ film prepared in the hydrochloric acid solution has the highest power factor of $111.5 \mu \mathrm{W} /\left(\mathrm{mK}^{2}\right)$, which had an electrical resistivity of $1.27 \times 10^{-4} \Omega \mathrm{m}$ and Seebeck coefficient of $119 \mu \mathrm{V} / \mathrm{K}$ (Li and Wang, 2009).

Diliberto et al. (2008) synthesized $\mathrm{Bi}_{2} \mathrm{Te}_{3}$ thin films using pulsed electrodeposition from electrolytes of $20 \mathrm{mM} \mathrm{Te}(\mathrm{IV})$ ion and $1 \mathrm{M} \mathrm{HNO}_{3}$. The $\mathrm{Bi}$ ion concentration was varied, where increasing $\mathrm{Bi}$ concentration in the electrolyte would lead to higher $\mathrm{Bi}$ composition. The results also indicated that pulsed electrodeposition would improve the morphology and the electrical conductivity of films compared to direct electrodeposition. The film near stoichiometry $\left(\mathrm{Bi}_{1.93} \mathrm{Te}_{3.07}\right)$ have a Seebeck coefficient of $-65 \mu \mathrm{V} / \mathrm{K}$ (Diliberto et al., 2008).

Zhu et al. (2008) synthesized $\mathrm{Bi}_{2} \mathrm{Te}_{3}$ thin sheets on $\mathrm{Au}$ by electrochemical atomic layer epitaxy method using Bi solution with $0.25 \mathrm{mM} \mathrm{Bi}\left(\mathrm{NO}_{3}\right)_{3}$ and $0.1 \mathrm{M} \mathrm{HClO}_{4}$, and Te solutions with $0.25 \mathrm{mM} \mathrm{TeO}_{2}$ and $0.1 \mathrm{M} \mathrm{HClO}_{4}$. The bandgap of the $\mathrm{Bi}_{2} \mathrm{Te}_{3}$ film was $0.33 \mathrm{eV}$ measured by Fourier transform infrared spectroscopy. Compared to the bulk $\mathrm{Bi}_{2} \mathrm{Te}_{3}$ single crystal, the bandgap is blue shifted (Zhu et al., 2008).

Mavrokefalos et al. (2009) reported electrodeposition of n-type $\mathrm{Bi}_{2} \mathrm{Te}_{3}$ nanowires (NW). The results showed that monocrystalline NWs have higher electrical conductivity and thermal conductivity than polycrystalline NWs. Additionally, the carrier mobility of the monocrystalline NW is about 2.5 times higher than that of the polycrystalline NW, but it about $19 \%$ lower than that of bulk materials. The electron mean-free path was decreased from $61 \mathrm{~nm}$ for bulk materials to $40 \mathrm{~nm}$ for the $52 \mathrm{~nm}$ nanowires, which is owing to electron scattering specularity parameter by nanowire surface is 0.7 . Furthermore, the thermal conductivity of the polycrystalline nanowires is lower. The ZT is about 0.1 at $400 \mathrm{~K}$ for both monocrystalline and polycrystalline NWs (Mavrokefalos et al., 2009).

$\mathrm{Li}$ et al. electrodeposited $\mathrm{Bi}_{0.5} \mathrm{Sb}_{1.5} \mathrm{Te}_{3}$ thin film from nitric acid baths. The results show that electrodeposition mechanism varied with applied potential, where at low applied potential, Te was deposited because of electrochemical reduction of $\mathrm{HTeO}_{2}{ }^{+}$, while at more negative applied potential the reduction reaction of $\mathrm{Bi}^{3+}$ with $\mathrm{Te}$ occurred with formation of $\mathrm{Bi}_{2} \mathrm{Te}_{3}$. Additionally, when the applied potential is negative enough, formation of $\mathrm{Bi}_{0.5} \mathrm{Sb}_{1.5} \mathrm{Te}_{3}$ compound took place (Köse et al., 2009).

$\mathrm{Li}$ et al. examined the electrodeposition of $\mathrm{Bi}_{2} \mathrm{Te}_{3}$ in a solution containing $\mathrm{TeCl}_{4}, \mathrm{Bi}\left(\mathrm{NO}_{3}\right)_{3}$ and dimethyl sulfoxide (DMSO) by combining cyclic voltammetry with electrochemical quartz crystal microbalance. The results indicated $\mathrm{Te}^{4+}$ concentrations in and applied potential had an effect on $\mathrm{Bi}_{2} \mathrm{Te}_{3}$ composition. $\mathrm{Bi}_{2} \mathrm{Te}_{3}$ was electrodeposited in applied potential between -0.2 and $-0.8 \mathrm{~V}$ vs. $\mathrm{Ag} / \mathrm{AgCl}$ with $10 \mathrm{mM} \mathrm{Te}{ }^{4+}$ and $7.5 \mathrm{mM} \mathrm{Bi}^{3+}$.
However, Te-rich $\mathrm{Bi}_{2} \mathrm{Te}_{3}$ were electrodeposited at applied potential between -0.2 and $-0.8 \mathrm{~V}$ vs. $\mathrm{Ag} / \mathrm{AgCl}$ in the solution with $50 \mathrm{mM} \mathrm{Te}{ }^{4+}$ and $37.5 \mathrm{mM} \mathrm{Bi}^{3+}(\mathrm{Li}, 2009)$.

Suresh et al. (2009) electrodeposited $\mathrm{Bi}_{2} \mathrm{Te}_{3}$ thin films at various $\mathrm{pH}$ values in $\mathrm{HNO}_{3}$ solution of $\mathrm{Bi}\left(\mathrm{NO}_{3}\right)_{3}$ and $\mathrm{TeO}_{2}$. The increase in $\mathrm{pH}$ resulted in a decrease in grain size and the film morphology transformed from dispersed nanoparticles to connected chain-like nanostructures as $\mathrm{pH}$ was increased. At the temperature between 300 and $425 \mathrm{~K}$, the data showed a fourtimes increase in Seebeck coefficient between its maximum and minimum value as the solution $\mathrm{pH}$ changes from 1 to 3.5 , which is attributed to the improved connectivity of the nanostructures at higher pH (Suresh et al., 2009).

Kim and $\mathrm{Oh}$ (2009) electrodeposited n-type $\mathrm{Bi}_{2} \mathrm{Te}_{3}$ and p-type $\mathrm{Sb}_{2} \mathrm{Te}_{3}$ films. The n-type $\mathrm{Bi}_{2} \mathrm{Te}_{3}$ had a power factor of $7.1 \times$ $10^{-4} \mathrm{~W} /\left(\mathrm{K}^{2} \cdot \mathrm{m}\right)$ with a Seebeck coefficient of $-51.6 \mu \mathrm{V} / \mathrm{K}$, which was electrodeposited at applied potential of $-0.05 \mathrm{~V}$ with $25 \mathrm{mM}$ $\mathrm{Bi}$ ion and $25 \mathrm{mM}$ Te ion. Additionally, The p-type $\mathrm{Sb}_{2} \mathrm{Te}_{3}$ film had a power factor of $1.7 \times 10^{-4} \mathrm{~W} /\left(\mathrm{K}^{2} \cdot \mathrm{m}\right)$ with a Seebeck coefficient of $52.1 \mu \mathrm{V} / \mathrm{K}$, which is deposited at applied potential of $0.02 \mathrm{~V}$ in the solution containing $63 \mathrm{mM} \mathrm{Sb}$ ion and $7 \mathrm{mM}$ Te ion. (Kim and Oh, 2009).

Mannam et al. (2009) electrodeposited $\mathrm{Bi}_{\mathrm{x}} \mathrm{Te}_{\mathrm{y}}$ nanowires from aqueous acidic solutions containing different $\left[\mathrm{Bi}^{3+}\right] /\left[\mathrm{HTeO}_{2}{ }^{+}\right]$ $(20 / 20$ and $20 / 10 \mathrm{mM})$ with $2.5 \mathrm{M} \mathrm{HNO}_{3}$. The nanowires deposited at low applied potentials had a dominant orientation of (110) according to the XRD pattern. In both electrolytes, n-type nanowires were deposited. However, p-type nanowires can be deposited only in the $\left[\mathrm{Bi}^{3+}\right] /\left[\mathrm{HTeO}_{2}{ }^{+}\right]=20 / 10 \mathrm{mM}$ solution. Nanowires formed in the $20 / 10 \mathrm{mM}$ electrolyte showed at transition from intrinsic to extrinsic. The Seebeck coefficient of -318.7 and $117 \mu \mathrm{V} / \mathrm{K}$ were achieved for $n$-type and p-type $\mathrm{Bi}_{\mathrm{x}} \mathrm{Te}_{\mathrm{y}}$ nanowires, respectively (Mannam et al., 2009).

Kuleshova et al. (2010) electrodeposited BiSbTe films in nitric acid baths. In the electrolyte, sodium ligninsulfonate was added as surfactant, which would improve uniformity of the films as well as the thermoelectric properties. Additionally, the surfactant would also affect the composition of films, where $\mathrm{Bi}_{0.32} \mathrm{Sb}_{1.33} \mathrm{Te}_{3}$ was deposited in the solution with surfactant and $\mathrm{Bi}_{0.35} \mathrm{Sb}_{1.33} \mathrm{Te}_{3}$ was deposited without surfactant in the solution with $10 \mathrm{mM}$ $\mathrm{HTeO}_{2}{ }^{+}, 1 \mathrm{mM} \mathrm{Bi}^{3+}, 20 \mathrm{mM} \mathrm{Sb}^{3+}, 1 \mathrm{M} \mathrm{HNO}_{3}, 0.1 \mathrm{M} \mathrm{H}_{3} \mathrm{Cit}$ and $50 \mathrm{mM} \mathrm{Na}_{3} \mathrm{Cit}$ (Kuleshova et al., 2010).

$\mathrm{Ma}$ et al. (2010) electrodeposited $\mathrm{Bi}_{2} \mathrm{Te}_{3}$ on stainless steel, in which the reaction mechanism and the effect of deposition parameters on composition and morphology were investigated. The CV results showed that onset potential for $\mathrm{Bi}_{2} \mathrm{Te}_{3}$ is more positive than $\mathrm{Bi}$ and $\mathrm{Te}$ deposition. Furthermore, the $\mathrm{Te}$ reduction reaction is kinetically hindered with the presence of Bi ions. (Ma et al., 2010).

Kim and Oh (2010a) synthesized p-type $\mathrm{Sb}_{\mathrm{x}} \mathrm{Te}_{\mathrm{y}}$ and n-type $\mathrm{Bi}_{\mathrm{x}} \mathrm{Te}_{\mathrm{y}}$ films by electrodeposition. The $\mathrm{Bi}_{\mathrm{x}} \mathrm{Te}_{\mathrm{y}}$ film with a thickness of $5.3 \mu \mathrm{m}$ was electrodeposited in $1 \mathrm{M} \mathrm{HNO}_{3}$ solution at $-0.05 \mathrm{~V}$, which contained $50 \mathrm{mM} \mathrm{Bi}$ and $\mathrm{Te}$ ion. Moreover, the $\mathrm{Bi} /(\mathrm{Bi}+\mathrm{Te})$ mole ratio is 0.5 . $\mathrm{The}_{\mathrm{Sb}} \mathrm{Te}_{\mathrm{y}}$ film with a thickness of $5.2 \mu \mathrm{m}$ was electrodeposited at $0.02 \mathrm{~V}$ in the electrolyte, where the total concentration of $\mathrm{Sb}$ and $\mathrm{Te}$ ion is 

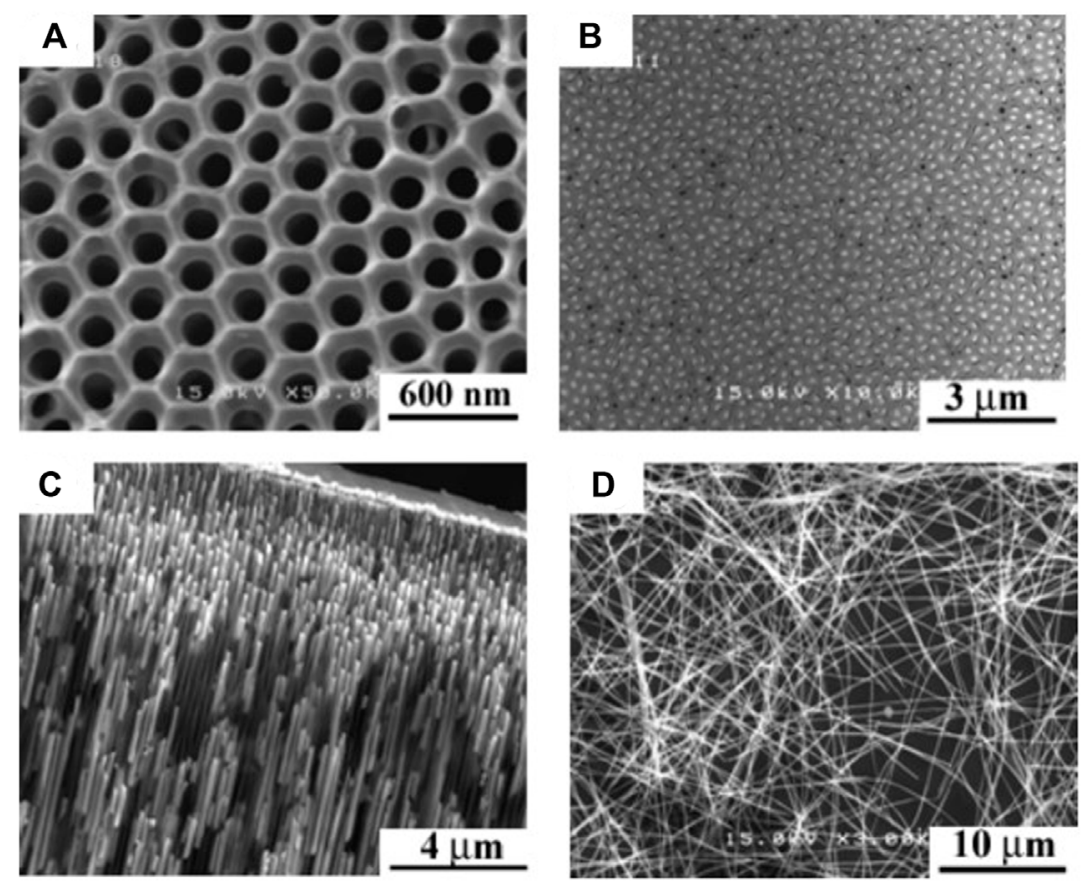

FIGURE 5 | Scanning electron micrographs of $A A O$ template and $\mathrm{Bi}_{2} \mathrm{Te}_{3}$ nanowires array: (A) $\mathrm{AAO}$, (B) $\mathrm{Top}$ view of $\mathrm{Bi}_{2} \mathrm{Te}_{3}$ nanowires array, (C) Side view of $\mathrm{Bi}_{2} \mathrm{Te}_{3}$ nanowires array, (D) individual nanowires after dissolving AAO (Chen et al., 2010).

$70 \mathrm{mM}$ and $\mathrm{Sb} /(\mathrm{Sb}+\mathrm{Te})$ mole ratio is 0.9 . $\mathrm{The}_{\mathrm{Bi}} \mathrm{Te}_{\mathrm{y}}$ and $\mathrm{Sb}_{\mathrm{x}} \mathrm{Te}_{\mathrm{y}}$ films have an electrical conductivity of -67 and $63 \mu \mathrm{V} / \mathrm{K}$ (Kim and Oh, 2010a).

Lee et al. (2010) electrodeposited $\mathrm{Bi}_{2} \mathrm{Te}_{3}$ nanowires in AAO templates. They claimed the electrical conductivity can be improved from 0.053 to $0.169 \times 10^{6} \mathrm{~S} / \mathrm{m}$ by tailoring the structural properties. Meanwhile, the Seebeck coefficient can be enhanced from $46.6 \mu \mathrm{V} / \mathrm{K}$ to $55 \mu \mathrm{V} / \mathrm{K}$. As a result, a power factor of $476.3 \mu \mathrm{W} /\left(\mathrm{K}^{2} \cdot \mathrm{m}\right)$ was achieved (Lee et al., 2010).

Richoux et al. (2010) synthesized p-type $\left(\mathrm{Bi}_{1-\mathrm{x}} \mathrm{Sb}_{\mathrm{x}}\right)_{2} \mathrm{Te}_{3}$ thermoelectric compounds by pulsed electrodeposition in the electrolyte with $1 \mathrm{M} \mathrm{HClO}_{4}$ and $0.1 \mathrm{M}$ tartaric acid. The deposited film had a Seebeck coefficient of $150 \mu \mathrm{V} / \mathrm{K}$. Additionally, pulsed electrodeposition method can be used to reduce resistivity of the films, where $200 \mu \Omega \mathrm{m}$ was achieved by pulsed electrodeposition method, compared to $5,000 \mu \Omega \mathrm{m}$ by direct-current electrodeposition method (Richoux et al., 2010).

$\mathrm{Li}$ et al. electrodeposited $\mathrm{Bi}_{\mathrm{x}} \mathrm{Sb}_{2-\mathrm{x}} \mathrm{Te}_{\mathrm{y}}$ film by potentiodynamic electrodeposition technique from mixed dimethyl sulfoxide solution containing $\mathrm{Bi}\left(\mathrm{NO}_{3}\right)_{3} \cdot 5 \mathrm{H}_{2} \mathrm{O}, \mathrm{TeCl}_{4}$ and $\mathrm{SbCl}_{3}$. Their results showed that electrodeposition of $\mathrm{Bi}_{\mathrm{x}} \mathrm{Sb}_{2-\mathrm{x}} \mathrm{Te}_{\mathrm{y}}$ can be realized in a wide range of applied potential. However, the films deposited at applied potential of -0.2 to $-0.4 \mathrm{~V}$ achieved the highest $\mathrm{S}$ of $185 \mu \mathrm{V} / \mathrm{K}$ and the lowest electrical resistivity of $3.34 \times 10^{-5} \Omega \mathrm{m}$ after annealing. Additionally, the deposited nano-crystalline $\mathrm{Bi}_{0.49} \mathrm{Sb}_{1.53} \mathrm{Te}_{2.98}$ film had a preferred orientation of (015) (Li and Wang, 2010).

Chen et al. (2010) fabricated Te-rich n-type $\mathrm{Bi}_{\mathrm{x}} \mathrm{Te}_{\mathrm{y}}$ films and nanowires array with rhombohedral structure (Figure 5) by potentiostatically electrodeposition from nitric baths. The
Seebeck coefficient was about $-70 \mu \mathrm{V} / \mathrm{K}$ at $300 \mathrm{~K}$ and decreased monotonically with temperature. Additionally, thermal conductivity of $0.75 \mathrm{~W} /(\mathrm{mK})$ was obtained at $300 \mathrm{~K}$. Aa a result, The $\mathrm{ZT} \mathrm{Bi}_{2} \mathrm{Te}_{3}$ nanowire was 0.45 at $300 \mathrm{~K}$ and 0.9 at $350 \mathrm{~K}$ for (Chen et al., 2010).

Frantz et al. (2010) also synthesized polycrystalline $\mathrm{Bi}_{2} \mathrm{Te}_{3}$ nanowires with rhombohedral phase by electrodeposition using porous polycarbonate as template. Their results showed that dimethyl sulfoxide would help to increase the filling ratio to $80 \%$. Moreover, DMSO in the electrolyte can help to improve the electrical conductivity of the nanowires (Frantz et al., 2010).

Gan et al. (2010) investigated Nanoscale Bi-Te particles with thermoelectric properties electrodeposited on copper substrate in 2.0 $\mathrm{M} \mathrm{HNO}_{3}$. The atomic ratio 1:1 for Bi:Te in the alloy, which is equivalent to the weight percentage of $\mathrm{Bi}: \mathrm{Te}=62 \%: 38 \%$ was confirmed from the EDS data (Gan et al., 2010).

Li et al. (2010a) investigated the electrochemical behavior $\mathrm{Bi}_{\mathrm{x}} \mathrm{Sb}_{2-\mathrm{x}} \mathrm{Te}_{\mathrm{y}}$ in the solution consisting of $20 \mathrm{mM} \mathrm{TeCl}_{4}, 20 \mathrm{mM}$ $\mathrm{Bi}\left(\mathrm{NO}_{3}\right)_{3}, 20 \mathrm{mM} \mathrm{SbCl}, \mathrm{DMSO}$, and $0.1 \mathrm{mM} \mathrm{KNO}_{3} . \mathrm{A}$ smooth morphology was obtained for $\mathrm{Bi}_{\mathrm{x}} \mathrm{Sb}_{2-\mathrm{x}} \mathrm{Te}_{\mathrm{y}}$ films deposited at different applied potential. The resistances reduced to about $0.04 \Omega$ by post-annealing process. Seebeck coefficient of $85 \mu \mathrm{V} / \mathrm{K}$ was obtained for $\mathrm{Bi}_{0.49} \mathrm{Sb}_{1.53} \mathrm{Te}_{2.98}$ film (Li et al., 2010a).

Li et al. (2010b) electrodeposited $\mathrm{Bi}_{2} \mathrm{Te}_{2.7} \mathrm{Se}_{0.3}$ nanowire arrays using AAO as template in the electrolyte composing of $2 \mathrm{mM}$ $\mathrm{TeO}_{2}, 2.5 \mathrm{mM} \mathrm{Bi}\left(\mathrm{NO}_{3}\right)_{3}, 0.3 \mathrm{mM} \mathrm{SeO}$ and $0.1 \mathrm{M} \mathrm{HNO}_{3}$. The post-annealing process was carried out at $300^{\circ} \mathrm{C}$ under an argon atmosphere. The single crystalline nanowires with diameter of about $14 \mathrm{~nm}$ were obtained (Li et al., 2010b). 
Golgovici et al. (2010) synthesized BiSbTe films by electrodeposition in choline chloride $(\mathrm{ChCl})$ and malonic acid based ionic liquids with a molar ratio of $1: 1$. The reaction temperature was controlled between 80 and $85^{\circ} \mathrm{C}$. The concentration of $\mathrm{Bi}, \mathrm{Sb}$ and $\mathrm{Te}$ ions ranged from 1.5 to $50 \mathrm{mM}$. The $\mathrm{CV}$ data showed that the Te reduction reaction happened first, followed by formation of binary or ternary compounds by codeposition. Furthermore, pulsed electrodeposition technique was also used to synthesize BiSbTe films (Golgovici et al., 2010).

Rostek et al. (2011) synthesized n-type $\mathrm{Bi}_{2} \mathrm{Te}_{3}$ films by electrochemical deposition. The films with composition near stoichiometric was deposited in the solution containing $20 \mathrm{mM}$ Te ions and $30 \mathrm{mM} \mathrm{Bi}$ ions at a current density of $3.75 \mathrm{~mA} / \mathrm{cm}^{2}$. The Seebeck coefficient of as-deposited $\mathrm{Bi}_{2} \mathrm{Te}_{3}$ films is about $-55 \mu \mathrm{V} / \mathrm{K}$. However, after annealed at $250^{\circ} \mathrm{C}$ for $60 \mathrm{~h}$, the Seebeck coefficient increased to $-130 \mu \mathrm{V} / \mathrm{K}$ (Rostek et al., 2011).

$\mathrm{Ma}$ et al. (2011) electrodeposited thin $\mathrm{Bi}_{2} \mathrm{Te}_{3}$ film onto stainless steel from acidic nitrate baths. The carrier concentration of the deposited films was ten times higher than the bulk $\mathrm{Bi}_{2} \mathrm{Te}_{3}$, while the Seebeck coefficient and Hall mobility is lower than bulk $\mathrm{Bi}_{2} \mathrm{Te}_{3}$ (Ma et al., 2011).

Erdogan et al. (2009) synthesized $\mathrm{Bi}_{2} \mathrm{Te}_{3}$ nanofilm and nanowire by electrodeposition. The acidic electrolyte containing $1 \mathrm{mM} \mathrm{TeO}_{2}$ and $1 \mathrm{mM} \mathrm{Bi}\left(\mathrm{NO}_{3}\right)_{3}$ with a $\mathrm{pH}$ of 1.5 , in which $\mathrm{Bi}_{2} \mathrm{Te}_{3}$ nanofilm was deposited with a preferential orientation of (015). Additionally, the alkaline electrolyte containing $2 \mathrm{mM} \mathrm{Bi}\left(\mathrm{NO}_{3}\right)_{3}, 1 \mathrm{mM} \mathrm{TeO}$, and $10 \mathrm{mM}$ EDTA with a $\mathrm{pH}$ of 9.0, in which nanowire was deposited with (110) as preferential orientation. They claimed that the EDTA in the basic solution leading to the $2 \mathrm{D}$ growth mechanism. Furthermore, the band gap energy of $\mathrm{Bi}_{2} \mathrm{Te}_{3}$ nanostructures can be tuned by size and morphology of the nanostructures, as shown in the reflection absorption Fourier transform infrared spectroscopy (Erdoan and Demir, 2011).

$\mathrm{Li}$ et al. (2011a) electrodeposited polycrystalline $\mathrm{Bi}_{2} \mathrm{Te}_{3}$ nanowire arrays using AAO templates by a pulse electrodeposition method from a electrolyte containing DMSO. The results showed that the applied potential can be used to tune the composition of the nanowires. The $\mathrm{Bi}_{2} \mathrm{Te}_{3}$ nanowire array have a preferential orientation of (110). Additionally, $\mathrm{Bi}_{2} \mathrm{Te}_{3} / \mathrm{Te}$ multilayered nanowires were electrodeposited by the same method (Li et al., 2011a).

Kose et al. (2009) electrodeposited thin $\mathrm{Bi}_{2} \mathrm{Te}_{3-y} \mathrm{Se}_{\mathrm{y}}$ films in the solution containing $2 \mathrm{mM} \mathrm{TeO}_{2}, 2.5 \mathrm{mM} \mathrm{Bi}\left(\mathrm{NO}_{3}\right)_{3}, 0.3 \mathrm{mM} \mathrm{SeO}_{2}$ and $0.1 \mathrm{M} \mathrm{HNO}_{3}$ on $\mathrm{Au}(111)$ at room temperature. $\mathrm{Bi}_{2} \mathrm{Te}_{2.7} \mathrm{Se}_{0.3}$ films was obtained at applied potential of $-0.02 \mathrm{~V}$ vs. $\mathrm{Ag} / \mathrm{AgCl}$ $(3 \mathrm{M} \mathrm{NaCl}$ ), which has micron-sized granular crystallites (Köse et al., 2009).

Lim et al. (2009) synthesized BiSbTe films via electrodeposition in the electrolyte containing $0.5 \mathrm{mM} \mathrm{Bi}{ }^{3+}$, $32 \mathrm{mM} \mathrm{SbO}^{+}, 2 \mathrm{mM} \mathrm{HTeO}_{2}{ }^{+}, 0.2 \mathrm{M}$ citric acid, $30 \mathrm{mM}$ EDTA and $1 \mathrm{M} \mathrm{HNO}_{3}$. A Seebeck coefficient of $71 \mu \mathrm{V} / \mathrm{K}$ and a power factor $1.2 \times 10^{-4} \mathrm{~W} /\left(\mathrm{K}^{2} \cdot \mathrm{m}\right)$ was achieved for BiSbTe films. Additionally, the amorphous $\mathrm{Sb}_{2} \mathrm{Te}_{3}$ films was electrodeposited at $0.01-0.03 \mathrm{~V}$ in the electrolyte containing $70 \mathrm{mM} \mathrm{Bi}^{3+}, 70 \mathrm{mM}$ $\mathrm{SbO}^{+}, 3.5 \mathrm{M}$ perchloric acid and $0.35 \mathrm{M}$ tartaric acid. A Seebeck coefficient of $250 \mu \mathrm{V} / \mathrm{K}$ and a power factor $57 \times 10^{-4} \mathrm{~W} /\left(\mathrm{K}^{2} \cdot \mathrm{m}\right)$ was achieved for $\mathrm{Sb}_{2} \mathrm{Te}_{3}$ films (Lim et al., 2009).

Kim et al. (2018a) electrodeposited $\mathrm{Bi}_{\mathrm{x}} \mathrm{Sb}_{2-\mathrm{x}} \mathrm{Te}_{\mathrm{y}}$ films in the solution with $2.4 \mathrm{mM} \mathrm{TeO}, 3.6 \mathrm{mM} \mathrm{Sb} \mathrm{Sb}_{3}, 400-1,000 \mu \mathrm{M}$ $\mathrm{Bi}\left(\mathrm{NO}_{3}\right)_{3} 5 \mathrm{H}_{2} \mathrm{O}, 33 \mathrm{mM}$ L-tartaric acid, and $1 \mathrm{M} \mathrm{HNO}_{3}$ at fixed applied potential of $-0.1 \mathrm{~V}$ (vs. SCE). The composition of the films were controlled by [Sb]/[Bi] ratio. The results showed that the substitution of $\mathrm{Bi}$ with $\mathrm{Sb}$ would improve the mobility, while suppress the carrier concentration. The deposited $\mathrm{Bi}_{10} \mathrm{Sb}_{30} \mathrm{Te}_{60}$ film has a high Seebeck coefficient, which results in a power factor (PF) of $\sim 490 \mu \mathrm{W} / \mathrm{m} \mathrm{K}^{2}$ (Kim et al., 2018a).

Ma et al. (2010) electrodeposited $\mathrm{Bi}_{1-\mathrm{x}} \mathrm{Sb}_{\mathrm{x}}$ and $\mathrm{Bi}_{2-\mathrm{x}} \mathrm{Sb}_{\mathrm{x}} \mathrm{Te}_{3}$ thin films at $25^{\circ} \mathrm{C}$ with different morphologies, such as thin sheets, rods, dendrites, and spherical particles. The $\mathrm{Bi}_{1-\mathrm{x}} \mathrm{Sb}_{\mathrm{x}}$ film was deposited in the electrolyte containing $2 \mathrm{mM} \mathrm{Bi}\left(\mathrm{NO}_{3}\right)_{3}, 1 \mathrm{mM}$ $\mathrm{SbCl}_{3}, 0.2 \mathrm{M} \mathrm{C}_{4} \mathrm{H}_{6} \mathrm{O}_{6}$, and $0.1 \mathrm{M} \mathrm{HNO}_{3}$. Additionally, The $\mathrm{Bi}_{2-}$ ${ }_{\mathrm{x}} \mathrm{Sb}_{\mathrm{x}} \mathrm{Te}_{3}$ film was deposited in the electrolyte containing $0.3 \mathrm{mM}$ $\mathrm{TeO}_{2}, 0.2 \mathrm{mM} \mathrm{Bi}\left(\mathrm{NO}_{3}\right)_{3}, 1 \mathrm{mM} \mathrm{SbCl}_{3}, 0.2 \mathrm{M} \mathrm{C}_{4} \mathrm{H}_{6} \mathrm{O}_{6}$, and $0.1 \mathrm{M}$ $\mathrm{HNO}_{3}$. Furthermore, the results indicated that the underpotential deposition mechanism would lead to the formation of $\left(\mathrm{Bi}_{0.5} \mathrm{Sb}_{0.5}\right)_{2} \mathrm{Te}_{3}$, however the overpotential deposition would result in the formation of $\mathrm{Bi}_{0.5} \mathrm{Sb}_{1.5} \mathrm{Te}_{3}$. Meanwhile different deposition mechanism can be triggered by applied potential (Ma et al., 2010).

Jin and Wang (2010) electrodeposited n-Type thin $\mathrm{Bi}_{2} \mathrm{Te}_{3-\mathrm{y}} \mathrm{Se}_{\mathrm{y}}$ films using $\mathrm{Au}, \mathrm{Bi}$, and $\mathrm{Bi}_{2} \mathrm{Te}_{3-\mathrm{y}} \mathrm{Se}_{\mathrm{y}}$ as substrates. The electrolyte contained $8 \mathrm{mM} \mathrm{HTeO}_{2}{ }^{+}, 8 \mathrm{mM} \mathrm{Bi}^{3+}, 1 \mathrm{mM} \mathrm{H}_{2} \mathrm{SeO}_{3}$, and $1 \mathrm{M}$ $\mathrm{HNO}_{3}$. The substrates have significant effect on the morphology of films, as well as the crystal orientation. The preferred orientation of (015) with rhombohedral structure was obtained when using $\mathrm{Bi}_{2} \mathrm{Te}_{3-\mathrm{y}} \mathrm{Se}_{\mathrm{y}}$ as substrate. Additionally, the films deposited on the $\mathrm{Bi}_{2} \mathrm{Te}_{3-\mathrm{y}} \mathrm{Se}_{\mathrm{y}}$ substrate showed the highest power factor after annealing (Jin and Wang, 2010).

Golgovici et al. (2011) investigated electrodeposition of $\mathrm{Bi}_{2} \mathrm{Te}_{3}$, $\mathrm{Sb}_{2} \mathrm{Te}_{3}, \mathrm{BiSb}$, and BiSbTe films in an aqueous solution containing $5 \mathrm{M} \mathrm{NaCl}$ and $1 \mathrm{M} \mathrm{HCl}$ or an ionic liquid with choline chloride and malonic acid mixture. The concentrations of $\mathrm{Bi}, \mathrm{Sb}$ and $\mathrm{Te}$ ion were controlled between 10 and $90 \mathrm{mM}$. Morphology and composition of BiSbTe was modified by increasing the current pulses (Golgovici et al., 2011).

Liu et al. electrodeposited $\mathrm{Bi}_{2} \mathrm{Te}_{3}$ pillars using multi-channel glass molds as template. The results showed that pulsed electrodeposition method is helpful to achieve high aspect ratio filling. The n-type $\mathrm{Bi}_{2} \mathrm{Te}_{3}$ arrays with aspect ratio exceeding ten was obtained at a pulse circle of $-0.2 \mathrm{~V}$ for $4 \mathrm{~s}$, $+0.5 \mathrm{~V}$ for $1 \mathrm{~s}$, and $0 \mathrm{mV}$ for $3 \mathrm{~s}$ (vs. SCE). The precursor concentration in the electrolyte includes $7.5 \mathrm{mM} \mathrm{Bi}^{3+}$ and $10 \mathrm{mM} \mathrm{HTeO}_{2}{ }^{+}$. Furthermore, the electrical conductivity of asdeposited $\mathrm{Bi}_{2} \mathrm{Te}_{3}$ pillars is the same magnitude as bulk $\mathrm{Bi}_{2} \mathrm{Te}_{3}$ (Liu and $\mathrm{Li}, 2011$ ).

Li et al. (2011b) synthesized heterogeneous thermoelectric nanowire arrays of multilayer $\mathrm{Bi}_{2} \mathrm{Te}_{2} \mathrm{Se} / \mathrm{Te}$ using template direction electrodeposition. The thickness of the Te section can be modulated by tailoring $\mathrm{Te}$ ion concentration. The diameter of the heterogeneous nanowires is from 60 to $85 \mathrm{~nm}$. Additionally, the $\mathrm{Bi}_{2} \mathrm{Te}_{2} \mathrm{Se}$ segment can change to $\mathrm{Bi}_{2} \mathrm{Se}_{2} \mathrm{Te}$ by lowing the Te ion concentration to a certain level (Li et al., 2011b). 
Pinisetty et al. (2011a) fabricated polycrystalline $\mathrm{Bi}_{2} \mathrm{Te}_{3}$ nanowires and nanotubes arrays by electrodeposition. The applied potential had effect on the composition, where both Bi-rich (p-type)and Te-rich (n-type) nanowires or nanotubes can be deposited. The lamellar thickness of bath morphologies were about $17-24 \mathrm{~nm}$. The nanowires and nanotubes had a Seebeck coefficient of 11.5 and $17 \mu \mathrm{V} / \mathrm{K}$, respectively, which were deposited at $-0.4 \mathrm{~V}$. However, when applied potential was $-0.065 \mathrm{~V}$, Seebeck coefficient of -48 and $-63 \mu \mathrm{V} / \mathrm{K}$ were obtained for the nanowires and nanotubes, respectively (Pinisetty et al., 2011a).

Lim et al. (2012a) synthesized $\mathrm{Bi}_{\mathrm{x}} \mathrm{Sb}_{2-\mathrm{x}} \mathrm{Te}_{3}$ films by electrodeposition in an electrolyte containing $0.8 \mathrm{mM} \mathrm{TeO}_{2}$,

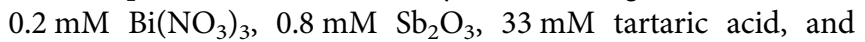
$1 \mathrm{M} \mathrm{HNO}_{3}$. The composition of the thin films can be controlled by applied potential, where stoichiometry can be achieved from -0.10 to $-0.15 \mathrm{~V}$ vs. SCE. Additionally, at more negative applied potential, the thermoelectric property of $\mathrm{Bi}_{\mathrm{x}} \mathrm{Sb}_{2}$ ${ }_{x} \mathrm{Te}_{3}$ films was degraded, which might owing to higher defect density. The electrical and thermoelectric properties can be enhanced by annealing in reducing environment (Lim et al., 2012a).

Peranio et al. (2012) synthesized $\mathrm{Bi}_{2} \mathrm{Te}_{3}$ nanowires by a potential-pulsed electrodeposition using $\mathrm{AAO}$ as template in a solution with $15 \mathrm{mM} \mathrm{HTeO}_{2}{ }^{+}, 10 \mathrm{mM} \mathrm{Bi}^{3+}$ and $1 \mathrm{M} \mathrm{HNO}_{3}$. The nanowires had a stoichiometric composition with diameters of $50-80 \mathrm{~nm}$ and a length of $56 \mu \mathrm{m}$. The nanowires are singlecrystalline with no grain boundaries. The XRD pattern revealed that growth direction of the nanowires were (110) and (210). Additionally, the $\mathrm{c}$ axis of the $\mathrm{Bi}_{2} \mathrm{Te}_{3}$ crystal was perpendicular to nanowire axis (Peranio et al., 2012).

Frantz et al. (2012) electrodeposited bismuth telluride nanowires from an electrolyte with $1.5 \mathrm{mM} \mathrm{Bi}{ }^{3+}, 15 \mathrm{mM}$ $\mathrm{HTeO}_{2}{ }^{+}$and DMSO using polycarbonate as template. The DMSO would shift the reduction potential to more negative side and inhibit the cation diffusion. The nanowires deposited $-0.1 \mathrm{~V}$ vs $\mathrm{Ag} / \mathrm{AgCl}$ at have a diameter of $60 \mathrm{~nm}$ diameter with stoichiometric composition. The crystal structure of the nanowires was polycrystalline with a preferential orientation perpendicular to the (015) planes (Frantz et al., 2012).

Ma et al. (2012a) synthesized thin $\mathrm{Sb}_{2} \mathrm{Te}_{3}$ and $\mathrm{Bi}_{2} \mathrm{Te}_{3}$ films using goldthe $\mathrm{Au}$-coated silicon as substrate in an acidic bath with $\mathrm{Bi}\left(\mathrm{NO}_{3}\right)_{3} \cdot 5 \mathrm{H}_{2} \mathrm{O}, \mathrm{TeO}_{2}, \mathrm{Sb}_{2} \mathrm{O}_{3}, 1 \mathrm{M} \mathrm{HNO}_{3}$ and $0.5 \mathrm{M}$ tartaric acid at room temperature by electrochemical deposition. The asdeposited $\mathrm{Bi}_{2} \mathrm{Te}_{3}$ films were polycrystalline, but the $\mathrm{Sb}_{2} \mathrm{Te}_{3}$ films were amorphous. Additionally, the $\mathrm{Sb}_{2} \mathrm{Te}_{3}$ films showed both $\mathrm{Sb}_{2} \mathrm{Te}_{3}$ and Te phase after annealing (Ma et al., 2012a).

Zhu et al. (2008) electrodeposited p-type quaternary thin BiSbTeSe films using $\mathrm{Au}$ as substrate in a acidic solution with $0.5 \mathrm{mM} \mathrm{Se}(\mathrm{IV}), 12 \mathrm{mM}$ Te(IV), $2.5 \mathrm{mM} \mathrm{Bi}(\mathrm{III}), 10 \mathrm{mM} \mathrm{Sb}$ (III), $0.67 \mathrm{M}$ tartaric acid at room temperature. The thickness of the films was controlled to $8 \mu \mathrm{m}$. The applied potential can be used to tailoring the composition of the films. The as-deposited films were amorphous, however they changed to polycrystalline after annealing based on the XRD patterns. A maximum power factor of $620 \mu \mathrm{W} /\left(\mathrm{K}^{2} \cdot \mathrm{m}\right)$ was achieved for the thin BiSbTeSe films after post-annealing with Seebeck coefficients of $116-133 \mu \mathrm{V} / \mathrm{K}$ (Zhu and Wang, 2012).

Banga et al. (2012) fabricated $\mathrm{Bi}_{2} \mathrm{Te}_{3} / \mathrm{Bi}_{2-\mathrm{x}} \mathrm{Sb}_{\mathrm{x}} \mathrm{Te}_{3}$ heterostructure by pulsed potentiostatic electrodeposition method. The solution consisted $\mathrm{Na}_{2} \mathrm{TeO}_{3}, \mathrm{Bi}\left(\mathrm{NO}_{3}\right)_{3}, \mathrm{Sb}(\mathrm{III})$, $2 \mathrm{M}$ nitric acid, and $0.3 \mathrm{M}$ tartaric acid. The heterostructure had a layer periodicity in the range of $10-30 \mathrm{~nm}$. The XRD data showed that the multilayer films possessed a (015) texture (Banga et al., 2012).

Zhu et al. (2008) synthesized n-type $\mathrm{Bi}_{2} \mathrm{Te}_{3-y} \mathrm{Se}_{\mathrm{y}}$ films using ITO-coated glass as substrates in the acidic solution containing $10.0 \mathrm{mM} \mathrm{HTeO}_{2}{ }^{+}, 7.5 \mathrm{mM} \mathrm{Bi}^{3+}, 1.1 \mathrm{mM} \mathrm{SeO}_{3}{ }^{2-}$ and $0.5 \mathrm{M} \mathrm{HNO}_{3}$ at room temperature by pulsed electrodeposition. The smooth and compact $\mathrm{Bi}_{2} \mathrm{Te}_{3-\mathrm{y}} \mathrm{Se}_{\mathrm{y}}$ films were obtained. Increasing the cathodic current density would decrease the grain size of the films. The $\mathrm{Bi}_{2} \mathrm{Te}_{3-\mathrm{y}} \mathrm{Se}_{\mathrm{y}}$ films had a Seebeck coefficient of about $-92 \mu \mathrm{V} / \mathrm{K}$ and electrical resistivity of about $109.4 \mu \Omega \mathrm{m}$ (Zou et al., 2012).

Naylor et al. (2012) synthesized $\mathrm{Bi}_{2} \mathrm{Te}_{3}$ films with stoichiometric composition $\mathrm{Bi}_{2} \mathrm{Te}_{3}$ in the electrolyte consisting of $10 \mathrm{mM} \mathrm{Te}(\mathrm{IV}), 7.5 \mathrm{mM} \mathrm{Bi}(\mathrm{III})$, sodium lignosulfonate (SL) and $1 \mathrm{M} \mathrm{HNO}_{3}$. The sodium lignosulfonate acted as a surfactant, which would improve morphology and roughness of the $\mathrm{Bi}_{2} \mathrm{Te}_{3}$ films and achieve better alignment in the (110) plane. The optimal concentration of SL is from 60 to $80 \mathrm{mg} / \mathrm{L}$ at a deposition potential of $-0.1 \mathrm{~V}$ vs SCE (Naylor et al., 2012).

Limmer et al. (2012) reported the electrodeposition of $75 \mathrm{~nm}$ diameter nanowire arrays with a composition of $\mathrm{Bi}_{2}\left(\mathrm{Te}_{0.95} \mathrm{Se}_{0.05}\right)_{3}$ onto $\mathrm{Si}$ substrates using $\mathrm{AAO}$ as template in the electrolyte containing $\quad 80 \mathrm{mM} \quad \mathrm{Bi}\left(\mathrm{NO}_{3}\right)_{3} \bullet 5 \mathrm{H}_{2} \mathrm{O}, \quad 40-80 \mathrm{mM} \quad \mathrm{TeCl}_{4}$, 0.8-1.2 $\mathrm{mM} \mathrm{SeO}_{2}$ and $0.1 \mathrm{M} \mathrm{KClO}_{4}$ in dimethyl sulfoxide. The nanowires are polycrystalline with grain size of 5-10 nm (Limmer et al., 2012).

$\mathrm{Ma}$ et al. (2012b) synthesized ternary compounds $\left(\mathrm{Bi}_{\mathrm{x}} \mathrm{Sb}_{1}\right.$ $\left.{ }_{\mathrm{x}}\right)_{2} \mathrm{Te}_{3}$ and $\mathrm{Bi}_{2}\left(\mathrm{Te}_{1-\mathrm{y}} \mathrm{Se}_{\mathrm{y}}\right)_{3}$ by electrodeposition using gold-coated silicon as substrates in the electrolyte with $\mathrm{TeO}_{2}, \mathrm{Bi}\left(\mathrm{NO}_{3}\right)_{3} \cdot 5 \mathrm{H}_{2} \mathrm{O}$, $\mathrm{SbCl}_{3}$ and $\mathrm{Na}_{2} \mathrm{SeO}_{3}, 1 \mathrm{M} \mathrm{HNO}_{3}$ and $0.67 \mathrm{M}$ tartaric acid at room temperature. The p-type $\left(\mathrm{Bi}_{\mathrm{x}} \mathrm{Sb}_{1-\mathrm{x}}\right)_{2} \mathrm{Te}_{3}$ films had the highest power factor obtained with composition close to $\mathrm{Bi}_{0.5} \mathrm{Sb}_{1.5} \mathrm{Te}_{3}$ deposited at a relatively large negative potential. In addition, $\mathrm{Bi}_{2}\left(\mathrm{Te}_{1-\mathrm{y}} \mathrm{Se}_{\mathrm{y}}\right)_{3}$ thin films showed n-type behaviors with composition close to $\mathrm{Bi}_{2} \mathrm{Te}_{2.7} \mathrm{Se}_{0.3}$ (Ma et al., 2012b).

Fu et al. (2013) fabricated $\mathrm{Ag} / \mathrm{Bi}_{2} \mathrm{Te}_{3}$ multilayer nanowires by pulse electrochemical deposition using $\mathrm{AAO}$ as the template in the electrolyte consisted of $0.1 \mathrm{M} \mathrm{HTeO}_{2}{ }^{+}, 75 \mathrm{mM} \mathrm{Bi}\left(\mathrm{NO}_{3}\right)_{3}$, $10 \mathrm{mM} \mathrm{AgNO}_{3}$, and $1 \mathrm{M} \mathrm{HNO}_{3}$. The deposited the $\mathrm{Bi}_{2} \mathrm{Te}_{3}$ had a rhombohedral lattice phase and $\mathrm{Ag}$ had a cubic lattice phase. The length of each layer ranged from 25 to $45 \mathrm{~nm}$ (Fu et al., 2013).

Nguyen et al. (2012) investigated the electrodeposition of $\mathrm{Bi}_{2} \mathrm{Te}_{3}$ film in the electrolyte consisting of $50 \mathrm{mM}$ of $50 \mathrm{mM}$ $\mathrm{TeCl}_{4}, \mathrm{Bi}\left(\mathrm{NO}_{3}\right)_{3}, 0.5 \mathrm{M}$ lithium nitrate, and ethylene glycol. The results showed that the electrochemical reduction reaction of both $\mathrm{Bi}^{3+}$ and $\mathrm{Te}^{4+}$ ions were carried out at applied potential more negative than 0.2 and $0.55 \mathrm{~V}$ vs. SHE, and the reaction is one step without the formation of intermediates. The $\mathrm{Bi}$ and $\mathrm{Te}$ ions had the similar diffusion coefficients and the reaction rate constants. 
$\mathrm{Bi}_{2} \mathrm{Te}_{3}$ films stoichiometric composition were deposited at current densities up to $5 \mathrm{~A} / \mathrm{dm}^{2}$ (Nguyen et al., 2012).

Agapescu et al. (2013) electrodeposited of $\mathrm{Bi}, \mathrm{Te}$, and $\mathrm{Bi}_{2} \mathrm{Te}_{3}$ films in an ionic liquids consisting of $10 \mathrm{mM} \mathrm{BiCl}$ and $\mathrm{TeO}_{2}$, choline chloride, and oxalic acid ( $\mathrm{ChCl}-\mathrm{OxA})$ at $60^{\circ} \mathrm{C}$.

Kim and Oh (2013) fabricated a thermoelectric device using n-type $\mathrm{Bi}_{2} \mathrm{Te}_{3}$ and p-type $\mathrm{Sb}_{2} \mathrm{Te}_{3}$ thin films as basic element legs. The device has a cross-plane configuration with 242 pairs of legs by flip-chip bonding of top electrodes. The thickness of both $\mathrm{Bi}_{2} \mathrm{Te}_{3}$ and $\mathrm{Sb}_{2} \mathrm{Te}_{3}$ films were about $20 \mu \mathrm{m}$. Additionally, the n-type $\mathrm{Bi}_{2} \mathrm{Te}_{3}$ and p-type $\mathrm{Sb}_{2} \mathrm{Te}_{3}$ films showed Seebeck coefficients of $-59 \mu \mathrm{V} / \mathrm{K}$ and $485 \mu \mathrm{V} / \mathrm{K}$, respectively. Furthermore, an open-circuit voltage of $0.294 \mathrm{~V}$ and a maximum output power of $5.9 \mu \mathrm{W}$ were achieved at a temperature difference of $22.3 \mathrm{~K}$ (Kim and $\mathrm{Oh}, 2013$ ).

Manzano et al. (2013) electrodeposited $\mathrm{Bi}_{2} \mathrm{Te}_{3}$ films with preferentially oriented of (110) direction in the electrolyte containing $10 \mathrm{mM} \mathrm{HTeO}_{2}{ }^{+}, 7.5 \mathrm{mM} \mathrm{Bi}^{3+}$ and $1 \mathrm{M} \mathrm{HNO}_{3}$ at applied potential of $0.02 \mathrm{~V}$ vs. $\mathrm{Ag} / \mathrm{AgCl}$ on a $\mathrm{Pt}$ substrate. When using pulsed electrodeposition method, the results indicated that at a pulse of on-time $=$ off-time $=0.1 \mathrm{~s}$ the films achieved a Seebeck coefficient of $-72 \mu \mathrm{V} / \mathrm{K}$ and power factor of $440 \mu \mathrm{W} /\left(\mathrm{K}^{2} \cdot \mathrm{m}\right)$, which is measured at $107^{\circ} \mathrm{C}$. Additionally, when using potentiostatic method, a Seebeck coefficient of $-73 \mu \mathrm{V} / \mathrm{K}$ at $107^{\circ} \mathrm{C}$ and power factor of $600 \mu \mathrm{W} /$ $\left(\mathrm{K}^{2} \cdot \mathrm{m}\right)$ was obtained at $107^{\circ} \mathrm{C}$ (Manzano et al., 2013).

Zhou et al. (2013) electrodeposited n-type phosphorus-doped $\mathrm{Bi}_{2} \mathrm{Te}_{3}$ films on a stainless-steel electrode in the solution containing $10 \mathrm{mM} \mathrm{TeO}_{2}, 8 \mathrm{mM} \mathrm{Bi}\left(\mathrm{NO}_{3}\right)_{3}, 4 \mathrm{mM} \mathrm{H}_{3} \mathrm{PO}_{4}$ and $1 \mathrm{M} \mathrm{HNO}_{3}$. The as-prepared films had the thermal conductivity of $0.47 \mathrm{~W} /(\mathrm{mK})$ and the electrical conductivity of $280 \mathrm{~S} / \mathrm{cm}$ (Zhou et al., 2013).

Rashid et al. (2013) synthesized $\mathrm{Bi}_{2} \mathrm{Te}_{3}$ films by galvanostatic electrodeposition in a solution containing $8 \mathrm{mM} \mathrm{HTeO}_{2}^{+}, 8 \mathrm{mM}$ $\mathrm{Bi}^{3+}$ and $1 \mathrm{M}$ nitric acid. The results indicated that annealing process would enhance the carrier mobility while suppressing the carrier concentration. Additionally, the Seebeck coefficient can be enhanced from -57 to $-169.49 \mu \mathrm{V} / \mathrm{K}$ and the power factor can be enhanced from 2.74 to $1737 \mu \mathrm{W} /\left(\mathrm{K}^{2} \cdot \mathrm{m}\right)$ by post annealing process for p-type $\mathrm{Bi}_{2} \mathrm{Te}_{3}$ film. Moreover, the Seebeck coefficient can be improved from 28 to $112.3 \mu \mathrm{V} / \mathrm{K}$ and the power factor can be improved from 2.57 to $443 \mu \mathrm{W} /\left(\mathrm{K}^{2} \cdot \mathrm{m}\right)$ by post-annealing process (Rashid et al., 2013).

Cao et al. (2013) fabricated thin $\mathrm{Bi}_{2} \mathrm{Te}_{3}$ films by electrodeposition in the solution with $10 \mathrm{mM} \mathrm{HTeO}_{2}{ }^{+}, 8 \mathrm{mM}$ $\mathrm{Bi}^{3+}$ and $1 \mathrm{M} \mathrm{HNO}_{3}$ at room temperature. The substrates used during the deposition had an epitaxial seed layer, which would help to reduce the lattice mismatch between $\mathrm{Bi}_{2} \mathrm{Te}_{3}$ and Silicon. Moreover, more uniform structure and better crystallinity can be achieved. Both doped and intrinsic silicon were used as substrate, while the results showed that a more compact thin $\mathrm{Bi}_{2} \mathrm{Te}_{3}$ film with preferential orientation of (001) was obtained for intrinsic silicon, which also showed better thermoelectric performance and smoother surface morphology. Compared to the thin film with preferential orientation of (110), the electrical conductivity is about $72 \%$ higher and the power factors is about $45 \%$ higher.
Additionally, the electrical conductivity and Seebeck coefficient was suppressed by reducing the seed layer thickness from 40 to $20 \mathrm{~nm}$, which can be attributed to the insufficient charge transfer during electrodeposition (Cao et al., 2013).

Wu et al. (2013) investigated the effect of chloride on the electrodeposition of $\mathrm{Bi}_{2} \mathrm{Te}_{3}$ films in the solution containing $\mathrm{TeCl}_{4}$, $\mathrm{Bi}\left(\mathrm{NO}_{3}\right)_{3} \cdot 5 \mathrm{H}_{2} \mathrm{O}$ and ethylene glycol. The results indicated that the presence of chloride could enhance the reduction reaction rate of Te significantly, where the reaction rate with chloride in the solution is three orders of magnitude higher than the rate without chloride. Additionally, $\mathrm{Bi}_{2} \mathrm{Te}_{3}$ films with stoichiometric composition and smooth morphology were electrodeposited in certain potential window. A Seebeck coefficient of $-120 \mu \mathrm{V} / \mathrm{K}$ was achieved for the $\mathrm{Bi}_{2} \mathrm{Te}_{3}$ films (Wu et al., 2013).

Yoo et al. (2013a) electrodeposited $\mathrm{Bi}_{\mathrm{x}} \mathrm{Te}_{\mathrm{y}}$ thin films from nitric acid baths with $2.5-10 \mathrm{mM} \mathrm{Bi}\left(\mathrm{NO}_{3}\right)_{3}, 10 \mathrm{mM} \mathrm{TeO}_{2}$, and $1.5 \mathrm{M} \mathrm{HNO}_{3}$ using $\mathrm{Au} / \mathrm{Ni} / \mathrm{Si}$ as substrates. The films with surface morphologies of granular and needle-like structures were deposited at different $\mathrm{Te}$ content. Higher of $\mathrm{Bi}$ ions concentration in electrolytes would result in higher power factor. Additionally, the power factor was not improved significantly owing to the interdependence of the electrical conductivity and the Seebeck coefficient (Yoo et al., 2013a).

Wang et al. (2013) synthesized $\mathrm{Bi}_{2} \mathrm{Te}_{2.7} \mathrm{Se}_{0.3}$ and $\mathrm{Bi}_{0.5} \mathrm{Sb}_{1.5} \mathrm{Te}_{3}$ by electrodeposition combined with post annealing. The solution to electrodeposit n-type $\mathrm{Bi}_{2} \mathrm{Te}_{2.7} \mathrm{Se}_{0.3}$ contained $8 \mathrm{mM} \mathrm{HTeO}_{2}{ }^{+}$, $8 \mathrm{mM} \mathrm{Bi}^{3+}, 1 \mathrm{mM} \mathrm{H}_{2} \mathrm{SeO}_{3}$ and $1 \mathrm{M} \mathrm{HNO}_{3}$, while the electrolyte to electrodeposit p-type $\mathrm{Bi}_{0.5} \mathrm{Sb}_{1.5} \mathrm{Te}_{3}$ contained $2 \mathrm{mM} \mathrm{Bi}^{3+}, 10 \mathrm{mM}$ $\mathrm{HTeO}_{2}{ }^{+}, 100 \mathrm{mM} \mathrm{Sb}(\mathrm{III})$ and $1 \mathrm{M} \mathrm{HNO}_{3}$. The as-deposited films possess amorphous structure and can be transferred to nanocrystalline after annealing. The annealed films show a preferred orientation of (015). The maximum power output of $77 \mu \mathrm{W}$ was achieved with open-circuit voltage of $660 \mathrm{mV}$ with a temperature difference of $20 \mathrm{~K}$ at $25^{\circ} \mathrm{C}$. Additionally, a power density of $770 \mu \mathrm{W} / \mathrm{cm}^{3}$ was obtained (Wang et al., 2013).

Rashid et al. (2013) synthesized n-type $\mathrm{Bi}_{2} \mathrm{Te}_{3}$ films with a prominent orientation of (110) in the acidic solution with $\mathrm{TeO}_{2}$ and $\mathrm{Bi}\left(\mathrm{NO}_{3}\right)_{3}$ on gold electrode. The $\mathrm{Bi}_{2} \mathrm{Te}_{3}$ films are nanocrystalline with grain size ranged from 21 to $45 \mathrm{~nm}$. The results showed that the electrodes distance could be used to tune electrical and thermoelectric properties of the films, thus improving carrier charge mobility without varying of the Seebeck coefficient and carrier concentration. The highest power factor of $820 \mu \mathrm{W} / \mathrm{K}^{2} \cdot \mathrm{m}$ was achieved with an electrical conductivity of $2.13 \times 10^{3} \mathrm{~S} / \mathrm{cm}$ and Seebeck coefficient of $-61.2 \mu \mathrm{V} / \mathrm{K}$ (Rashid and Chung, 2013).

Yoo et al. (2013b) synthesized $\mathrm{Bi}_{\mathrm{x}} \mathrm{Sb}_{2-\mathrm{x}} \mathrm{Te}_{3}$ films use potentiostatic electrodeposition method at room temperature in an acidic electrolyte containing $0.8 \mathrm{mM} \mathrm{TeO}_{2}, 0.2 \mathrm{mM}$ $\mathrm{Bi}\left(\mathrm{NO}_{3}\right)_{3}, 0.8 \mathrm{mM} \mathrm{Sb} \mathrm{O}_{3}, 1 \mathrm{M} \mathrm{HNO}_{3}$, and $33 \mathrm{mM}$ tartaric acid. When the applied potential was controlled between -0.10 and $-0.15 \mathrm{~V}$ versus SCE, thin films with composition near stoichiometric were deposited. Additionally, reducing the applied potentials would result in suppressing the electrical and thermoelectric properties, probably owing to higher defect density (Yoo et al., 2013b). 
$\mathrm{Ng}$ et al. (2014) fabricated the binary $\mathrm{Bi}_{2} \mathrm{Te}_{3}$ and ternary BiSbTe nanowires using template (AAO) directed electrodeposition method in a solution compose of $10 \mathrm{mM}$ $\mathrm{TeO}_{2}, 20 \mathrm{mM} \mathrm{Bi}\left(\mathrm{NO}_{3}\right)_{3} \cdot 5 \mathrm{H}_{2} \mathrm{O}$ and $1 \mathrm{M} \mathrm{HNO}_{3}$, The results showed that reducing the applied potentials can increase the $\mathrm{Sb}$ composition, while increasing the applied potentials would facilitate the formation of $\mathrm{Bi}_{2} \mathrm{Te}_{3}$ ( $\mathrm{Ng}$ et al., 2014).

Zou et al. (2014) investigated electrodeposition of n-type $\mathrm{Bi}_{2} \mathrm{Te}_{3-\mathrm{y}} \mathrm{Se}_{\mathrm{y}}$ film in the solution containing $10.0 \mathrm{mM} \mathrm{HTeO}_{2}{ }^{+}$, $1.1 \mathrm{mM} \mathrm{SeO}{ }^{2-}, 7.5 \mathrm{mM} \mathrm{Bi}^{3+}$, and $1 \mathrm{M} \mathrm{HNO}_{3}$ at room temperature. The nucleation and growth mechanism were examined. The electrochemical reaction rate was controlled by diffusion and irreversible with the limiting current density of $1.78 \mathrm{~mA} / \mathrm{cm}^{2}$. A flocculent film was deposited when the applied potential was larger than limiting current without agitation. However, $\mathrm{Bi}_{2} \mathrm{Te}_{3-y} \mathrm{Se}_{\mathrm{y}}$ film with smooth morphology was deposited at $4 \mathrm{~mA} / \mathrm{cm}^{2}$ with agitation. $\mathrm{Bi}_{2} \mathrm{Te}_{3-\mathrm{y}} \mathrm{Se}_{\mathrm{y}}$ film deposited at $1 \mathrm{~mA} / \mathrm{cm}^{2}$ have relatively high power factor and electrical conductivity (Zou et al., 2014).

Maas et al. (2014) electrodeposited $\mathrm{Bi}_{2} \mathrm{Te}_{3}$ in acidic solution with $20 \mathrm{mM} \mathrm{HTeO}_{2}{ }^{+}$and $20 \mathrm{mM} \mathrm{Bi}^{3+}$. The anode is $\mathrm{Bi}_{2} \mathrm{Te}_{3}$ as a sacrificial the source of cations. A homogeneous $\mathrm{Bi}_{2} \mathrm{Te}_{3}$ film with a thickness of $300 \mu \mathrm{m}$ was deposited using $\mathrm{Bi}_{2} \mathrm{Te}_{3}$ as anode, while without $\mathrm{Bi}_{2} \mathrm{Te}_{3}$ as anode the thickness can be obtained is 10 times thinner. A power factor of $500 \mu \mathrm{W} /\left(\mathrm{K}^{2} \cdot \mathrm{m}\right)$ was achieved (Maas et al., 2014).

Szymczak et al. (2014) electrodeposited n-type $\mathrm{Bi}_{2} \mathrm{Te}_{3}$ films in an ionic liquid with 1-ethyl-1-octyl-piperidinium bis(trifluoromethylsulfonyl)imide (EOPipTFSI) and 1-ethyl-1octyl- piperidinium bromide (EOPipBr). The atomic ratio of EOPipTFSI and EOPipBr is 95:5. According to the result, this ionic liquid is stable at high cathodic applied potential, which provide a larger window to deposited $\mathrm{Bi}_{2} \mathrm{Te}_{3}$ compound. The morphology of the $\mathrm{Bi}_{2} \mathrm{Te}_{3}$ film can be tuned by precursor concentration, in which mirror-like films can be deposited with good uniformity. Additionally, an electrical resistivity of $133 \mu \Omega \mathrm{m}$ and Seebeck coefficient of $-70 \mu \mathrm{V} / \mathrm{K}$ were achived (Szymczak et al., 2014).

Jiang et al. (2014) fabricated $\mathrm{Bi}_{2} \mathrm{Te}_{3} / \mathrm{PEDOT}: \mathrm{PSS} / \mathrm{Bi}_{2} \mathrm{Te}_{3}$ composite film by electrodeposition of $\mathrm{Bi}_{2} \mathrm{Te}_{3}$ onto poly $(3,4-$ ethylenedioxythiophene): poly (styrenesulfonate) (PEDOT:PSS) film. The solution contained $\mathrm{TeO}_{2}, \mathrm{Bi}\left(\mathrm{NO}_{3}\right)_{3}$, and $1 \mathrm{M} \mathrm{HNO}_{3}$. A thermal conductivity of $0.169-0.179 \mathrm{~W} /(\mathrm{mK})$ was obtained. ZT value of $1.72 \times 10^{-2}$ was achieved for Bi2Te3/PEDOT:PSS $/ \mathrm{Bi}_{2} \mathrm{Te}_{3}$ composite film with electrical conductivity of $403.5 \mathrm{~S} / \mathrm{cm}$ (Jiang et al., 2014).

Caballero-Calero et al. (2014) electrodeposited $\mathrm{Bi}_{2} \mathrm{Te}_{3}$ films in a solution with $10 \mathrm{mM} \mathrm{HTeO}_{2}{ }^{+}, 7.5 \mathrm{mM} \mathrm{Bi}^{3+}, 1 \mathrm{M} \mathrm{HNO}_{3}$. The $\mathrm{Bi}_{2} \mathrm{Te}_{3}$ films have a preferred orientation of (110) with $\mathrm{c}$-axis parallel the substrate. Additionally, the effect of sodium lignosulfonate as surfactant on morphology was examined. Seebeck coefficient was determined to be $-80 \pm 6 \mu \mathrm{V} / \mathrm{K}$ (Caballero-Calero et al., 2014).

Wu et al. (2014) electrodeposited $\mathrm{SbBi}, \mathrm{Sb}_{2} \mathrm{Te}_{3}$, and BiSbTe alloys in the electrolyte containing $\mathrm{TeCl}_{4}, \mathrm{SbCl}_{3}, \mathrm{Bi}\left(\mathrm{NO}_{3}\right)_{3}$, and ethylene glycol. The electrochemical reaction mechanism of $\mathrm{Sb}$ in chloride-free ethylene glycol was investigated. The results showed that the diffusion coefficients of $\mathrm{Sb}$ (III), $\mathrm{Te}(\mathrm{IV})$ and $\mathrm{Bi}$ (III) were comparable in ethylene glycol. Additionally, the onset potential of $\mathrm{Sb}$ is more negative than that of Te. During the electrodeposition of BiSbTe alloys, BiTe was deposited first followed by increase of $\mathrm{Sb}$ composition at more negative applied potential. (Wu et al., 2014).

Patil et al. (2015) electrodeposited fern shaped $\mathrm{Bi}_{2} \mathrm{Te}_{3}$ thin film in the solution containing $10 \mathrm{mM} \mathrm{Te}(\mathrm{IV}), 7 \mathrm{mM} \mathrm{Bi}\left(\mathrm{NO}_{3}\right)_{3}$, and $1 \mathrm{M} \mathrm{HNO}_{3}$.

Matsuoka et al. (2015) electrodeposited $\mathrm{Bi}_{2} \mathrm{Te}_{3} / \mathrm{Bi}_{2} \mathrm{Se}_{3}$ multiplayer heterostructure in two baths sequentially. The layer thickness was fixed to about $1 \mu \mathrm{m}$ and the number of layers were varied from 2 to 10 . The deposited multilayer structure is n-type with nanocrystalline. The boundaries between different layers were not clear planar. The number of the layers had a dramatic effect on the electrical conductivity, where more layers resulted in higher electrical conductivity, while Seebeck coefficient remained unchanged. The 10-layer $\mathrm{Bi}_{2} \mathrm{Te}_{3} /$ $\mathrm{Bi}_{2} \mathrm{Se}_{3}$ heterostructure has a power factor of $144 \mu \mathrm{W} /\left(\mathrm{K}^{2} \cdot \mathrm{m}\right)$, which is about 3 times higher than that of the 2-layer heterostructure (Matsuoka et al., 2015).

Caballero-Calero et al. (2015) electrodeposited $\mathrm{Bi}_{2} \mathrm{Te}_{3-\mathrm{y}} \mathrm{Se}_{\mathrm{y}}$ films in a conventional three electrode cell in the solution containing $9 \mathrm{mM} \mathrm{HTeO}_{2}{ }^{+}, 7.5 \mathrm{mM} \mathrm{Bi}^{3+}, 1 \mathrm{mM} \mathrm{H}_{2} \mathrm{SeO}_{3}$, and $1 \mathrm{M} \mathrm{HNO}_{3}$. The influence of additives (i.e., sodium signosulfonate (SLS) and EDTA) in morphology, stoichiometry, structure and Seebeck coefficient was studied. The films synthesized with SLS had high crystallographic orientation and better morphology, while films deposited in the presence of EDTA had higher content of bismuth. The combination of both additives would improve the quality of stoichiometric $\mathrm{Bi}_{2} \mathrm{Te}_{2.7} \mathrm{Se}_{0.3}$ films, namely denser morphology, higher orientation and higher Seebeck coefficients (60\% larger) when compared with films deposited without additives. (Caballero-Calero et al., 2015).

Zhou et al. (2015) synthesized $\mathrm{Bi}_{2} \mathrm{Te}_{3}$ thin films by the pulsed electrodeposition method in the solution consisting of $40 \mathrm{mM}$ $\mathrm{HTeO}_{2}{ }^{+}, 30 \mathrm{mM} \mathrm{Bi}^{3+}$ and $1.7 \mathrm{M} \mathrm{HNO}_{3}$. The effect of deposition parameters on the composition and microstructure was investigated. The results indicated that the stoichiometry and morphology can be improved by a large pulse off-to-on ratio with a pulsed applied potential of $0 \mathrm{mV}$ vs. Ag/AgCl. Additionally, larger pulse off-to-on ratio would enhance the $\mathrm{ZT}$ of $\mathrm{Bi}_{2} \mathrm{Te}_{3}$ films owing to suppressing the thermal conductivity and improving the Seebeck coefficient. The highest ZT value was 0.16 obtained at a pulse off-to-on ratio of 50 (Zhou et al., 2015).

$\mathrm{Li}$ et al. (2015) reported the electrodeposition of BiSbTe nanowires in the electrolyte containing $15 \mathrm{mM} \mathrm{HTeO}_{2}{ }^{+}$, $40 \mathrm{mM} \mathrm{SbO}^{+}, 2 \mathrm{mM} \mathrm{Bi}^{3+}, 0.3 \mathrm{M}$ tartaric acid and $1 \mathrm{M} \mathrm{HNO}_{3}$. Their data showed that the pulse electrodeposit method would help to improve the uniformity and crystallinity of $\mathrm{Bi}_{0.5} \mathrm{Sb}_{1.5} \mathrm{Te}_{3}$ nanowires, which resulted in higher electrical and thermal conductivity, compared to the direct current deposited nanowires. Additionally, the pulse electrodeposit method would also enhance the Seebeck coefficient of nanowires, which was attributed to a more homogeneous distribution of 
the elements. The highest ZT value was 1.14 at $330 \mathrm{~K}$ achieve by pulse-deposited $\mathrm{Bi}_{0.5} \mathrm{Sb}_{1.5} \mathrm{Te}_{3}$ nanowires (Li et al., 2015).

Song et al. (2015) synthesized thin $\mathrm{Bi}_{2} \mathrm{Te}_{3}$ films in a acidic bath with $\quad 7.5 \mathrm{mM} \quad \mathrm{Bi}\left(\mathrm{NO}_{3}\right)_{3}, \quad 10 \mathrm{mM} \quad \mathrm{TeO}_{2}$, cetyltrimethylammonium bromide (CTAB) and $1.5 \mathrm{M}$ $\mathrm{HNO}_{3}$ at room temperature. CTAB acted as a surfactant. The results indicated that the presence of CTAB would help to improve the surface morphology and mechanical properties $\mathrm{Bi}_{2} \mathrm{Te}_{3}$ films. However, the electrical and thermoelectric properties were preserved (Song et al., 2015).

Uda et al. (2015) fabricated $\mathrm{Bi}_{2} \mathrm{Te}_{3}$ thermoelectric microdevice by electrodeposition in an electrolyte composing of $\mathrm{Bi}\left(\mathrm{NO}_{3}\right)_{3} \cdot 5 \mathrm{H}_{2} \mathrm{O}, \mathrm{TeO}_{2}$, and $\mathrm{HNO}_{3}$. The size effect of electrode was examined. The cross-section of the TE units is $50 \times 50 \mu^{2}$ with depth of $20 \mu \mathrm{m}$. Additionally, the device had a eight arrays, which composed of 110 TE units. A maximum power output of $0.96 \mu \mathrm{W}$ was achieved with an open-circuit voltage of $17.6 \mathrm{mV}$ (Uda et al., 2015).

Chang et al. (2015) examined the electrodeposition of individual n-type $\mathrm{Bi}_{2} \mathrm{Te}_{3}$ nanowires (NWs) using polycarbonate membranes (PCM) as templates in the solution $10 \mathrm{mM} \mathrm{HTeO}_{2}{ }^{+}, 15 \mathrm{mM} \mathrm{Bi}^{3+}, 1 \mathrm{M} \mathrm{HNO}_{3}$ and $50 \mathrm{v} / \mathrm{v} \%$ DMSO. The electrodeposition conditions, such as the applied potential can be used to control the composition of $\mathrm{Bi}_{2} \mathrm{Te}_{3}$. Additionally, increase the Te composition would increase the average grain size of NWs, as well as the electrical conductivity. The maximum power factor of $195.8 \mu \mathrm{W} /\left(\mathrm{mK}^{2}\right)$ was achieved at $300 \mathrm{~K}$ for the Te-rich NW with diameter of $162 \mathrm{~nm}$ (Chang et al., 2015).

Shin and Oh (2015) fabricated a thermoelectric device based on thin film by combining electrodeposition and the flip-chip process. The thermoelectric materials used in the device are the n-type $\mathrm{Bi}_{2} \mathrm{Te}_{3}$ and p-type $\mathrm{Sb}_{2} \mathrm{Te}_{3}$ thin film, which is deposited on $\mathrm{Ti} / \mathrm{Cu} / \mathrm{Au}$ substrate in the solutions with $25 \mathrm{mM}$ Bi ion, $25 \mathrm{mM}$ Te ion and $1 \mathrm{M} \mathrm{HNO}_{3}$ for $\mathrm{Bi}_{2} \mathrm{Te}_{3}$ and $63 \mathrm{mM} \mathrm{Sb}$ ion, $7 \mathrm{mM} \mathrm{Te}$ ion. The device with 242 pairs thermoelectric legs have a internal resistance of $21.4 \Omega$, which have a output voltage of $320 \mathrm{mV}$ and output power of $1.1 \mathrm{~mW}$ at $39.7 \mathrm{~K}$ temperature difference. Additionally, the calculated power density of $3.84 \mathrm{~mW} / \mathrm{cm}^{2}$ (Shin and Oh, 2015).

Abellán et al. (2015) synthesized thin $\mathrm{Bi}_{2} \mathrm{Te}_{3}$ films containing $\mathrm{TeCl}_{4}, \mathrm{Bi}\left(\mathrm{NO}_{3}\right)_{3}$ and dimethyl sulfoxide. Different substrates were used, such as $\mathrm{CdTe} / \mathrm{FTO}$ and $\mathrm{SnO}_{2}: \mathrm{F}$ coated glasses. Additionally, the deposits films were n-type semiconductors with trigonal crystal structure and stoichiometric composition dimethyl sulfoxide (Abellán et al., 2015).

Kulsi et al. (2015) synthesized thin $\mathrm{Bi}_{2} \mathrm{Te}_{3}$ films with preferred crystal orientation of (018) in the solution consisting of $15 \mathrm{mM}$ $\mathrm{TeO}_{2}$ and $10 \mathrm{mM} \mathrm{Bi}\left(\mathrm{NO}_{3}\right)_{3}$. The effect of different surfactant on the morphology was examined, including sodium dodecyl sulfate (SDS) and polyvinylpyrrolidone (PVP). The results indicated that improving the surface morphology would help to enhancing the carrier mobility. A ZT value of 0.28 was achieved using SDS as surfactant, which was measured at room temperature (Kulsi et al., 2015).

Şişman and Başoğlu (2016) fabricated thin $\mathrm{Bi}_{2} \mathrm{Te}_{3-\mathrm{y}} \mathrm{Se}_{\mathrm{y}}$ films by electrodeposition in the solution containing $2 \mathrm{mM} \mathrm{TeO}_{2}, 2.5 \mathrm{mM}$ $\mathrm{Bi}\left(\mathrm{NO}_{3}\right)_{3}, \mathrm{SeO}_{2}$ and $0.1 \mathrm{M} \mathrm{HNO}_{3}$ with $\mathrm{Au}$ as substrate. The Se composition was controlled to be 0.3 to 2.5 . The results showed that replacement of Te by Se atoms would push the XRD diffraction peaks positions $\mathrm{Bi}_{2} \mathrm{Te}_{3-\mathrm{y}} \mathrm{Se}_{\mathrm{y}}$ to higher angle, which is attributed to the change of crystal lattice constant (Şişman and Başoğlu, 2016).

Lei et al. (2016a) synthesized of $600 \mu$ m-thick n-type $\mathrm{Bi}_{2} \mathrm{Te}_{3}$ films by pulsed and potentiostatic electrodeposition in the electrolyte consisting of $70 \mathrm{mM} \mathrm{TeO}_{2}, 52.5 \mathrm{mM} \mathrm{Bi}^{3+}, 2 \mathrm{M}$ nitric acid and polyvinyl alcohol (PVA). The results indicated that compact and uniform $\mathrm{Bi}_{2} \mathrm{Te}_{3}$ films was electrodeposited which composition near stoichiometric and hexagonal crystal structure. Moreover, the film growth can reach $100 \mu \mathrm{m} / \mathrm{h}$. Additionally, a Seebeck coefficient of $-200 \mu \mathrm{V} / \mathrm{K}$ and an electrical conductivity of $400 \mathrm{~S} / \mathrm{cm}$ were achieved, resulting in a power factor of $1.6 \times 10^{3} \mu \mathrm{W} /\left(\mathrm{mK}^{2}\right)$ (Lei et al., 2016a).

Yang et al. (2016) electrodeposited p-type BiSbTe thin films using ITO glasses as substrate in the electrolyte composing of $2 \mathrm{mM} \mathrm{TeO}_{2}, 0.5 \mathrm{mM} \mathrm{Bi}_{2} \mathrm{O}_{3}, 3.5 \mathrm{M} \mathrm{HClO}_{4}, 1 \mathrm{M} \mathrm{HNO}_{3}$ and $0.35 \mathrm{M}$ $\mathrm{C}_{4} \mathrm{H}_{6} \mathrm{O}_{6}$. The $\mathrm{Sb}^{3+}$ concentration and current density were the variables during the electrodeposition. Thin BiSbTe films showed different morphologies, such as ball-type, mixed-type and acicular-type. The Seebeck coefficient of $32.89 \mu \mathrm{V} / \mathrm{K}$ was obtained (Yang et al., 2016).

Patil et al. (2016) electrodeposited thin $\mathrm{Bi}_{2} \mathrm{Te}_{3}$ film in a solution with $10 \mathrm{mM}$ Te(IV), $7 \mathrm{mM} \mathrm{Bi}\left(\mathrm{NO}_{3}\right)_{3} \cdot 5 \mathrm{H}_{2} \mathrm{O}$ and $1 \mathrm{M}$ $\mathrm{HNO}_{3}$. The XRD pattern showed that the $\mathrm{Bi}_{2} \mathrm{Te}_{3}$ film was nanocrystalline with grain size of $18.08 \mathrm{~nm}$ and had a preferred orientation of (015) with rhombohedral crystal structure (Patil et al., 2016).

$\mathrm{Na}$ et al. (2016) electrodeposited n-type $\mathrm{Bi}_{2} \mathrm{Te}_{3}$ films in the electrolyte with $10 \mathrm{mM} \mathrm{HTeO}_{2}{ }^{+}, 8 \mathrm{mM} \mathrm{Bi}^{3+}$ and $1 \mathrm{M} \mathrm{HNO}_{3}$ on a flexible substrate. The effect of applied potential on the crystal structure and thermoelectric properties were systematically studied. The $\mathrm{Bi}_{2} \mathrm{Te}_{3}$ film with preferred orientation of (110) is deposited. The highest power factor of $1,473 \mu \mathrm{W} /\left(\mathrm{K}^{2} \cdot \mathrm{m}\right)$ was achieved for the film electrodeposited at applied potential of $0.02 \mathrm{~V}$ with electrical conductivity of $691 \mathrm{~S} / \mathrm{cm}$. The effect of applied potential and grain size on the electrical and thermoelectric properties were shown in Figure 6. A flexible thermoelectric device was fabricated using $\mathrm{Bi}_{2} \mathrm{Te}_{3}$ as n-type material and poly (3,4-ethylene dioxythiophene)s as p-type material. The generator achieved a output voltage of $5 \mathrm{mV}$ and output power of $56 \mathrm{nW}$ with temperature difference of $12 \mathrm{~K}$ ( Na et al., 2016).

Lal et al. (2017) synthesized p-type $\left(\mathrm{Bi}_{\mathrm{x}} \mathrm{Sb}_{1-\mathrm{x}}\right)_{2} \mathrm{Te}_{3}$ thin films using pulsed electrodeposition in the electrolyte consisting of $15 \mathrm{mM} \mathrm{HTeO}_{2}{ }^{+}, 5 \mathrm{mM} \mathrm{Sb} \mathrm{O}_{3}, 5 \mathrm{mM} \mathrm{Bi}\left(\mathrm{NO}_{3}\right)_{3}, 0.2 \mathrm{M}$ tartaric acid, sodium dodecyl sulfate (SDS) and dimethyl sulfoxide. The results indicated that the present of SDS would improve the Seebeck coefficient and power factor of the films as shown in Figure 7. (Lal et al., 2017).

Additionally, many other groups reported the results of characterization of $\mathrm{BiTe} / \mathrm{Se}$ electrodeposits based on various experimental conditions which are summarized on Table 1. (Jagadish et al., 2015; Lei et al., 2016b; Wu et al., 2016b; Hasan et al., 2016; Kulsi et al., 2016; Manzano et al., 2016; Wu et al., 2017b; Kang et al., 2017; Lal et al., 2017; Lei et al., 2017). 


\section{A}

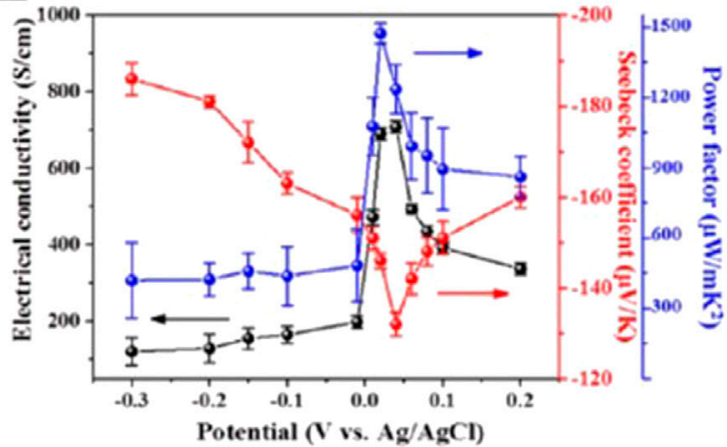

B

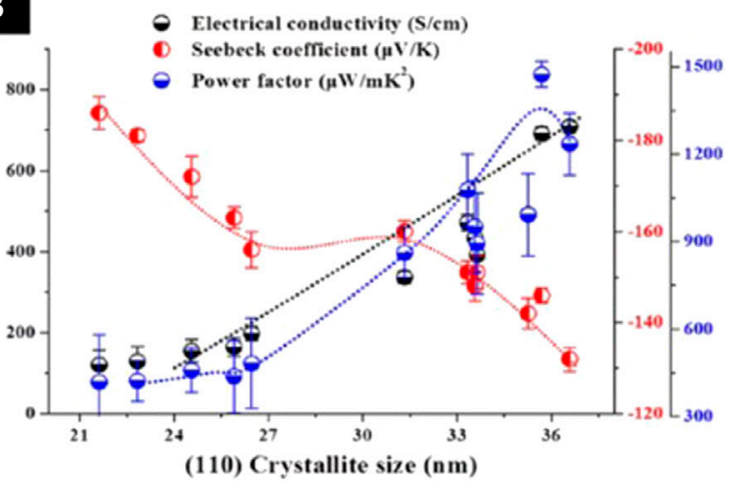

FIGURE 6 | (A) Corelation of electrical conductivity (black circle), Seebeck coefficient (red circle), and power factor (blue circle) with different applied potentials ( $V$ vs $\mathrm{Ag} / \mathrm{AgCl}$ ) (B) Corelation of the electrical conductivity (black), Seebeck coefficient (red), and power factor (blue) with (110) crystallite size (Na et al., 2016)

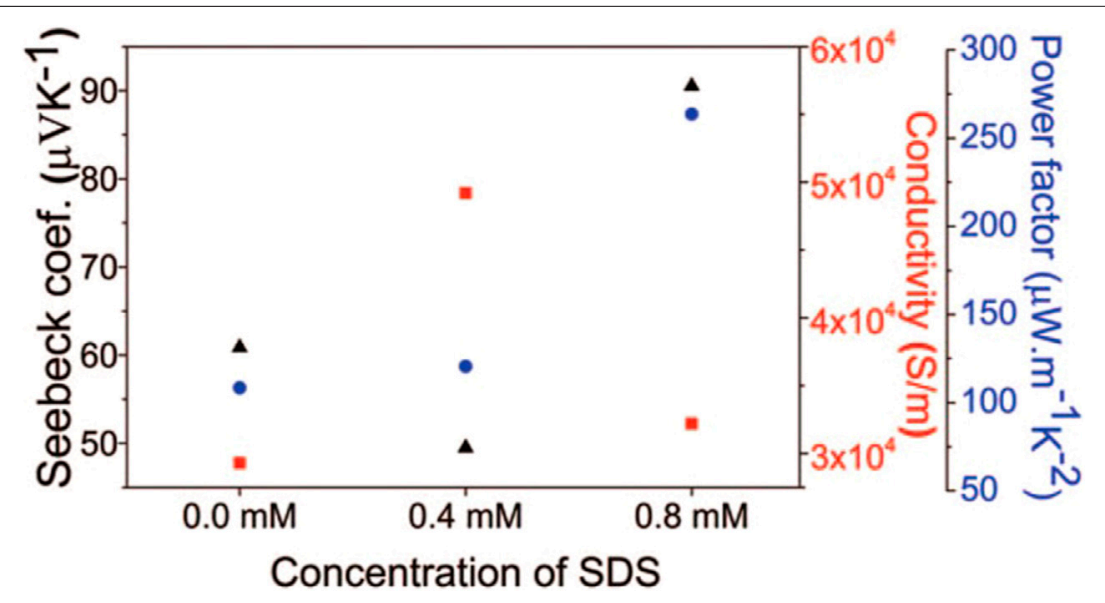

FIGURE 7 | Electrical resistivity (square), Seebeck coefficient (triangle), and power factor (circle) of annealed films deposited with different concentrations of SDS (Lal et al., 2017).

Electrodeposition of $\mathrm{Bi}_{\mathrm{x}} \mathrm{Sb}_{\mathrm{y}}$ Based Materials Dou et al. (2008) synthesize Bi/BiSb superlattice nanowires by template-directed electrodeposition method, in which AAO was used as template. The electrolyte for electrodeposition contains a mixture of $80 \mathrm{mM} \mathrm{SbCl}_{3}, 40 \mathrm{mM} \mathrm{BiCl}, 50 \mathrm{~g} / \mathrm{L}$ citric acid, $40 \mathrm{~g} / \mathrm{L}$ tartaric acid, $70 \mathrm{~g} / \mathrm{L} \mathrm{NaCl}, 100 \mathrm{~g} / \mathrm{L}$ glycerol and $1.0 \mathrm{M} \mathrm{HCl}$ at $\mathrm{pH}$ value of 0.82 (Dou et al., 2008).

Weber et al. (2008) electrodeposited high density nanowire arrays in AAO templates from the electrolyte of $50 \mathrm{mM} \mathrm{Bi}^{3+}+$ $50 \mathrm{mM} \mathrm{Sb}^{3+}$ in dimethyl sulfoxide.

Dou et al. (2009) synthesized Bi/BiSb multilayer nanowires by pulsed electrodeposition with small bilayer thickness. The electrolyte for the deposition contained a mixture of $80 \mathrm{mM} \mathrm{SbCl}_{3}, 40 \mathrm{mM} \mathrm{BiCl}, 0.24 \mathrm{M}$ citric acid, $0.27 \mathrm{M}$ tartaric acid, $1.2 \mathrm{M} \mathrm{NaCl}, 0.1 \mathrm{M}$ glycerol and $1.0 \mathrm{M} \mathrm{HCl}$. Additionally, the modulating time was used to control the segment length and layer thickness of the nanowires (Dou et al., 2009).
Muller et al. (2012) synthesized $\mathrm{Bi}_{1-\mathrm{x}} \mathrm{Sb}_{\mathrm{x}}$ nanowires with $\mathrm{Sb}$ composition in the range from 0.05 to 0.40 and diameter in the range from 20 to $100 \mathrm{~nm}$. The results showed that applied potential and ratio of $\mathrm{Bi} / \mathrm{Sb}$ ions would influence the composition of $\mathrm{Bi}_{1-\mathrm{x}} \mathrm{Sb}_{\mathrm{x}}$ nanowires (Müller et al., 2012).

Limmer et al. (2015) electrodeposited $\mathrm{Bi}_{\mathrm{x}} \mathrm{Sb}_{\mathrm{y}}$ in the nonaqueous baths consisting of $\mathrm{Sb}$ salts, $\mathrm{Bi}\left(\mathrm{NO}_{3}\right)_{3} \cdot 5 \mathrm{H}_{2} \mathrm{O}$, dimethyl sulfoxide and $\mathrm{KClO}_{4}$. The effect of different $\mathrm{Sb}$ salts on the crystalline quality and preferred orientations were investigated. The results showed that nanowire arrays synthesized with $\mathrm{SbI}_{3}$ based bath were polycrystalline. However, nanowire arrays synthesized with $\mathrm{SbCl}_{3}$-based bath have a trigonal orientation, and composition of these nanowires remained constant along the nanowires. Additionally, there was a composition gradient along the radius of the nanowires array, where nanowires of $\mathrm{Bi}_{0.75} \mathrm{Sb}_{0.25}$ were obtained in the center area and nanowires of $\mathrm{Bi}_{0.70} \mathrm{Sb}_{0.30}$ were obtained in the edge region (Limmer et al., 2015). 


\section{Electrodeposition of $\mathrm{Bi}_{2} \mathrm{Se}_{3}$ Based Materials} Xiao et al. (2009) electrodeposited thin $\mathrm{Bi}_{2} \mathrm{Se}_{3}$ films using $\mathrm{Pt}$ as substrate by atomic layer epitaxy. The electrochemical reaction mechanism of $\mathrm{Bi}$ and $\mathrm{Se}$ alone were investigated by cyclic voltammetry. The electrodeposition mechanism $\mathrm{Bi}_{2} \mathrm{Se}_{3}$ is underpotential deposition (UPD). The synthesized $\mathrm{Bi}_{2} \mathrm{Se}_{3}$ films had an orthorhombic structure with stoichiometric composition. Additionally, the bandgap of $\mathrm{Bi}_{2} \mathrm{Se}_{3}$ films the was $0.35 \mathrm{eV}$. (Xiao et al., 2009).

$\mathrm{Li}$ et al. (2010c) synthesized $\mathrm{Bi}_{2} \mathrm{Se}_{3}$ thin films by electrodeposition in the solution containing $\mathrm{SeO}_{2}, \mathrm{Bi}\left(\mathrm{NO}_{3}\right)_{3}$, and $\mathrm{HNO}_{3}$ using $\mathrm{Ti}$ and indium tin oxide-coated glass as substrates at room temperature. The results indicated that the substrate had dramatic effect on the crystal structure of $\mathrm{Bi}_{2} \mathrm{Se}_{3}$ thin films. Pure rhombohedral crystal structure was obtained on the indium tin oxide-coated glass substrate, while both rhombohedral and orthorhombic crystal structure was obtained on $\mathrm{Ti}$ (Li et al., 2010c).

Xue et al. (2014) fabricated $\mathrm{Bi}_{2} \mathrm{Se}_{3} / \mathrm{Bi}$ multilayered nanowire arrays by pulsed electrodeposition using $\mathrm{AAO}$ as template in the electrolyte with $7.5 \mathrm{mM} \mathrm{H}_{2} \mathrm{SeO}_{3}, 25 \mathrm{mM} \mathrm{Bi}^{3+}$ and $7 \mathrm{mM} \mathrm{HNO}_{3}$. Each layer of $\mathrm{Bi}$ or $\mathrm{Bi}_{2} \mathrm{Se}_{3}$ had a thickness of about $100 \mathrm{~nm}$, and the total length of the nanowire was $10 \mu \mathrm{m}$ with a diameter of $50 \mathrm{~nm}$ (Xue et al., 2014).

$\mathrm{Li}$ et al. electrodeposited thick $\mathrm{Bi}_{2} \mathrm{Se}_{3}$ films using ITO-coated glass as substrate in a acidic solution containing $25 \mathrm{mM} \mathrm{SeO}_{2}$, $25 \mathrm{mM} \mathrm{Bi}\left(\mathrm{NO}_{3}\right)_{3}$ and $1.3 \mathrm{M} \mathrm{HNO}_{3}$. The results showed that the as-deposited films were p-type $\mathrm{Bi}_{2} \mathrm{Se}_{3}$ films. The power factors of $52.57 \mu \mathrm{W} / \mathrm{mK}^{2}$ were obtained for the as-deposited films (Xiaolong and Zhen, 2014).

Tumelero et al. (2016) electrodeposited $\mathrm{Bi}_{2} \mathrm{Se}_{3}$ using $\mathrm{Si}$ (100) substrate as substrate in the electrolyte consisting of $1.5 \mathrm{mM}$ $\mathrm{SeO}_{2}, 1 \mathrm{mM} \mathrm{Bi}\left(\mathrm{NO}_{3}\right)_{3}$ and $0.5 \mathrm{M}$ nitric acid. The results indicated that $\mathrm{Bi}_{2} \mathrm{Se}_{3}$ with single orthorhombic phase and stoichiometric composition can be deposited by tuning the applied potential, while the potential window was narrow. Additionally, the deposited $\mathrm{Bi}_{2} \mathrm{Se}_{3}$ had a bandgap of $1.25 \mathrm{eV}$ (Tumelero et al., 2016).

Souza et al. (2017) synthesized $\mathrm{Bi}_{2} \mathrm{Se}_{3}$ films by potentiostatic electrodeposition method in the electrolyte consisting of $1.5 \mathrm{mM}$ $\mathrm{SeO}_{2}, 0.5 \mathrm{mM} \mathrm{Bi}_{2} \mathrm{O}_{3}$ and $1.0 \mathrm{M} \mathrm{HClO}_{4}$ using silicon (100) as substrate. The deposited $\mathrm{Bi}_{2} \mathrm{Se}_{3}$ films is compact with uniform and smooth morphology. The as-deposited films had a dominant orthorhombic phase with mixture of rhombohedral and amorphous phases. However, pure rhombohedral structure was obtained after annealing (Souza et al., 2017).

\section{Electrodeposition of $\mathrm{Bi}_{2} \mathbf{S}_{3}$ Based Materials}

Jagadish et al. (2016) synthesized n-type $\mathrm{Bi}_{2} \mathrm{~S}_{3}$ films in the solution consisting of $20.6 \mathrm{mM} \mathrm{Bi}\left(\mathrm{NO}_{3}\right)_{3}, 0.54 \mathrm{M}$ of lactic acid, $0.78 \mathrm{M}$ of nitric acid and $140.8 \mathrm{mM} \mathrm{Na}_{2} \mathrm{SO}_{4}$. Virgin carbon fiber and recycled carbon fiber were used as substrates. The deposited $\mathrm{Bi}_{2} \mathrm{~S}_{3}$ had a composition near stoichiometry. The surface morphology and the Seebeck coefficient of $\mathrm{Bi}_{2} \mathrm{~S}_{3}$ films can be tuned by post annealing process. The $\mathrm{Bi}_{2} \mathrm{~S}_{3}$ films had Seebeck coefficient of -16.3 and $-12.4 \mu \mathrm{V} / \mathrm{K}$ deposited on virgin carbon fiber and recycled carbon fiber, respectively (Jagadish et al., 2016).

\section{Electrodeposition of $\mathrm{Sb}_{2} \mathrm{Te}_{3}$ Based Materials}

Ueda et al. (2008) synthesized $\mathrm{Sb}_{2} \mathrm{Te}_{3}$ alloy in the $\mathrm{AlCl}_{3}-\mathrm{NaCl}$ $\mathrm{KCl}$ molten salt electrolyte containing $10 \mathrm{mM} \mathrm{TeCl}_{4}$ and $7 \mathrm{mM}$ $\mathrm{SbCl}_{3}$, at the temperature of $423 \mathrm{~K}$ and applied potential of $0.85 \mathrm{~V}$ vs. $\mathrm{Al} / \mathrm{Al}(\mathrm{III})$. The composition of $\mathrm{Sb}$ can be controlled by concentration ratio of the $\mathrm{Sb}(\mathrm{III})$ to $[\mathrm{Sb}(\mathrm{III})+\mathrm{Te}(\mathrm{IV})]$. The morphology of deposited $\mathrm{Sb}_{2} \mathrm{Te}_{3}$ alloy is disk-like granule, which had a size of around $10 \mu \mathrm{m}$ (Ueda et al., 2008).

Park et al. (2009) electrodeposited thin $\mathrm{Sb}_{\mathrm{x}} \mathrm{Te}_{\mathrm{y}}$ films and nanowires at room temperature in an acidic electrolyte. $\mathrm{Pt} / \mathrm{Si}$ and $\mathrm{Au}$ were used as substrate. The applied voltage and film thickness had significant effect on the morphology and grain size of the $\mathrm{Sb}_{\mathrm{x}} T \mathrm{Te}_{\mathrm{y}}$ films. Amorphous $\mathrm{Sb}_{\mathrm{x}} \mathrm{Te}_{\mathrm{y}}$ films was electrodeposited, while the films became the rhombohedral R3m structure after annealing (Park et al., 2009).

Kim and Oh (2010b) investigated the crystallization behavior of the electrodeposited $\mathrm{Sb}_{2} \mathrm{Te}_{3}$ film in the electrolyte containing $7 \mathrm{mM}$ Te ion, $63 \mathrm{mM} \mathrm{Sb}$ ion, $3.5 \mathrm{M}$ perchloric acid, $0.35 \mathrm{M}$ tartaric acid. The transition crystal structure from amorphous to crystalline would influence the Seebeck coefficient. Moreover, the addition of $\mathrm{Cu}$ can improve the thermal stability of the $\mathrm{Sb}_{2} \mathrm{Te}_{3}$ film, where CuSbTe film had a crystallization temperature of $149.5^{\circ} \mathrm{C}$ (Kim and Oh, 2010b).

Pinisetty et al. (2011b) electrodeposited polycrystalline $\mathrm{Sb}_{2} \mathrm{Te}_{3}$ nanowires and nanotubes arrays in the electrolyte consisting of $0.7 \mathrm{mM} \mathrm{TeO}_{2}, 1.6 \mathrm{mM} \mathrm{Sb}_{2} \mathrm{O}_{3}, 33$ or $330 \mathrm{mM}$ tartaric acid, and $3 \mathrm{M} \mathrm{HNO}_{3}$. The nanowires and nanotube had an average lamellar thickness of 36 and $43 \mathrm{~nm}$, respectively (Pinisetty et al., 2011b).

Lim et al. (2011) electrodeposited $p$-tyape $\mathrm{Sb}_{\mathrm{x}} \mathrm{Te}_{\mathrm{y}}$ thin films in an acidic solutions. The effect of $\mathrm{TeO}_{2}$ concentrations was investigated. $\mathrm{Sb}_{2} \mathrm{Te}_{3}$ films with composition near stoichiometry was deposited with a rhombohedral structure and preferred orientation of (015). The films had a carrier concentration of $5.8 \times 10^{18} \mathrm{~cm}^{-3}$ and mobility of $54.8 \mathrm{~cm}^{2} /(\mathrm{Vs})$. Additionally, more negative applied potential would reduce the carrier concentration and mobility, which is possibly owing to increase in defects. A Seebeck coefficient of $118 \mu \mathrm{V} / \mathrm{K}$ was obtained at room temperature for the as-deposited $\mathrm{Sb}_{2} \mathrm{Te}_{3}$ film (Lim et al., 2011).

Qiu et al. (2011) synthesized $\mathrm{Sb}_{2} \mathrm{Te}_{\mathrm{x}}(2<x<6)$ films in the alkaline solution with $\mathrm{TeO}_{3}{ }^{2-}, \mathrm{SbO}_{2}{ }^{-}$, diaminourea polymer and triethanolamine. The solution was pretreated by argon gas to fully deaerate, which would enhance the Seebeck coefficient of the films by reducing oxygen contamination in the deposited films. $\mathrm{The}_{\mathrm{Sb}} \mathrm{Te}_{\mathrm{x}}$ films were amorphous before annealing. A maximum power factor $1.58 \mathrm{~mW} / \mathrm{mK}^{2}$ was achieved with a Seebeck coefficient of $532 \mu \mathrm{V} / \mathrm{K}$ after annealing (Qiu et al., 2011).

Schumacher et al. (2012) electrodeposited $\mathrm{Sb}_{2} \mathrm{Te}_{3}$ films in the electrolyte composing of $10 \mathrm{mM} \mathrm{TeO}_{2}, 5.6 \mathrm{mM} \mathrm{Sb}_{2} \mathrm{O}_{3}, 0.84 \mathrm{M}$ tartaric acid and $1 \mathrm{M}$ nitric acid with $\mathrm{pH}$ of 1 . Both $\mathrm{Au}$ and stainless steel were used as substrates. The results showed that morphology and composition of the films could be improved by pulsed electrodeposition methods. The p-type $\mathrm{Sb}_{2} \mathrm{Te}_{3}$ films fabricated by pulsed electrodeposition methods achieved a power factors of about $700 \mu \mathrm{W} /\left(\mathrm{mK}^{2}\right)$ at room temperature 


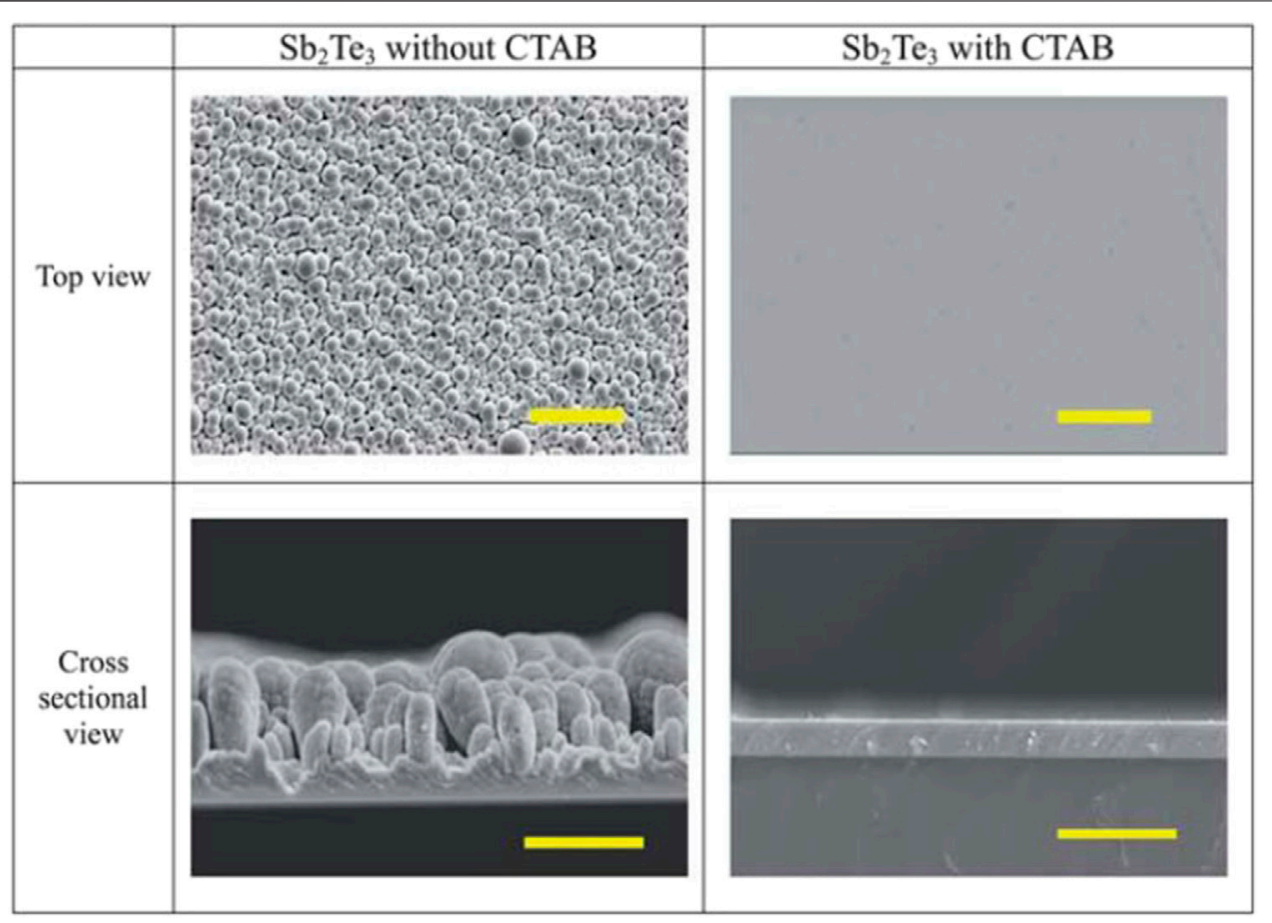

FIGURE 8|Comparison of the top view (scale bar $=30 \mu \mathrm{m}$ ) and the cross-sectional (scale bar $=20 \mu \mathrm{m}$ ) SEM images of the Sb $\mathrm{Se}_{3}$ films electrodeposited with and without CTAB (Yoo et al., 2013c).

with the electrical conductivity of $280 \mathrm{~S} / \mathrm{cm}$ and Seebeck coefficients of $160 \mu \mathrm{V} / \mathrm{K}$. Additionally, a maximum power factors obtained is $852 \mu \mathrm{W} /\left(\mathrm{mK}^{2}\right)$ after annealing (Schumacher et al., 2012).

Li et al. (2012) electrodeposited $\mathrm{Sb}_{\mathrm{x}} \mathrm{Te}_{\mathrm{y}}$ films in a nonaqueous electrolyte containing $20 \mathrm{mM} \mathrm{SbCl}_{3}, 20 \mathrm{mM} \mathrm{TeCl}_{4}$ and $0.1 \mathrm{M}$ $\mathrm{KNO}_{3}$. The $\mathrm{Sb}_{\mathrm{x}} \mathrm{Te}_{\mathrm{y}}$ films had a smooth morphology, which is independent of applied potential. The composition obtained nearest to stoichiometry is $\mathrm{Sb}_{1.87} \mathrm{Te}_{3.13}$. Additionally, all the films were p-type after annealing (Li et al., 2012).

Lim et al. (2012b) synthesized $\mathrm{Sb}_{\mathrm{x}} \mathrm{Te}_{\mathrm{y}}$ films in the electrolyte with $2.4 \mathrm{mM} \mathrm{HTeO}_{2}{ }^{+}, 0.8 \mathrm{mM} \mathrm{SbO}^{+}, 33 \mathrm{mM}$ tartaric acid, and $1 \mathrm{M} \mathrm{HNO}_{3}$ by electrodeposition. The thin $\mathrm{Sb}_{2} \mathrm{Te}_{3}$ films with composition near stoichiometry were deposited in the applied potential range of -0.15 to $-0.30 \mathrm{~V}$ vs. SCE. The post-annealing process would reduce the FWHM of the major diffraction peaks and enhance the electrical conductivity. Additionally, the power factor was improved from 44.2 to $372.1 \mathrm{~mW} /\left(\mathrm{mK}^{2}\right)$ by annealing (Lim et al., 2012b).

Lensch-Falk et al. (2012) electrodeposited thin $\mathrm{Sb}_{2} \mathrm{Te}_{3}$ films in the electrolyte consisting of $7 \mathrm{mM}$ sodium tellurite (IV), $16 \mathrm{mM}$ antimony (III) oxide, $0.3 \mathrm{M}$ tartaric acid, and $2 \mathrm{M}$ nitric acid at room temperature by pulsed electrodeposition method. The results showed that the pulse duration have a significant effect on the texture and microstructure of films, where lamellar microstructure was deposited at short pulse durations, while equiaxed and randomly oriented microstructure was deposited at relative long pulse durations. Additionally, reducing pulse duration would also help to suppress the thermal conductivity of the films, where thermal conductivity of less than $2 \mathrm{~W} /(\mathrm{Km})$ was obtained (Lensch-Falk et al., 2012).

Nguyen et al. (2013) fabricated $\mathrm{Sb}, \mathrm{Te}$ and $\mathrm{Sb}_{\mathrm{x}} \mathrm{Te}_{\mathrm{y}}$ from molten salts containing acetamide - antimony chloride and tellurium chloride by electrodeposition. The Te composition of $\mathrm{Sb}_{\mathrm{x}} \mathrm{Te}_{\mathrm{y}}$ alloy films is ranged from 20 to 81 at\%, which is obtained in the electrolyte with $\mathrm{SbCl}_{3}$ up to $0.48 \mathrm{M}$ and $\mathrm{TeCl}_{4}$ up to $0.12 \mathrm{M}$ (Nguyen et al., 2013).

Yoo et al. (2013c) synthesized $\mathrm{Sb}_{2} \mathrm{Te}_{3}$ films in the solution consisting of $2.4 \mathrm{mM} \mathrm{TeO}_{2}, 0.8 \mathrm{mM} \mathrm{Sb}_{2} \mathrm{O}_{3}, 33 \mathrm{mM}$ tartaric acid, and $1 \mathrm{M} \mathrm{HNO}_{3}$ at room temperature. Additionally, cetyltrimethylammonium bromide (CTAB) was used as surfactant to improve the surface morphology, where the effect of $\mathrm{CTAB}$ on the morphology of $\mathrm{Sb}_{2} \mathrm{Te}_{3}$ films was shown in Figure 8. Moreover, $\mathrm{CTAB}$ would also help to enhance the adhesion of $\mathrm{Sb}_{2} \mathrm{Te}_{3}$ films to substrate. Post-annealing at $200^{\circ} \mathrm{C}$ can improve electrical conductivity and Seebeck coefficient of the $\mathrm{Sb}_{2} \mathrm{Te}_{3}$ films, which was attributed to Te nanodots formation within the $\mathrm{Sb}_{2} \mathrm{Te}_{3}$ crystal structure. A power factor of $716.0 \mathrm{~mW} /$ $\mathrm{mK}^{2}$ was obtained for $\mathrm{Sb}_{2} \mathrm{Te}_{3}$ films with $10-20 \mathrm{~nm}$ Te nanodots (Yoo et al., 2013c).

Kim et al. (2015) synthesized Te-rich $\mathrm{Sb}_{2} \mathrm{Te}_{3}$ film in a solution with $3.6 \mathrm{mM} \mathrm{Sb}_{2} \mathrm{O}_{3}, 2.4 \mathrm{mM} \mathrm{TeO}_{2}, 33 \mathrm{mM}$ L-tartaric acid, $1 \mathrm{M}$ $\mathrm{HNO}_{3}$. The as deposited films were amorphous, while $\gamma$-SbTe embedded nanocrystalline $\mathrm{Sb}_{2} \mathrm{Te}_{3}$ film was obtained by post annealing process because of solid-state phase transition. The results indicated that $\gamma$-SbTe embedded $\mathrm{Sb}_{2} \mathrm{Te}_{3}$ had higher Seebeck coefficient and P.F. than single phase $\mathrm{Sb}_{2} \mathrm{Te}_{3}$ film. This was attributed to strong energy-dependent charge 

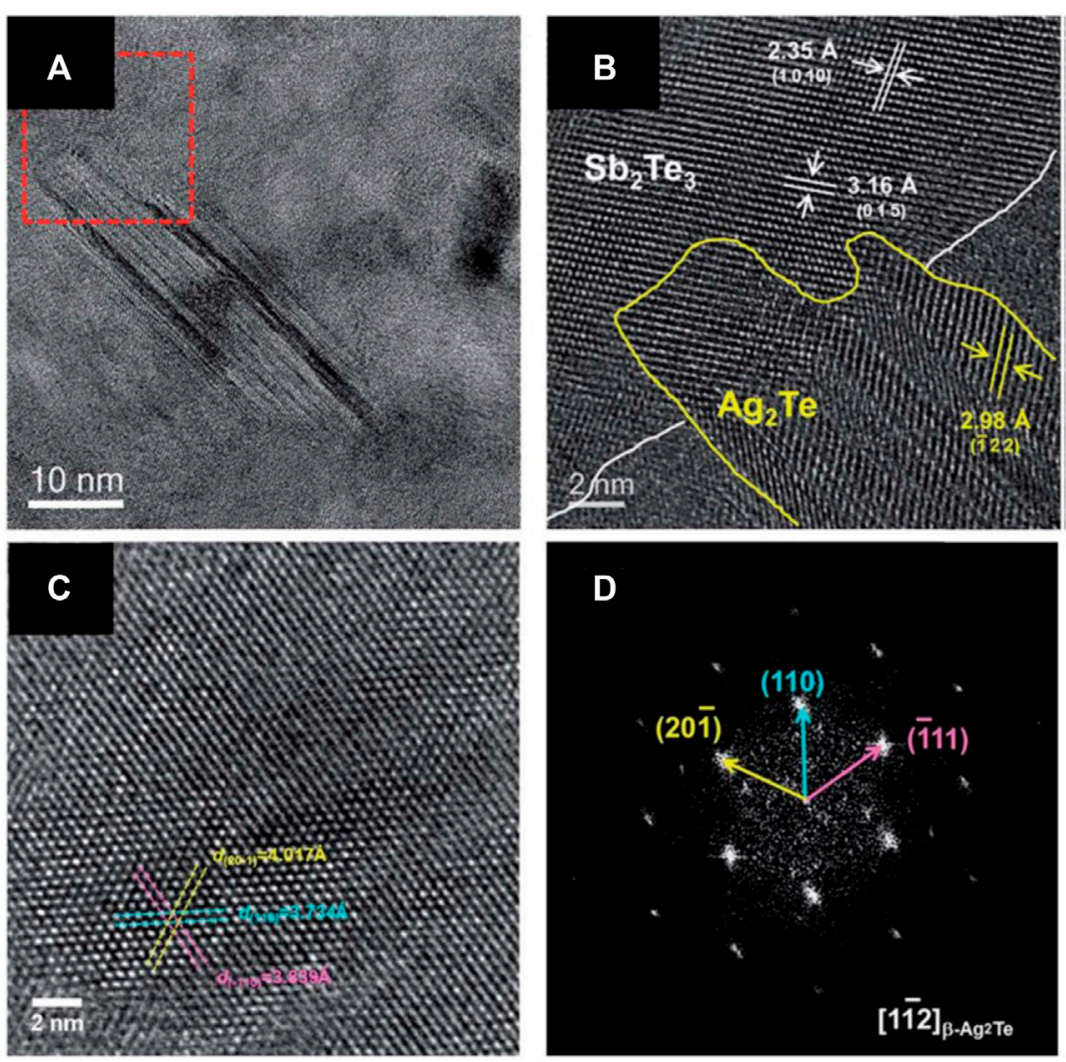

FIGURE 9 | Microstructure of the precipitated Ag2Te phase embedded in Sb2Te3 film. (A) HRTEM image and (B) a lattice image showing the precipitated Ag2Te nanodots within the $\mathrm{Sb}_{2} \mathrm{Te}_{3}$ matrix. (C) HRTEM image taken at a (Nolas et al., 2001; Snyder and Ursell, 2003; Hsu et al., 2004; Zide et al., 2006; Zeng et al., 2007; Faleev and Léonard, 2008; Poudel et al., 2008; Snyder and Toberer, 2008; Sootsman et al., 2009; Ko et al., 2011; Szczech et al., 2011; Zebarjadi et al., 2012) zone axis and (D) the corresponding FFT image (Kim et al., 2018b).

scattering, which is confirmed by UPS analysis showing $90 \mathrm{meV}$ valence band difference between $\mathrm{Sb}_{2} \mathrm{Te}_{3}$ and $\gamma$-SbTe nanocrystalline. As a consequence, a Seebeck coefficient of $320 \mu \mathrm{V} / \mathrm{K}$ was obtained for $\gamma$-SbTe/Sb $\mathrm{Te}_{3}$ nanocomposite (Kim et al., 2015).

Kim et al. (2018b) also electrodeposited $\mathrm{Ag}_{2} \mathrm{Te}$ nanoprecipitates embedded p-type $\mathrm{Sb}_{2} \mathrm{Te}_{3}$ films (Figure 9). The same electrolyte condition and applied potential ( 0.1 vs. SCE) was applied to deposit the films except adding $100 \mu \mathrm{M}$ $\mathrm{AgNO}_{3}$ as $\mathrm{Ag}$ sources. The results indicated that the presence of the $\beta-\mathrm{Ag}_{2} \mathrm{Te}$ phase would improve the Electrical property $\mathrm{Sb}_{2} \mathrm{Te}_{3}$ films dramatically, which was attributed to energy-dependent charge carrier filtering effect at the $\beta-\mathrm{Ag}_{2} \mathrm{Te} / \mathrm{Sb}_{2} \mathrm{Te}_{3}$ interface. Additionally, density of states effective mass $\left(\mathrm{m}^{\star} \sim 1.8 \mathrm{~m}_{0}\right)$ increased, leading to a high power factor of $1870 \mathrm{~mW} / \mathrm{mK}^{2}$ at $300 \mathrm{~K}$ without any dramatic suppression of electrical conductivity (Kim et al., 2018b).

Catrangiu et al. (2016) electrodeposited $\mathrm{Sb}_{2} \mathrm{Te}_{3}$ film in the ionic liquid with 4-10 $\mathrm{mM} \mathrm{TeO}_{2}, 4-10 \mathrm{mM} \mathrm{SbCl}$, choline chloride and oxalic acid. The composition of the films can be controlled by precursor concentration and applied potential. The electrodeposited mechanism is that Te layer was deposited followed by the deposition of $\mathrm{Sb}_{\mathrm{x}} \mathrm{Te}_{\mathrm{y}}$ compounds at more negative applied potential (Catrangiu et al., 2016).
Hatsuta et al. (2016) synthesized $\mathrm{Sb}_{2} \mathrm{Te}_{3}$ thin films in the solution consisting of $1.6 \mathrm{mM} \mathrm{TeO}_{2}, 1.3 \mathrm{mM} \mathrm{SbF}_{3}$, and $0.39 \mathrm{M}$ $\mathrm{HCl}$ by electrodeposition using stainless steel as substrate. The results indicated that a stoichiometric atomic composition was achieved for the as-deposited thin film. Moreover, the composition of thin film kept at stoichiometry after annealed at the temperature below $250^{\circ} \mathrm{C}$. However, when the annealing temperature go up to $300^{\circ} \mathrm{C}$, a portion a of alien element, including $\mathrm{Fe}, \mathrm{Cr}, \mathrm{Ni}$, was detected in the film, which lead to lower Seebeck coefficient and higher electrical conductivity. As a consequence, a maximum power factor of $13.6 \mu \mathrm{W} /\left(\mathrm{cmK}^{2}\right)$ was obtained for the $\mathrm{Sb}_{2} \mathrm{Te}_{3}$ film (Hatsuta et al., 2016).

Kim et al. (2016) electrodeposited thin $\mathrm{AgSbTe}_{2}$ films. The deposited amorphous $\mathrm{Ag}_{15} \mathrm{Sb}_{27} \mathrm{Te}_{58}$ film showed a Seebeck coefficient of $1,270 \mu \mathrm{V} / \mathrm{K}$. The carrier concentration of about $10^{16}$ to $10^{19} \mathrm{~cm}^{-3}$ was obtained. For deposited nanocrystalline film, The power factors of $90-553 \mathrm{~mW} / \mathrm{mK}^{2}$ was obtained owing to higher Hall mobility and Seebeck coefficients (Kim et al., 2016).

\section{CONCLUSION}

Electrochemical deposition is a cost effective and manufacturable synthesis method, which can be used to deposit thermoelectric 
materials with controlled morphology, composition and crystal structures. The electrodeposition baths including aqueous solution (e.g., acidic and alkaline solutions), ionic liquid, deep eutectic solvents solutions were used to deposit TE materials. Most of the papers investigated the electrodeposition mechanism and kinetics, and the control of morphology, composition and crystal structure of the deposits by electrodeposition parameters, such as precursor concentration, solution $\mathrm{pH}$ in aqueous solution, agitation, additives, temperature, applied potential/current, substrate and so on. The correlation between electrodeposition parameters and TE properties was reported, which is indirect correlation because the material properties (e.g., morphology, composition and crystal structure) are the direct effects on the TE properties. The correlation between material properties and TE properties was also discussed by various groups.

Thermoelectric micro-devices have a great potential to serve as a generator/cooler for portable electronic devices. Electrodeposition have an advantage to be utilized to fabricate TE micro-devices, attributed to its ability to deposit thick films, which can be used to fabricate cross-plane devices, with controlled morphology, composition, and crystal structure.

\section{REFERENCES}

Abad, B., Rull-Bravo, M., Hodson, S. L., Xu, X., and Martin-Gonzalez, M. (2015). Thermoelectric Properties of Electrodeposited Tellurium Films and the Sodium Lignosulfonate Effect. Electrochimica Acta 169, 37-45. doi:10.1016/ j.electacta.2015.04.063

Abellán, M., Schrebler, R., and Gómez, H. (2015). Electrodeposition of Bi2Te3 Thin Films onto FTO Substrates from DMSO Solution. Int. J. Electrochem. Sci. 10 (9), 7409-7422.

Agapescu, C., Cojocaru, A., Cotarta, A., and Visan, T. (2013). Electrodeposition of Bismuth, Tellurium, and Bismuth telluride Thin Films from Choline ChlorideOxalic Acid Ionic Liquid. J. Appl. Electrochem. 43 (3), 309-321. doi:10.1007/ s10800-012-0487-0

Bae, S., Lee, S., Sohn, H.-S., and Lee, H. S. (2017). Synthesis and Characteristics of PbTe1-xSex Thin Films Formed via Electrodeposition. Met. Mater. Int. 23 (5), 1056-1061. doi:10.1007/s12540-017-7009-x

Banga, D., Lensch-Falk, J. L., Medlin, D. L., Stavila, V., Yang, N. Y. C., Robinson, D. B., et al. (2012). Periodic Modulation of Sb Stoichiometry in Bi2Te3/Bi2xSbxTe3Multilayers Using Pulsed Electrodeposition. Cryst. Growth Des. 12 (3), 1347-1353. doi:10.1021/cg2014418

Banga, D. O., Vaidyanathan, R., Xuehai, L., Stickney, J. L., Cox, S., and Happeck, U. (2008). Formation of PbTe Nanofilms by Electrochemical Atomic Layer Deposition (ALD). Electrochimica Acta 53 (23), 6988-6994. doi:10.1016/ j.electacta.2008.02.108

Boulanger, C. (2010). Thermoelectric Material Electroplating: A Historical Review. J. Elec Materi 39 (9), 1818-1827. doi:10.1007/s11664-010-1079-6

Caballero-Calero, O., Díaz-Chao, P., Abad, B., Manzano, C. V., Ynsa, M. D., Romero, J. J., et al. (2014). Improvement of Bismuth Telluride Electrodeposited Films by the Addition of Sodium Lignosulfonate. Electrochimica Acta 123, 117-126. doi:10.1016/j.electacta.2013.12.185

Caballero-Calero, O., Mohner, M., Casas, M., Abad, B., Rull, M., Borca-Tasciuc, D. A., et al. (2015). Improvements on Electrodeposited Bi2Te3-ySey Films by Different Additives. Mater. Today Proc. 2 (2), 620-628. doi:10.1016/ j.matpr.2015.05.087

Cao, Y., Zeng, Z., Liu, Y., Zhang, X., Shen, C., Wang, X., et al. (2013). Electrodeposition and Thermoelectric Characterization of (00L)-Oriented Bi2Te3Thin Films on Silicon with Seed Layer. J. Electrochem. Soc. 160 (11), D565-D569. doi:10.1149/2.099311jes

Catrangiu, A.-S., Sin, I., Prioteasa, P., Cotarta, A., Cojocaru, A., Anicai, L., et al. (2016). Studies of Antimony telluride and Copper telluride Films
The performance of the TE micro-devices are for now limited because of low efficiency. More researches about thermoelectric properties of electrodeposited materials and the performance of devices need to be further studied for wide applications.

\section{AUTHOR CONTRIBUTIONS}

JK, J-HL, and NM contributed conception and design of the study; TW and M-SK organized the database; TW and JK performed the statistical analysis; TW and JK wrote the draft of the manuscript. All authors contributed to manuscript revision, read and approved the submitted version.

\section{FUNDING}

This work was supported by the Technology Innovation Program (No. 20010638, No. 20016338) funded By the Ministry of Trade, Industry and Energy (MOTIE, Korea).

Electrodeposition from Choline Chloride Containing Ionic Liquids. Thin Solid Films 611, 88-100. doi:10.1016/j.tsf.2016.04.030

Chang, C. H., Rheem, Y., Choa, Y.-H., Shin, D. H., Park, D.-Y., and Myung, N. V. (2010). Bi and Te Thin Films Synthesized by Galvanic Displacement from Acidic Nitric Baths. Electrochimica Acta 55 (3), 743-752. doi:10.1016/ j.electacta.2009.09.038

Chang, T., Cho, S., Kim, J., Schoenleber, J., Frantz, C., Stein, N., et al. (2015). Individual Thermoelectric Properties of Electrodeposited Bismuth telluride Nanowires in Polycarbonate Membranes. Electrochimica Acta 161, 403-407. doi:10.1016/j.electacta.2015.02.105

Chen, C.-L., Chen, Y.-Y., Lin, S.-J., Ho, J. C., Lee, P.-C., Chen, C.-D., et al. (2010). Fabrication and Characterization of Electrodeposited Bismuth telluride Films and Nanowires. J. Phys. Chem. C 114 (8), 3385-3389. doi:10.1021/jp909926z

Diliberto, S., Richoux, V., Stein, N., and Boulanger, C. (2008). Influence of Pulsed Electrodeposition on Stoichiometry and Thermoelectric Properties of Bismuth telluride Films. Phys. Stat. Sol. (A) 205 (10), 2340-2344. doi:10.1002/ pssa.200779416

Dou, X., Li, G., Lei, H., Huang, X., Li, L., and Boyd, I. W. (2009). Template Epitaxial Growth of Thermoelectric Bi/BiSb Superlattice Nanowires by ChargeControlled Pulse Electrodeposition. J. Electrochem. Soc. 156 (9), K149-K154. doi:10.1149/1.3156639

Dou, X., Li, G., and Lei, H. (2008). Kinetic versus Thermodynamic Control over Growth Process of Electrodeposited Bi/BiSb Superlattice Nanowires. Nano Lett. 8 (5), 1286-1290. doi:10.1021/nl073039b

Dughaish, Z. H. (2002). Lead telluride as a Thermoelectric Material for Thermoelectric Power Generation. Physica B: Condensed Matter 322 (1-2), 205-223. doi:10.1016/s0921-4526(02)01187-0

Elazem, D., Jung, H., Wu, T., Lim, J.-H., Lee, K.-H., and Myung, N. V. (2013). Morphology Change of Galvanically Displaced One-Dimensional Tellurium Nanostructures via Controlling the Microstructure of Sacrificial Ni Thin Films. Electrochimica Acta 106, 447-452. doi:10.1016/j.electacta.2013.05.117

Erdoan, B. Y., and Demir, Ü. (2011). Orientation-controlled Synthesis and Characterization of Bi $2 \mathrm{Te} 3$ Nanofilms, and Nanowires via Electrochemical Co-deposition. Electrochimica Acta 56 (5), 2385-2393.

Erdoğan, İ. Y., Ozar, T. O., and Demir, U. (2009). PbTe Alkaline _ Co-deposition. Thin Solid Films 517 (18), 5419-5424.

Faleev, S. V., and Léonard, F. (2008). Theory of Enhancement of Thermoelectric Properties of Materials with Nanoinclusions. Phys. Rev. B 77 (21), 214304. doi:10.1103/physrevb.77.214304 
Frantz, C., Stein, N., Gravier, L., Granville, S., and Boulanger, C. (2010). Electrodeposition and Characterization of Bismuth telluride Nanowires. J. Elec Materi 39 (9), 2043-2048. doi:10.1007/s11664-009-1001-2

Frantz, C., Stein, N., Zhang, Y., Bouzy, E., Picht, O., Toimil-Molares, M. E., et al. (2012). Electrodeposition of Bismuth telluride Nanowires with Controlled Composition in Polycarbonate Membranes. Electrochimica Acta 69, 30-37. doi:10.1016/j.electacta.2012.01.040

Frantz, C., Vichery, C., Michler, J., and Philippe, L. (2015). Electrodeposition of $\mathrm{PbTe}$ Thin Films: Electrochemical Behavior and Effect of Reverse Pulse Potential. Electrochimica Acta 173, 490-496. doi:10.1016/ j.electacta.2015.05.045

Frantz, C., Zhang, Y., Michler, J., and Philippe, L. (2016). On the Growth Mechanism of Electrodeposited PbTe Dendrites. CrystEngComm 18 (13), 2319-2326. doi:10.1039/c6ce00107f

Fu, J., Shi, J., Zhu, M., Liang, Y., Zhang, G., Shi, H., et al. (2013). Large-scale Synthesis and Characterisation of $\mathrm{Ag} / \mathrm{Bi} 2 \mathrm{Te} 3$ Superlattice Nanowires via Pulse Electrodeposition. Micro Nano Lett. 8 (4), 188-190. doi:10.1049/mnl.2012.0850

Gan, Y. X., Sweetman, J., and Lawrence, J. G. (2010). Electrodeposition and Morphology Analysis of Bi-te Thermoelectric alloy Nanoparticles on Copper Substrate. Mater. Lett. 64 (3), 449-452. doi:10.1016/j.matlet.2009.11.045

Glatz, W., Durrer, L., Schwyter, E., and Hierold, C. (2008). Novel Mixed Method for the Electrochemical Deposition of Thick Layers of $\mathrm{Bi} 2+\mathrm{xTe} 3-\mathrm{x}$ with Controlled Stoichiometry. Electrochimica Acta 54 (2), 755-762. doi:10.1016/ j.electacta.2008.06.065

Golgovici, F., Cojocaru, A., Anicai, L., and Visan, T. (2011). Surface Characterization of BiSbTe Thermoelectric Films Electrodeposited from Chlorides Aqueous Solutions and Choline Chloride Based Ionic Liquids. Mater. Chem. Phys. 126 (3), 700-706. doi:10.1016/j.matchemphys.2010.12.058

Golgovici, F., Cojocaru, A., Nedelcu, M., and Visan, T. (2010). Cathodic Deposition of Components in BiSbTe Ternary Compounds as Thermoelectric Films Using Choline-Chloride-Based Ionic Liquids. J. Elec Materi 39 (9), 2079-2084. doi:10.1007/s11664-009-1006-x

Ha, Y. C., Sohn, H. J., Jeong, G., Lee, C., and Rhee, K. I. (2000). Electrowinning of Tellurium From Alkaline Leach Liquor of Cemented Te. J. Appl. Electrochem. 30 (3), 315-322.

Hangarter, C. M., Lee, Y.-I., Hernandez, S. C., Choa, Y.-h., and Myung, N. V. (2010). Nanopeapods by Galvanic Displacement Reaction. Angew. Chem. Int. Edition 49 (39), 7081-7085. doi:10.1002/anie.201001559

Hasan, M., Gautam, D., and Enright, R. (2016). Electrodeposition of Textured Bi27Sb28Te45 Nanowires with Enhanced Electrical Conductivity. Mater. Chem. Phys. 173, 438-445. doi:10.1016/j.matchemphys.2016.02.035

Hatsuta, N., Takemori, D., and Takashiri, M. (2016). Effect of thermal Annealing on the Structural and Thermoelectric Properties of Electrodeposited Antimony telluride Thin Films. J. Alloys Comp. 685, 147-152. doi:10.1016/ j.jallcom.2016.05.268

Hsu, K. F., Loo, S., Guo, F., Chen, W., Dyck, J. S., Uher, C., et al. (2004). Cubic AgPb M SbTe 2+ M : Bulk Thermoelectric Materials with High Figure of Merit. Science 303 (5659), 818-821. doi:10.1126/ science. 1092963

Ikemiya, N., Iwai, D., Yamada, K., Vidu, R., and Hara, S. (1996). Atomic Structures and Growth Morphologies of Electrodeposited Te Film on $\mathrm{Au}(100)$ and $\mathrm{Au}(111)$ Observed by In Situ Atomic Force Microscopy. Surf. Sci. 369 (1-3), 199-208. doi:10.1016/s0039-6028(96)00881-3

Jagadish, P. R., Li, L. P., Chan, A., and Khalid, M. (2016). Effect of Annealing on Virgin and Recycled Carbon Fiber Electrochemically Deposited with N-type Bismuth Telluride and Bismuth Sulfide. Mater. Manufacturing Process. 31 (9), 1223-1231. doi:10.1080/10426914.2015.1090590

Jagadish, R., Lau, P., and Chan, A. (2015). Effect of Annealing on Virgin and Recycled Carbon Fibre Electrochemically-Deposited with N-type Bismuth Telluride. Chem. Eng. Trans. 45, 1435-1440.

Jiang, C. H., Wei, W., Yang, Z. M., Tian, C., and Zhang, J. S. (2011). Electrodeposition of Tellurium Film on Polyaniline-Coated Macroporous Phenolic Foam and its Thermopower. J. Porous Mater. 19 (5), 819-823. doi:10.1007/s10934-011-9536-z

Jiang, C. H., Wei, W., Yang, Z. M., Tian, C., and Zhang, J. S. (2012). Electrodeposition of Tellurium Film on Polyaniline-Coated Macroporous Phenolic Foam and its Thermopower. J. Porous Mater. 19 (5), 819-823. doi:10.1007/s10934-011-9536-z
Jiang, Q., Liu, C., Song, H., Xu, J., Mo, D., Shi, H., et al. (2014). Free-standing PEDOT: PSS Film as Electrode for the Electrodeposition of Bismuth telluride and its Thermoelectric Performance. Int. J. Electrochem. Sci. 9 (12), 7540-7551.

Jin, Y., and Wang, W. (2010). Effect of Substrate on the Structure and Thermoelectric Properties of N-type Bi2Te3-y Se Y Thin Films Prepared by Electrodeposition. J. Elec Materi 39 (9), 1469-1475. doi:10.1007/s11664-0101306-1

Jung, H., Park, D.-Y., Xiao, F., Lee, K. H., Choa, Y.-H., Yoo, B., et al. (2011). Electrodeposited Single Crystalline PbTe Nanowires and Their Transport Properties. J. Phys. Chem. C 115 (7), 2993-2998. doi:10.1021/jp110739v

Jung, H., Suh, H., Hangarter, C., and Lim, J. H. (2012). Programmable Synthesis of Shape-, Structure-, and Composition-Modulated One-Dimensional Heterostructures by Galvanic Displacement Reaction. Appl. Phys. Lett. 100 (22), 1. doi:10.1063/1.4722919

Kang, W.-S., Li, W.-J., Chou, W.-C., Tseng, M.-F., and Lin, C.-S. (2017). Microstructure and Thermoelectric Properties of Bi 2 Te 3 Electrodeposits Plated in Nitric and Hydrochloric Acid Baths. Thin Solid Films 623, 90-97. doi:10.1016/j.tsf.2016.12.047

Kim, J., Lee, J.-Y., Lim, J.-H., and Myung, N. V. (2016). Optimization of Thermoelectric Properties of P-type AgSbTe2 Thin Films via Electrochemical Synthesis. Electrochimica Acta 196, 579-586. doi:10.1016/ j.electacta.2016.02.206

Kim, J., Lee, K. H., Kim, S.-D., Lim, J.-H., and Myung, N. V. (2018). Simple and Effective Fabrication of Sb2Te3 Films Embedded with Ag2Te Nanoprecipitates for Enhanced Thermoelectric Performance. J. Mater. Chem. A. 6, 349-356. doi:10.1039/c7ta09013g

Kim, J., Lim, J.-H., and Myung, N. V. (2018). Composition- and Crystallinitydependent Thermoelectric Properties of Ternary BixSb2-xTey Films. Appl. Surf. Sci. 429, 158-163. doi:10.1016/j.apsusc.2017.06.260

Kim, J., Zhang, M., Bosze, W., Park, S.-D., Lim, J.-H., and Myung, N. V. (2015). Maximizing Thermoelectric Properties by Nanoinclusion of $\gamma$-SbTe in Sb2Te3 Film via Solid-State Phase Transition from Amorphous Sb-Te Electrodeposits. Nano Energy 13, 727-734. doi:10.1016/j.nanoen.2015.03.020

Kim, M.-Y., and Oh, T.-S. (2010b). Crystallization Behavior and Thermoelectric Characteristics of the Electrodeposited Sb2Te3 Thin Films. Thin Solid Films 518 (22), 6550-6553. doi:10.1016/j.tsf.2010.03.052

Kim, M.-Y., and Oh, T.-S. (2009). Electrodeposition and Thermoelectric Characteristics of Bi2Te3 and Sb2Te3 Films for Thermopile Sensor Applications. J. Elec Materi 38 (7), 1176-1181. doi:10.1007/s11664-0080653-7

Kim, M.-Y., and Oh, T.-S. (2010a). Thermoelectric Characteristics of the Thermopile Sensors Processed with the Electrodeposited Bi-te and Sb-Te Thin Films. Surf. Rev. Lett. 17 (03), 311-316. doi:10.1142/s0218625x10013813

Kim, M.-Y., and Oh, T.-S. (2013). Thermoelectric Power Generation Characteristics of a Thin-Film Device Consisting of Electrodeposited N-Bi2Te3 and P-Sb2Te3 Thin-Film Legs. J. Elec Materi 42 (9), 2752-2757. doi:10.1007/s11664-013-2671-3

Ko, D.-K., Kang, Y., and Murray, C. B. (2011). Enhanced Thermopower via Carrier Energy Filtering in Solution-Processable Pt-Sb2Te3 Nanocomposites. Nano Lett. 11 (7), 2841-2844. doi:10.1021/nl2012246

Köse, H., Bicer, M., Tutunoglu, C., Aydin, A. O., and Sisman, I. (2009). The Underpotential Deposition of Bi2Te3-ySey Thin Films by an Electrochemical Co-deposition Method. Electrochimica Acta 54 (6), 1680-1686.

Kuleshova, J., Koukharenko, E., Li, X., Frety, N., Nandhakumar, I. S., Tudor, J., et al. (2010). Optimization of the Electrodeposition Process of High-Performance Bismuth Antimony telluride Compounds for Thermoelectric Applications. Langmuir 26 (22), 16980-16985. doi:10.1021/la101952y

Kulsi, C., Kargupta, K., and Banerjee, D. (2016). "Process Dependent Thermoelectric Properties of EDTA Assisted Bismuth telluride," in AIP Conference Proceedings (IEEE). doi:10.1063/1.4945148

Kulsi, C., Mitra, M., Kargupta, K., Ganguly, S., Banerjee, D., and Goswami, S. (2015). Effect of Different Surfactants and Thicknesses on Electrodeposited Films of Bismuth telluride and its Thermoelectric Performance. Mater. Res. Express 2 (10), 106403. doi:10.1088/2053-1591/2/10/106403

Lal, S., Gautam, D., and Razeeb, K. M. (2017). The Impact of Surfactant Sodium Dodecyl Sulfate on the Microstructure and Thermoelectric Properties of P-type (Sb1-xBix)2Te3Electrodeposited Films. ECS J. Solid State. Sci. Technol. 6 (3), N3017-N3021. doi:10.1149/2.0041703jss 
Lee, J., Farhangfar, S., Lee, J., Cagnon, L., Scholz, R., Gösele, U., et al. (2008). Tuning the Crystallinity of Thermoelectric Bi2Te3nanowire Arrays Grown by Pulsed Electrodeposition. Nanotechnology 19 (36), 365701. doi:10.1088/0957-4484/19/ $36 / 365701$

Lee, J., Kim, Y., Caglon, L., and Gosele, U. (2010). Power Factor Measurements of Bismuth telluride Nanowires Grown by Pulsed Electrodeposition. physica status solidi (Rrl) - Rapid Res. Lett. 4 (1-2), 43-45. doi:10.1002/pssr.200903368

Lee, K.-J., Song, H., Lee, Y.-I., Jung, H., Zhang, M., Choa, Y.-H., et al. (2011). Synthesis of Ultra-long Hollow Chalcogenide Nanofibers. Chem. Commun. 47 (32), 9107-9109. doi:10.1039/c1cc12312b

Lei, C., Burton, M., and Nandhakumar, I. S. (2017). Electrochemical Formation of P-type Bi0.5Sb1.5Te3Thick Films onto Nickel. J. Electrochem. Soc. 164 (4), D192-D195. doi:10.1149/2.1151704jes

Lei, C., Burton, M. R., and Nandhakumar, I. S. (2016). Facile Production of Thermoelectric Bismuth telluride Thick Films in the Presence of Polyvinyl Alcohol. Phys. Chem. Chem. Phys. 18 (21), 14164-14167. doi:10.1039/ c6cp02360f

Lei, C., Ryder, K. S., Koukharenko, E., Burton, M., and Nandhakumar, I. S. (2016). Electrochemical Deposition of Bismuth telluride Thick Layers onto Nickel. Electrochemistry Commun. 66, 1-4. doi:10.1016/j.elecom.2016.02.005

Lensch-Falk, J. L., Banga, D., Hopkins, P. E., Robinson, D. B., Stavila, V., Sharma, P. A., et al. (2012). Electrodeposition and Characterization of Nano-Crystalline Antimony telluride Thin Films. Thin Solid Films 520 (19), 6109-6117. doi:10.1016/j.tsf.2012.05.078

Li, F.-H., and Wang, W. (2010). Electrodeposition of P-type BixSb2-xTey Thermoelectric Film from Dimethyl Sulfoxide Solution. Electrochimica Acta 55 (17), 5000-5005. doi:10.1016/j.electacta.2010.04.005

Li, F.-H., Wang, W., and Gao, J.-p. (2010). Electrodeposition of Bi X Sb2-x Te Y Thermoelectric Films from DMSO Solution. J. Elec Materi 39 (9), 1562-1565. doi:10.1007/s11664-010-1284-3

Li, F.-H., Wang, W., Gong, Y.-L., and Li, J.-Y. (2012). Electrodeposition of Sb X Te Y Thermoelectric Films from Dimethyl Sulfoxide Solution. J. Elec Materi 41 (11), 3039-3043. doi:10.1007/s11664-012-2202-7

Li, F., and Wang, W. (2009). Electrodeposition of BixSb2-xTey Thermoelectric Thin Films from Nitric Acid and Hydrochloric Acid Systems. Appl. Surf. Sci. 255 (7), 4225-4231. doi:10.1016/j.apsusc.2008.11.013

Li, G.-R., Yao, C.-Z., Lu, X.-H., Zheng, F.-L., Feng, Z.-P., Yu, X.-L., et al. (2008). Facile and Efficient Electrochemical Synthesis of PbTe Dendritic Structures. Chem. Mater. 20 (10), 3306-3314. doi:10.1021/cm8001942

Li, G.-r., Zheng, F.-l., and Tong, Y.-x. (2008). Controllable Synthesis of Bi2Te3 Intermetallic Compounds with Hierarchical Nanostructures via Electrochemical Deposition Route. Cryst. Growth Des. 8 (4), 1226-1232. doi: $10.1021 / \mathrm{cg} 700790 \mathrm{~h}$

Li, L., Xu, S., and Li, G. (2015). Enhancement of Thermoelectric Properties in Bisb-te Alloy Nanowires by Pulsed Electrodeposition. Energ. Tech. 3 (8), 825-829. doi:10.1002/ente.201500071

Li, W.-J. (2009). Electrodeposition of Bismuth telluride Films from a Nonaqueous Solvent. Electrochimica Acta 54 (27), 7167-7172. doi:10.1016/ j.electacta.2009.07.008

Li, W.-J., Yu, W.-L., and Yen, C.-Y. (2011). Pulsed Electrodeposition of Bi2Te3 and Bi2Te3/Te Nanowire Arrays from a DMSO Solution. Electrochimica Acta 58 (1), 510-515. doi:10.1016/j.electacta.2011.09.075

Li, X.-H., Zhou, B., Pu, L., and Zhu, J.-J. (2008). Electrodeposition of Bi2Te3 and Bi2Te3 Derived Alloy Nanotube Arrays. Cryst. Growth Des. 8 (3), 771-775. doi: $10.1021 / \mathrm{cg} 7006759$

Li, X.-l., Cai, K.-f., Li, H., Wang, L., and Zhou, C.-w. (2010). Electrodeposition and Characterization of Thermoelectric Bi2Se3 Thin Films. Int. J. Miner Metall. Mater. 17 (1), 104-107. doi:10.1007/s12613-010-0118-x

Li, X. L., Cai, K. F., Li, H., Yu, D. H., Wang, X., and Wang, H. F. (2010). Alumina Template-Assisted Electrodeposition of Bi2Te2.7Se0.3 Nanowire Arrays. Superlattices and Microstructures 47 (6), 710-713. doi:10.1016/ j.spmi.2010.03.009

Li, X. L., Cai, K. F., Yu, D. H., and Wang, Y. Y. (2011). Electrodeposition and Characterization of Thermoelectric Bi2Te2Se/Te Multilayer Nanowire Arrays. Superlattices and Microstructures 50 (5), 557-562. doi:10.1016/ j.spmi.2011.09.001

Lim, J.-H., Park, M., Lim, D.-C., Myung, N. V., Lee, J.-H., Jeong, Y.-K., et al. (2012). Synthesis and Thermoelectric/electrical Characterization of Electrodeposited
SbxTey Thin Films. Mater. Res. Bull. 47 (10), 2748-2751. doi:10.1016/ j.materresbull.2012.04.140

Lim, J.-H., Park, M. Y., Lim, D. C., Yoo, B., Lee, J.-H., Myung, N. V., et al. (2011). Electrodeposition of P-type Sb X Te Y Thermoelectric Films. J. Elec Materi 40 (5), 1321-1325. doi:10.1007/s11664-011-1629-6

Lim, J. H., Park, M., Lim, D.-C., and Myung, N. V. (2012). Electrical/Themoelectric Characterization of Electrodeposited Bi xSb2-xTe3 Thin Films. AIP Conf. Proc. 1449, 91-94. doi:10.1063/1.4731504

Lim, S.-K., Kim, M.-Y., and Oh, T.-S. (2009). Thermoelectric Properties of the Bismuth-Antimony-telluride and the Antimony-telluride Films Processed by Electrodeposition for Micro-device Applications. Thin Solid Films 517 (14), 4199-4203. doi:10.1016/j.tsf.2009.02.005

Limmer, S. J., Medlin, D. L., Siegal, M. P., Hekmaty, M., Lensch-Falk, J. L., Erickson, K., et al. (2015). Using Galvanostatic Electroforming of Bi1-xSbx Nanowires to Control Composition, Crystallinity, and Orientation. J. Mater. Res. 30 (02), 164-169. doi:10.1557/jmr.2014.354

Limmer, S. J., Yelton, W. G., Siegal, M. P., Lensch-Falk, J. L., Pillars, J., and Medlin, D. L. (2012). Electrochemical Deposition of Bi2(Te,Se)3Nanowire Arrays on Si. J. Electrochem. Soc. 159 (4), D235-D239. doi:10.1149/2.084204jes

Liu, D.-W., and Li, J.-F. (2008). Electrocrystallization Process during Deposition of Bi-te Films. J. Electrochem. Soc. 155 (7), D493. doi: $10.1149 / 1.2907398$

Liu, D.-W., and Li, J.-F. (2011). Microfabrication of Thermoelectric Modules by Patterned Electrodeposition Using a Multi-Channel Glass Template. J. Solid State. Electrochem. 15 (3), 479-484. doi:10.1007/s10008-010-1104-y

Ma, Y., Johansson, A., Ahlberg, E. P., and Anders, E. C. (2010). A Mechanistic Study of Electrodeposition of Bismuth Telluride on Stainless Steel Substrates. Electrochimica Acta 55 (15), 4610-4617. doi:10.1016/j.electacta.2010.03.018

Ma, Y., Ahlberg, E., Sun, Y., Iversen, B. B., and Palmqvist, A. E. C. (2011). Thermoelectric Properties of Thin Films of Bismuth telluride Electrochemically Deposited on Stainless Steel Substrates. Electrochimica Acta 56 (11), 4216-4223. doi:10.1016/j.electacta.2011.01.093

Ma, Y., Wijesekara, W., and Palmqvist, A. E. C. (2012). Thermoelectric Characteristics of Electrochemically Deposited Bi2Te3 and Sb2Te3 Thin Films of Relevance to Multilayer Preparation. J. Electrochem. Soc. 159 (2), D50.

Ma, Y., Wijesekara, W., and Palmqvist, A. E. C. (2012). Electrochemical Deposition and Characterization of Thermoelectric Ternary (Bi X Sb1-x )2Te3 and Bi2(Te1-y Se Y )3 Thin Films. J. Elec Materi 41 (6), 1138-1146. doi:10.1007/s11664-011-1790-y

Maas, M., Diliberto, S., de Vaulx, C., Azzouz, K., and Boulanger, C. (2014). Use of a Soluble Anode in Electrodeposition of Thick Bismuth Telluride Layers. J. Elec Materi 43 (10), 3857-3862. doi:10.1007/s11664-014-3292-1

Mannam, R., Agarwal, M., Roy, A., Singh, V., Varahramyan, K., and Davis, D. (2009). Electrodeposition and Thermoelectric Characterization of Bismuth Telluride Nanowires. J. Electrochem. Soc. 156 (8), B871. doi:10.1149/1.3139011

Manzano, C. V., Abad, B., Muñoz Rojo, M., Koh, Y. R., Hodson, S. L., Lopez Martinez, A. M., et al. (2016). Anisotropic Effects on the Thermoelectric Properties of Highly Oriented Electrodeposited Bi2Te3 Films. Sci. Rep. 6 (1), 19129. doi:10.1038/srep19129

Manzano, C. V., Rojas, A. A., Decepida, M., Abad, B., Feliz, Y., Caballero-Calero, O., et al. (2013). Thermoelectric Properties of Bi2Te3 Films by Constant and Pulsed Electrodeposition. J. Solid State. Electrochem. 17 (7), 2071-2078. doi:10.1007/s10008-013-2066-7

Martin, J., Wang, L., Chen, L., and Nolas, G. S. (2009). Enhanced Seebeck Coefficient through Energy-Barrier Scattering in $\mathrm{PbTe}$ Nanocomposites. Phys. Rev. B 79 (11), 115311. doi:10.1103/ physrevb.79.115311

Matsuoka, K., Okuhata, M., and Takashiri, M. (2015). Dual-bath Electrodeposition of N-type Bi-Te/Bi-se Multilayer Thin Films. J. Alloys Comp. 649, 721-725. doi:10.1016/j.jallcom.2015.07.166

Mavrokefalos, A., Moore, A. L., Pettes, M. T., Shi, L., Wang, W., and Li, X. (2009). Thermoelectric and Structural Characterizations of Individual Electrodeposited Bismuth telluride Nanowires. J. Appl. Phys. 105 (10), 104318. doi:10.1063/ 1.3133145

Müller, S., Schötz, C., Picht, O., Sigle, W., Kopold, P., Rauber, M., et al. (2012). Electrochemical Synthesis of Bi 1- X Sb X Nanowires with Simultaneous Control on Size, Composition, and Surface Roughness. Cryst. Growth Des. 12 (2), 615-621. 
Na, J., Kim, Y., Park, T., Park, C., and Kim, E. (2016). Preparation of Bismuth Telluride Films with High Thermoelectric Power Factor. ACS Appl. Mater. Inter. 8 (47), 32392-32400. doi:10.1021/acsami.6b10188

Narducci, D., Selezneva, E., Cerofolini, G., Frabboni, S., and Ottaviani, G. (2012). Impact of Energy Filtering and Carrier Localization on the Thermoelectric Properties of Granular Semiconductors. J. Solid State. Chem. 193 (0), 19-25. doi:10.1016/j.jssc.2012.03.032

Naylor, A. J., Koukharenko, E., Nandhakumar, I. S., and White, N. M. (2012). Surfactant-Mediated Electrodeposition of Bismuth Telluride Films and its Effect on Microstructural Properties. Langmuir 28 (22), 8296-8299. doi:10.1021/la301367m

Ng, I. K., Kok, K.-Y., Rahman, C. Z., Saidin, N. U., Ilias, S. H., Choo, T.-F., et al. (2014). Electrochemically Deposited BiTe-Based Nanowires for Thermoelectric Applications. AIP Conf. Proc. 1584, 125-128. doi:10.1063/1.4866117

Nguyen, H. P., Peng, X., Murugan, G., Vullers, R. J. M., Vereecken, P. M., and Fransaer, J. (2013). Electrodeposition of Antimony, Tellurium and Their Alloys from Molten Acetamide Mixtures. J. Electrochem. Soc. 160 (2), D75-D79. doi:10.1149/2.003303jes

Nguyen, H. P., Wu, M., Su, J., Vullers, R. J. M., Vereecken, P. M., and Fransaer, J. (2012). Electrodeposition of Bismuth telluride Thermoelectric Films from a Nonaqueous Electrolyte Using Ethylene Glycol. Electrochimica Acta 68, 9-17. doi:10.1016/j.electacta.2012.01.091

Ni, Y., Zhang, Y., and Hong, J. (2011). Potentiostatic Electrodeposition Route for Quick Synthesis of Featherlike PbTe Dendrites: Influencing Factors and Shape Evolution. Cryst. Growth Des. 11 (6), 2142-2148. doi:10.1021/ cg101400w

Nolas, G. S., Sharp, J., and Goldsmid, H. J. (2001). Thermoelectrics : Basic Principles and New Materials Developments. New York: Springer.

Park, H., Jung, H., Zhang, M., Chang, C. H., Ndifor-Angwafor, N. G., Choa, Y., et al. (2013). Branched Tellurium Hollow Nanofibers by Galvanic Displacement Reaction and Their Sensing Performance toward Nitrogen Dioxide. Nanoscale 5 (7), 3058-3062. doi:10.1039/c3nr00060e

Park, K., Xiao, F., Yoo, B. Y., Rheem, Y., and Myung, N. V. (2009). Electrochemical Deposition of Thermoelectric SbxTey Thin Films and Nanowires. J. Alloys Comp. 485 (1-2), 362-366. doi:10.1016/j.jallcom.2009.05.106

Patil, P. B., Mali, S. S., Khot, K. V., Kondalkar, V. V., Ghanwat, V. B., Mane, R. M., et al. (2016). Synthesis of Bismuth Telluride Thin Film for Thermoelectric Application via Electrodeposition Technique. Macromol. Symp. 361 (1), 152-155. doi:10.1002/masy.201400234

Patil, P. B., Mali, S. S., Kondalkar, V. V., Mane, R. M., Patil, P. S., Hong, C. K., et al. (2015). Morphologically Controlled Electrodeposition of Fern Shaped Bi2Te3 Thin Films for Photoelectrochemical Performance. J. Electroanalytical Chem. 758, 178-190. doi:10.1016/j.jelechem.2015.09.019

Pelz, U., Jaklin, J., Rostek, R., Thoma, F., Kröner, M., and Woias, P. (2016). Fabrication Process for Micro Thermoelectric Generators ( $\mu$ TEGs). J. Elec Materi 45 (3), 1502-1507. doi:10.1007/s11664-015-4088-7

Peranio, N., Leister, E., Töllner, W., Eibl, O., and Nielsch, K. (2012). Stoichiometry Controlled, Single-Crystalline Bi2Te3 Nanowires for Transport in the Basal Plane. Adv. Funct. Mater. 22 (1), 151-156. doi:10.1002/adfm.201101273

Pinisetty, D., Davis, D., Podlaha-Murphy, E. J., Murphy, M. C., Karki, A. B., Young, D. P., et al. (2011). Characterization of Electrodeposited Bismuth-Tellurium Nanowires and Nanotubes. Acta Materialia 59 (6), 2455-2461. doi:10.1016/ j.actamat.2010.12.047

Pinisetty, D., Gupta, M., Karki, A. B., Young, D. P., and Devireddy, R. V. (2011). Fabrication and Characterization of Electrodeposited Antimony telluride Crystalline Nanowires and Nanotubes. J. Mater. Chem. 21 (12), 4098-4107. doi:10.1039/c0jm01969k

Poudel, B., Hao, Q., Ma, Y., Lan, Y., Minnich, A., Yu, B., et al. (2008). HighThermoelectric Performance of Nanostructured Bismuth Antimony Telluride Bulk Alloys. Science 320 (5876), 634-638. doi:10.1126/ science. 1156446

Qiu, C. X., and Shih, I. (1989). Epitaxial Growth of Tellurium by Electrodeposition. Mater. Lett. 8 (8), 309-312. doi:10.1016/0167-577x(89)90173-0

Qiu, W. J., Yang, S. H., Zhu, T. J., Xie, J., and Zhao, X. B. (2011). Antimony telluride Thin Films Electrodeposited in an Alkaline Electrolyte. J. Elec Materi 40 (7), 1506-1511. doi:10.1007/s11664-011-1647-4
Qiu, X., Lou, Y., Samia, A. C. S., Devadoss, A., Burgess, J. D., Dayal, S., et al. (2005). $\mathrm{PbTe}$ Nanorods by Sonoelectrochemistry. Angew. Chem. Int. Ed. 44 (36), 5855-5857. doi:10.1002/anie.200501282

Rashid, M. M., Cho, K. H., and Chung, G.-S. (2013). Rapid thermal Annealing Effects on the Microstructure and the Thermoelectric Properties of Electrodeposited Bi2Te3 Film. Appl. Surf. Sci. 279, 23-30. doi:10.1016/ j.apsusc.2013.03.112

Rashid, M. M., and Chung, G.-S. (2013). Effect of Deposition Conditions on the Microstructure and the Thermoelectric Properties of Galvanostatically Electrodeposited $\mathrm{Bi}_{2} \mathrm{Te}_{3}$ Film. Surf. Rev. Lett. 20 (05), 1350044. doi:10.1142/ s0218625x13500443

Mirandaa, C. R. B., Abramof, P. G., Melo, F. C. L., and Ferreira, N. G. (2004). Morphology and Stress Study of Nanostructured Porous Silicon as a Substrate for $\mathrm{PbTe}$ Thin Films Growth by Electrochemical Process. Mater. Res. 7, 619-623.

Richoux, V., Diliberto, S., and Boulanger, C. (2010). Pulsed Electroplating: a Derivate Form of Electrodeposition for Improvement of (Bi1-x Sb X )2Te3 Thin Films. J. Elec Materi 39 (9), 1914-1919. doi:10.1007/s11664-009-1054-2

Rostek, R., Sklyarenko, V., and Woias, P. (2011). Influence of Vapor Annealing on the Thermoelectric Properties of Electrodeposited Bi2Te3. J. Mater. Res. 26 (15), 1785-1790. doi:10.1557/jmr.2011.141

Rostek, R., Stein, N., and Boulanger, C. (2015). A Review of Electroplating for V-VI Thermoelectric Films: from Synthesis to Device Integration. J. Mater. Res. 30 (17), 2518-2543. doi:10.1557/jmr.2015.203

Roth, R., Rostek, R., Cobry, K., Kohler, C., Groh, M., and Woias, P. (2014). Design and Characterization of Micro Thermoelectric Cross-Plane Generators with Electroplated $\$\{\mid \mathrm{rm} \mathrm{Bi}\}_{-}\{2\}\{\mid \mathrm{rm} \mathrm{Te}\}_{-}\{3\} \$, \$\{\mid \mathrm{rm} \mathrm{Sb}\}_{-}\{\mathrm{x}\}\{\mid \mathrm{rm} \mathrm{Te}\}_{-}\{\mathrm{y}\} \$$, and Reflow Soldering. J. Microelectromech. Syst. 23 (4), 961-971. doi:10.1109/ jmems.2014.2303198

Sadeghi, M., Dastan, M., Ensaf, M. R., Tehrani, A. A., Tenreiro, C., and Avila, M. (2008). Thick Tellurium Electrodeposition on Nickel-Coated Copper Substrate for 124I Production. Appl. Radiat. Isot. 66 (10), 1281-1286. doi:10.1016/ j.apradiso.2008.02.082

Saloniemi, H., Kanniainen, T., Ritala, M., and Leskela, M. (1998). PbTe Alkaline Underpotential Deposition _ Potential \& Composition. Thin Solid Films 326 (1-2), 78-82. doi:10.1016/s0040-6090(98)00524-0

Saloniemi, H., Kemell, M., Ritala, M., and Leskelä, M. (2000). PbTe Electrodeposition Studied by Combined Electrochemical Quartz crystal Microbalance and Cyclic Voltammetry. J. Electroanalytical Chem. 482 (2), 139-148. doi:10.1016/s0022-0728(00)00038-3

Schumacher, C., Reinsberg, K. G., Akinsinde, L., Zastrow, S., Heiderich, S., Toellner, W., et al. (2012). Optimization of Electrodeposited P-Doped Sb2Te3 Thermoelectric Films by Millisecond Potentiostatic Pulses. Adv. Energ. Mater. 2 (3), 345-352. doi:10.1002/aenm.201100585

Shin, K.-J., and Oh, T.-S. (2015). Micro-Power Generation Characteristics of Thermoelectric Thin Film Devices Processed by Electrodeposition and FlipChip Bonding. J. Elec Materi 44 (6), 2026-2033. doi:10.1007/s11664-0153647-2

Şişman, İ., and Başoğlu, A. (2016). Effect of Se Content on the Structural, Morphological and Optical Properties of Bi2Te3-ySey Thin Films Electrodeposited by under Potential Deposition Technique. Mater. Sci. Semiconductor Process. 54, 57-64.

Snyder, G. J., Lim, J. R., Huang, C.-K., and Fleurial, J.-P. (2003). Thermoelectric Microdevice Fabricated by a MEMS-like Electrochemical Process. Nat. Mater 2 (8), 528-531. doi:10.1038/nmat943

Snyder, G. J., and Toberer, E. S. (2008). Complex Thermoelectric Materials. Nat. Mater 7 (2), 105-114. doi:10.1038/nmat2090

Snyder, G. J., and Ursell, T. S. (2003). Thermoelectric Efficiency and Compatibility. Phys. Rev. Lett. 91 (14), 148301. doi:10.1103/physrevlett.91.148301

Song, Y., Yoo, I.-J., Heo, N.-R., Lim, D. C., Lee, D., Lee, J. Y., et al. (2015). Electrodeposition of Thermoelectric Bi2Te3 Thin Films with Added Surfactant. Curr. Appl. Phys. 15 (3), 261-264. doi:10.1016/j.cap.2014.12.004

Sootsman, J. R., Chung, D. Y., and Kanatzidis, M. G. (2009). New and Old Concepts in Thermoelectric Materials. Angew. Chem. Int. Ed. 48 (46), 8616-8639. doi:10.1002/anie.200900598

Sorenson, T. A., Suggs, D. W., Nandhakumar, I. S., and Stickney, J. L. (1999). Phase Transitions in the Electrodeposition of Tellurium Atomic Layers on $\mathrm{Au}(100)$. 
J. Electroanalytical Chem. 467 (1-2), 270-281. doi:10.1016/s0022-0728(99) 00053-4

Sorenson, T. A., Varazo, K., Suggs, D. W., and Stickney, J. L. (2001). Formation of and Phase Transitions in Electrodeposited Tellurium Atomic Layers on $\mathrm{Au}(111)$. Surf. Sci. 470 (3), 197-214. doi:10.1016/ s0039-6028(00)00861-x

Souza, P. B., Tumelero, M. A., Zangari, G., and Pasa, A. A. (2017). Tuning Electrodeposition Conditions towards the Formation of Smooth Bi2Se3Thin Films. J. Electrochem. Soc. 164 (7), D401-D405. doi:10.1149/2.0531707jes

Suggs, D. W., and Stickney, J. L. (1991). Characterization of Atomic Layers of Tellurium Electrodeposited on the Low-index Planes of Gold. J. Phys. Chem. 95 (24), 10056-10064. doi:10.1021/j100177a081

Suh, H., Jung, H. S., Myung, N. V., and Hong, K. (2014). Bamboo-like Te Nanotubes with Tailored Dimensions Synthesized from Segmental NiFe Nanowires as Sacrificial Templates. Bull. Korean Chem. Soc. 35 (11), 3227-3231. doi:10.5012/bkcs.2014.35.11.3227

Suh, H., Noh, J., Lee, J.-H., Lee, S.-H., Myung, N. V., Hong, K., et al. (2017). Morphological Evolution of Te and Bi2Te3 Microstructures during Galvanic Displacement of Electrodeposited Co Thin Films. Electrochimica Acta 255, 1-8. doi:10.1016/j.electacta.2017.09.049

Sumithra, S., Takas, N. J., Misra, D. K., Nolting, W. M., Poudeu, P. F. P., and Stokes, K. L. (2011). Enhancement in Thermoelectric Figure of Merit in Nanostructured Bi2Te3 with Semimetal Nanoinclusions. Adv. Energ. Mater. 1 (6), 1141-1147. doi:10.1002/aenm.201100338

Suresh, A., Chatterjee, K., Sharma, V. K., Ganguly, S., Kargupta, K., and Banerjee, D. (2009). Effect of $\mathrm{pH}$ on Structural and Electrical Properties of Electrodeposited Bi2Te3 Thin Films. J. Elec Materi 38 (3), 449-452. doi:10.1007/s11664-008-0635-9

Szczech, J. R., Higgins, J. M., and Jin, S. (2011). Enhancement of the Thermoelectric Properties in Nanoscale and Nanostructured Materials. J. Mater. Chem. 21 (12), 4037-4055. doi:10.1039/c0jm02755c

Szymczak, J., Legeai, S., Michel, S., Diliberto, S., Stein, N., and Boulanger, C. (2014). Electrodeposition of Stoichiometric Bismuth telluride Bi2Te3 Using a Piperidinium Ionic Liquid Binary Mixture. Electrochimica Acta 137, 586-594. doi:10.1016/j.electacta.2014.06.036

Tumelero, M. A., Benetti, L. C., Isoppo, E., Faccio, R., Zangari, G., and Pasa, A. A. (2016). Electrodeposition and Ab Initio Studies of Metastable Orthorhombic Bi2Se3: A Novel Semiconductor with Bandgap for Photovoltaic Applications. J. Phys. Chem. C 120 (22), 11797-11806. doi:10.1021/acs.jpcc.6b02559

Uda, K., Seki, Y., Saito, M., Sonobe, Y., Hsieh, Y.-C., Takahashi, H., et al. (2015). Fabrication of $\Pi$-structured Bi-te Thermoelectric Micro-device by Electrodeposition. Electrochimica Acta 153, 515-522. doi:10.1016/ j.electacta.2014.12.019

Ueda, M., Mito, Y., and Ohtsuka, T. (2008). Electrodeposition of Sb-Te Alloy in AlCl3-NaCl-KCl Molten Salt. Mater. Trans. 49 (8), 1720-1722. doi:10.2320/ matertrans.e-mra2008811

Wang, W., Ji, Y., Xu, H., Li, H., Visan, T., and Golgovici, F. (2013). A High Packing Density Micro-thermoelectric Power Generator Based on Film Thermoelectric Materials Fabricated by Electrodeposition Technology. Surf. Coat. Tech. 231, 583-589. doi:10.1016/j.surfcoat.2012.04.048

Wang, W., Zhang, G., and Li, X. (2008). Manipulating Growth of Thermoelectric Bi2Te3/Sb Multilayered Nanowire Arrays. J. Phys. Chem. C 112 (39), 15190-15194. doi:10.1021/jp803207r

Weber, J. E., Yelton, W. G., and Kumar, A. (2008). "Electrodeposition of Bi1-xSbx Nanowires as an Advanced Material for Thermoelectric Applications," in Functionalized Nanoscale Materials, 2008 (Springer, Dordrecht: Devices and Systems), 425-429.

Wu, M., Binnemans, K., and Fransaer, J. (2014). Electrodeposition of Antimony from Chloride-free Ethylene Glycol Solutions and Fabrication of Thermoelectric Bi2Te3/(Bi1-xSbx)2Te3 Multilayers Using Pulsed Potential Electrodeposition. Electrochimica Acta 147, 451-459. doi:10.1016/ j.electacta.2014.08.111

Wu, M., Nguyen, H. P., Vullers, R. J. M., Vereecken, P. M., Binnemans, K., and Fransaer, J. (2013). Electrodeposition of Bismuth Telluride Thermoelectric Films from Chloride-free Ethylene Glycol Solutions. J. Electrochem. Soc. 160 (4), D196-D201. doi:10.1149/2.089304jes
Wu, M., Ramírez, S. A., Shafahian, E., Guo, L., Glorieux, C., Binnemans, K., et al. (2017). Electrodeposition of Bismuth telluride Thin Films Containing Silica Nanoparticles for Thermoelectric Applications. Electrochimica Acta 253, 554-562. doi:10.1016/j.electacta.2017.09.012

$\mathrm{Wu}, \mathrm{T}$., Lee, H.-K., and Myung, N. V. (2016). Electrodeposition of Dense Lead Telluride Thick Films in Alkaline Solutions. J. Electrochem. Soc. 163 (14), D801-D808. doi:10.1149/2.0631614jes

Wu, T., Zhang, M., Lee, K.-H., Lee, C.-M., Lee, H.-K., Choa, Y., et al. (2017) Electrodeposition of Compact Tellurium Thick Films from Alkaline Baths. J. Electrochem. Soc. 164 (2), D82-D87. doi:10.1149/2.1191702jes

Wu, Y., Lin, Z., Tian, Z., Han, C., Liu, J., Zhang, H., et al. (2016). Fabrication of Microstructured Thermoelectric Bi2Te3 Thin Films by Seed Layer Assisted Electrodeposition. Mater. Sci. Semiconductor Process. 46, 17-22. doi:10.1016/ j.mssp.2016.01.014

Xiao, C., Yang, J., Zhu, W., Peng, J., and Zhang, J. (2009). Electrodeposition and Characterization of Bi2Se3 Thin Films by Electrochemical Atomic Layer Epitaxy (ECALE). Electrochimica Acta 54 (27), 6821-6826. doi:10.1016/ j.electacta.2009.06.089

Xiao, F., Hangarter, C., Yoo, B., Rheem, Y., Lee, K.-H., and Myung, N. V. (2008). Recent Progress in Electrodeposition of Thermoelectric Thin Films and Nanostructures. Electrochimica Acta 53 (28), 8103-8117. doi:10.1016/ j.electacta.2008.06.015

Xiaolong, L., and Zhen, X. (2014). The Effect of Electrochemical Conditions on Morphology and Properties of Bi2Se3 Thick Films by Electrodeposition. Mater. Lett. 129, 1-4. doi:10.1016/j.matlet.2014.05.009

Xue, Z., Li, X.-L., and Yu, D.-m. (2014). Bi2Se3/Bi Multiple Heterostructure Nanowire Arrays Formed by Pulsed Electrodeposition. Superlattices and Microstructures 74, 273-278. doi:10.1016/j.spmi.2014.06.012

Yagi, I., Lantz, J. M., Nakabayashi, S., Corn, R. M., and Uosaki, K. (1996). In Situ optical Second Harmonic Generation Studies of Electrochemical Deposition of Tellurium on Polycrystalline Gold Electrodes. J. Electroanalytical Chem. 401 (1-2), 95-101. doi:10.1016/0022-0728(95) 04285-7

Yang, C.-K., Cheng, T.-C., Chen, T.-H., and Chu, S.-H. (2016). The Thermoelectric Properties of Electrochemically Deposited Te-Sb-Bi Films on Ito Glass Substrate. Int. J. Electrochem. Sci. 11 (5), 3767-3775. doi:10.20964/110371

Yang, Y., Kung, S. C., Taggart, D. K., Xiang, C., Yang, F., Brown, M. A., et al. (2008). Synthesis of $\mathrm{PbTe}$ Nanowire Arrays Using Lithographically Patterned Nanowire Electrodeposition. Nano Lett. 8 (8), 2447-2451. doi:10.1021/ $\mathrm{nl} 801442 \mathrm{c}$

Yoo, I.-J., Lim, D. C., Myung, N. V., Jeong, Y.-K., Kim, Y. D., Lee, K. H., et al. (2013). Electrical/thermoelectric Characterization of Electrodeposited Bi X Sb2-x Te3 Thin Films. Electron. Mater. Lett. 9 (5), 687-691. doi:10.1007/ s13391-013-2246-8

Yoo, I.-J., Myung, N. V., Lim, D. C., Song, Y., Jeong, Y.-K., Kim, Y. D., et al. (2013). Electrodeposition of BixTey Thin Films for Thermoelectric Application. Thin Solid Films 546 (3), 48-52. doi:10.1016/j.tsf.2013.05.036

Yoo, I.-J., Song, Y., Chan Lim, D., Myung, N. V., Lee, K. H., Oh, M., et al. (2013). Thermoelectric Characteristics of Sb2Te3 Thin Films Formed via SurfactantAssisted Electrodeposition. J. Mater. Chem. A. 1 (17), 5430. doi:10.1039/ c3ta01631e

Zebarjadi, M., Esfarjani, K., Dresselhaus, M. S., Ren, Z. F., and Chen, G. (2012). Perspectives on Thermoelectrics: from Fundamentals to Device Applications. Energy Environ. Sci. 5 (1), 5147-5162. doi:10.1039/ clee02497c

Zeng, G., Zide, J. M. O., Kim, W., Bowers, J. E., Gossard, A. C., Bian, Z., et al. (2007). Cross-plane Seebeck Coefficient of ErAs:InGaAs $\ n G a A l A s$ Superlattices. J. Appl. Phys. 101 (3), 034502. doi:10.1063/1.2433751

Zhang, Y., Snedaker, M. L., Birkel, C. S., Mubeen, S., Ji, X., Shi, Y., et al. (2012). Silver-Based Intermetallic Heterostructures in Sb2Te3 Thick Films with Enhanced Thermoelectric Power Factors. Nano Lett. 12 (2), 1075-1080. doi: $10.1021 / \mathrm{nl} 204346 \mathrm{~g}$

Zhou, A., Fu, Q., Zhang, W., Yang, B., Li, J., Ziolkowski, P., et al. (2015). Enhancing the Thermoelectric Properties of the Electroplated Bi 2 Te 3 Films by Tuning the Pulse Off-To-On Ratio. Electrochimica Acta 178, 217-224. doi:10.1016/ j.electacta.2015.07.164 
Zhou, J., Lin, Q., Li, H., and Cheng, X. (2013). Phosphorus-doped Bismuth telluride Films by Electrodeposition. Mater. Chem. Phys. 141 (1), 401-405. doi:10.1016/ j.matchemphys.2013.05.033

Zhu, W., Yang, Y., Zhou, D., and Xiao, C. (2008). Electrochemical Atom-By-Atom Growth of Highly Uniform Thin Sheets of Thermoelectric Bismuth telluride via the Route of ECALE. J. Electroanalytical Chem. 614 (1-2), 41-48. doi:10.1016/ j.jelechem.2007.11.014

Zhu, Y.-B., and Wang, W. (2012). Microstructure and Thermoelectric Properties of P-type Bi-sb-te-se Thin Films Prepared by Electrodeposition Method. Thin Solid Films 520 (7), 2474-2478. doi:10.1016/j.tsf.2011.10.020

Zide, J. M. O., Vashaee, D., and Gossard, A. (2006). Demonstration of Electron Filtering to Increase the Seebeck Coefficient in In0.53Ga0.47As/ In0.53Ga0.28Al0.19As Superlattices. Phys. Rev. B 74, 205335. doi:10.1103/ PHYSREVB.74.205335

Zou, Z., Chen, S., and Cai, K. (2014). Preparation and Characterization of Electrodeposited $\mathrm{Cu}_{\mathrm{x}} \mathrm{Bi}_{2} \mathrm{Te}_{3}$ Thermoelectric Films. Mater. Sci. Forum 787, 205-209.

Zou, Z. G., Cai, K. F., Chen, S., and Qin, Z. (2012). Pulsed Electrodeposition and Characterization of Bi2Te3-ySey Films. Mater. Res. Bull. 47 (11), 3292-3295. doi:10.1016/j.materresbull.2012.07.036
Conflict of Interest: The authors declare that the research was conducted in the absence of any commercial or financial relationships that could be construed as a potential conflict of interest.

The handling Editor declared a past co-authorship with the authors JK and JL.

Publisher's Note: All claims expressed in this article are solely those of the authors and do not necessarily represent those of their affiliated organizations, or those of the publisher, the editors and the reviewers. Any product that may be evaluated in this article, or claim that may be made by its manufacturer, is not guaranteed or endorsed by the publisher.

Copyright (c) $2021 \mathrm{Wu}, \mathrm{Kim}, \mathrm{Lim}, \mathrm{Kim}$ and Myung. This is an open-access article distributed under the terms of the Creative Commons Attribution License (CC BY). The use, distribution or reproduction in other forums is permitted, provided the original author(s) and the copyright owner(s) are credited and that the original publication in this journal is cited, in accordance with accepted academic practice. No use, distribution or reproduction is permitted which does not comply with these terms. 